\title{
Managing Water in Rainfed Agriculture in the Greater Mekong Subregion
}

Final report prepared by

International Water Management Institute (IWMI)

for

Swedish International Development Cooperation Agency (Sida) 


\section{CREDITS}

\section{Authors}

Robyn Johnston, International Water Management Institute (IWMI), Colombo, Sri Lanka Chu Thai Hoanh, International Water Management Institute (IWMI), Vientiane, Lao PDR Guillaume Lacombe, International Water Management Institute (IWMI), Vientiane, Lao PDR Rod Lefroy, International Center for Tropical Agriculture (CIAT), Hanoi, Vietnam Paul Pavelic, International Water Management Institute (IWMI), Hyderabad, India Carolyn Fry, Consultant to International Water Management Institute (IWMI), London, UK

\section{Contributors}

Laure Collet, International Center for Tropical Agriculture (CIAT), Cali, Colombia Andrew Noble, Australian Centre for International Agricultural Research (ACIAR), Canberra, Australia (formerly International Water Management Institute (IWMI), Vientiane, Lao PDR)

Deborah Bossio, International Center for Tropical Agriculture (CIAT), Nairobi, Kenya (formerly International Water Management Institute (IWMI), Addis Ababa, Ethiopia)

Corentin Clement, Intern at International Water Management Institute (IWMI), Colombo, Sri Lanka Somphasith Douangsavanh, International Water Management Institute (IWMI), Vientiane, Lao PDR Oloth Sengtaheuanghoung, National Agriculture and Forestry Research Institute (NAFRI),

Vientiane, Lao PDR

Nguyen Duy Phuong, Soils and Fertilizers Research Institute (SFRI), Hanoi, Vietnam

Tran Duc Toan, Soils and Fertilizers Research Institute (SFRI), Hanoi, Vietnam

Teoh Shwu Jiau, International Water Management Institute (IWMI)/WorldFish Center, Penang, Malaysia Thuon Try - Consultant to International Water Management Institute (IWMI), Phnom Penh, Cambodia Lu Caizhen - World Agroforestry Centre (ICRAF), Yunnan, China

Johnston, R.; Hoanh, C. T.; Lacombe, G.; Lefroy, R.; Pavelic, P.; Fry, C. 2012. Managing water in rainfed agriculture in the Greater Mekong Subregion. Final report prepared by IWMI for Swedish International Development Cooperation Agency (Sida). Colombo, Sri Lanka: International Water Management Institute (IWMI); Stockholm, Sweden: Swedish International Development Cooperation Agency (Sida). 100p. doi: 10.5337/2012.201

/ water management / agroecology / environment / rainfed farming / irrigated farming / farming systems / crop production / agricultural production / yields / poverty / climate change / drought / floodplains / rain / mapping / case studies / reservoirs / deltas / groundwater / farm ponds / water storage / rivers / lowland / highlands / plains / landscape / coastal area / urban areas / aquifers / Southeast Asia / Cambodia / Laos / Myanmar / Thailand / Vietnam /

ISBN 978-92-9090-749-7

Copyright (C) 2012, by IWMI and Sida. All rights reserved. 


\section{ACKNOWLEDGEMENTS}

\section{Project}

This research study was initiated as part of the project titled 'Scoping and Project Development Study on Managing Water in Rainfed Agriculture: The Key to Food Security in the GMS'.

\section{Collaborators}

This study is a collaboration of the following organizations:

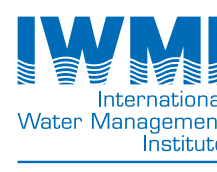

International Water Management Institute (IWMI)

\section{Donors}

This work was funded by the Swedish International Development Cooperation Agency (Sida).

The opinions and interpretations expressed within are those of the authors and do not necessarily reflect the views of the International Water Management Institute (IWMI) or the Swedish International Development Cooperation Agency (Sida). 



\section{CONTENTS}

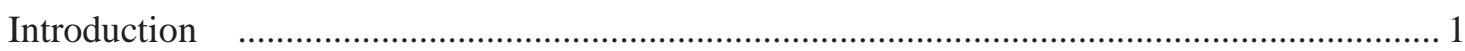

Part 1: Rainfed Agriculture in the Greater Mekong Subregion.................................................. 4

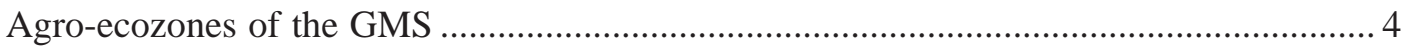

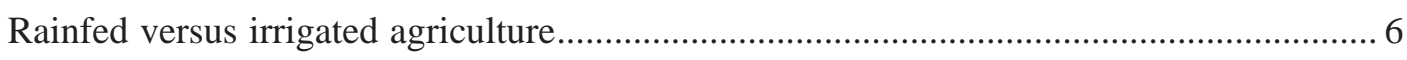

Farming systems of the GMS by agro-ecozone ……...................................................... 7

Part 2: Impacts of Climate Change on Agriculture in the GMS ............................................. 22

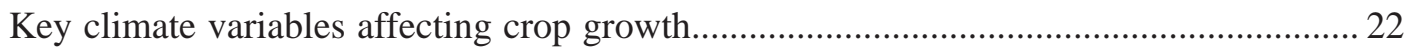

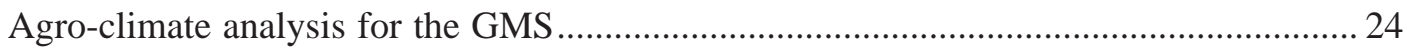

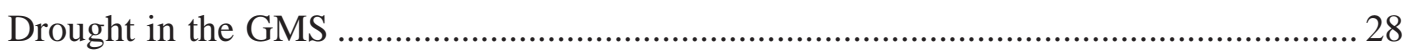

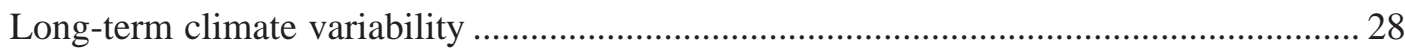

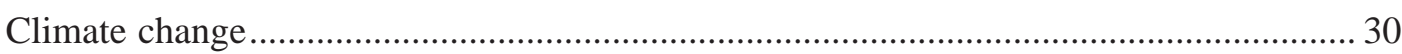

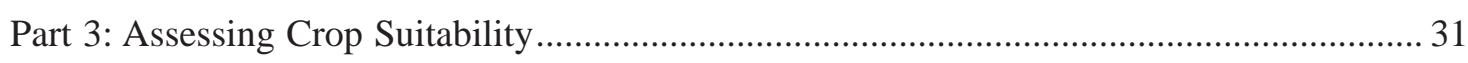

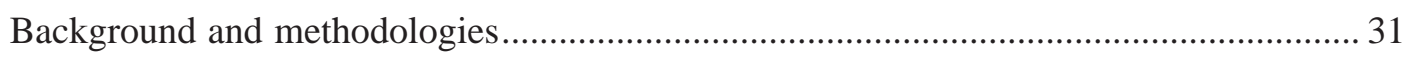

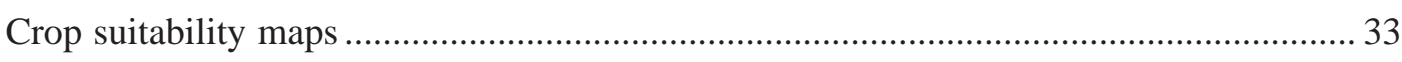

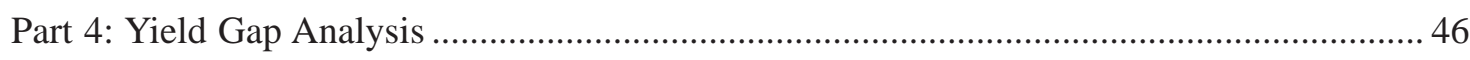

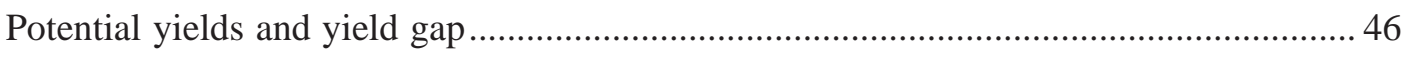

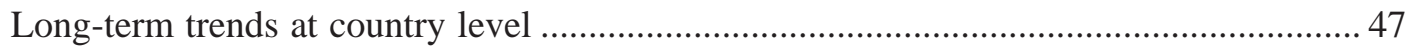

Part 5: Agricultural Water Management Interventions ............................................................. 54

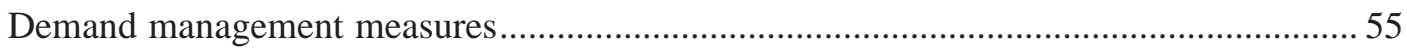

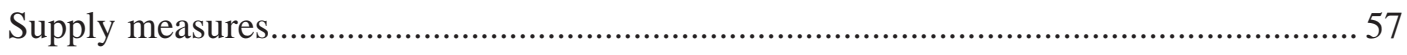

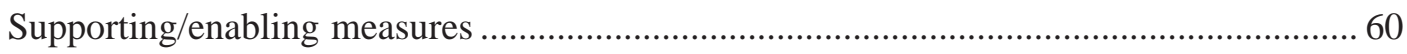

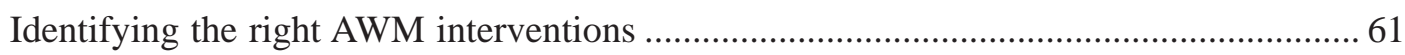

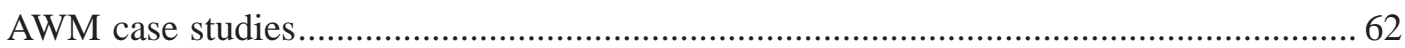

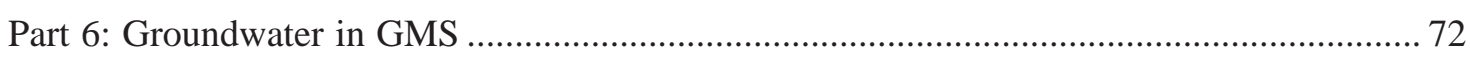

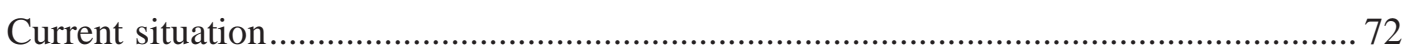

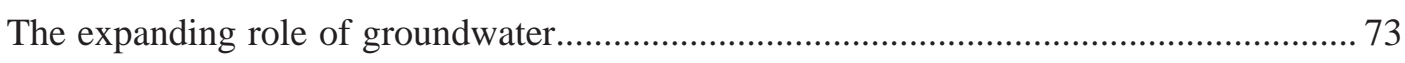

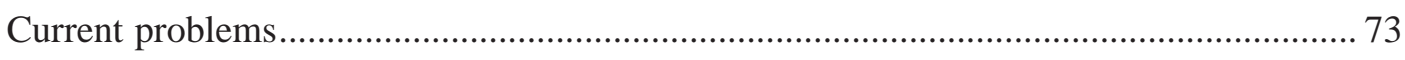

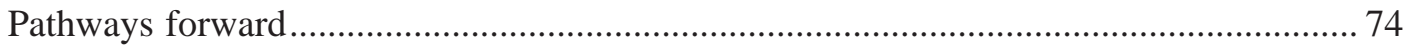

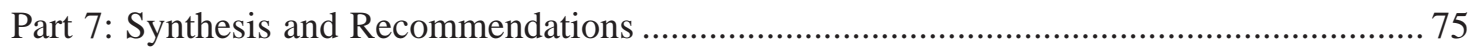

Priority areas for regional interventions in rainfed agriculture..................................... 78

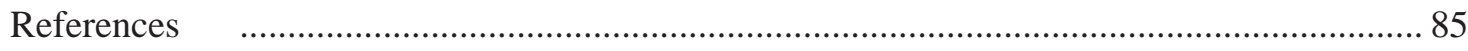





\section{EXECUTIVE SUMMARY}

To keep pace with growing populations and dietary changes, food production in the Greater Mekong Subregion (GMS) will need to increase by an estimated $25 \%$ over the next 15 years. The majority of agricultural production systems in the GMS are rainfed; upgrading these systems promises large social, economic and environmental paybacks in terms of reducing poverty and boosting economic development. This study was commissioned by the Swedish International Development Cooperation Agency (Sida) to investigate opportunities for improving production in rainfed agriculture in the GMS through small-scale water management interventions.

Agroecosystems of the GMS can be described using six zones with broadly similar biophysical conditions and farming systems. Farming systems in the GMS fall into two distinct groups: 'lowland' systems, where inundated rice production predominates, and 'upland' systems, where rice and a mix of other crops are grown under non-flooded (aerobic) conditions. Both systems exist in all Agro-Ecological Zones (AEZs), distributed according to local topography. Generally, inundated rice systems predominate in the deltas and lowland plains, while upland systems dominate in the sloping uplands and highlands.

Annual rainfall is more than adequate to support rainfed cropping throughout the GMS, but its highly seasonal distribution, driven by the southwest monsoon, means the growing season is restricted to six to eight months of the year. Producing crops during the dry season requires some degree of water management. The distinction between irrigated and rainfed cropping in lowland systems is often blurred. Growing lowland rice intrinsically involves water management to maintain inundated conditions, but most of the wet-season crop is rainfed in the sense that the water used mainly comes from rainfall, or from the recession of seasonal floods. On average, more than half of crop water requirements for irrigated crops come from rainfall. Because of the importance of flood-recession agriculture, water levels in the major rivers are as important to rainfed cropping as it is to irrigated crop production. Hydrological drought caused by low flood extent can be as important for rainfed crops as local rainfall deficits.

Analyses of the suitability of major crops show that most crops are constrained in terms of rainfall, emphasizing the critical importance of water management in regional production. Indicatype paddy rice, the region's major crop, is highly sensitive to water availability and is thus only suitable for cultivation with careful water management. In lowland locations where water supply is assured throughout the season, rice systems can be highly productive. However, for many marginal rainfed lowland rice systems, there is a high risk that there will be insufficient water for a good yield. Other important crops, including maize, sugarcane and, to a lesser extent, cassava, are only marginally suitable in terms of precipitation. Growing these crops carries high production risks and the need to assure water for the crop through soil water management and supplementary irrigation. The analyses highlight risks involved in the rapid spread of rubber and coffee as plantation crops in the region, since both these crops are constrained by their temperature and rainfall requirements, and are unsuitable for cultivation over wide areas.

There is significant variation in productivity from different farming systems, reflected in differences in yield across AEZs and between countries. Gains in yields across a range of crops over the last 20 years are the result of water management, improved varieties and better agronomic practices. The largest yield gaps are in two areas: the cultivation of lowland rice in traditional wet-season paddy systems on the lowland plains of Cambodia, northeast Thailand, Lao PDR and Myanmar; and upland agriculture, across a range of crop types, reflecting difficult agricultural conditions in sloping lands with poor soils. 
Water management is a critical first step in improving yields; when water-related risks are reduced, farmers are more willing to invest in other yield-increasing strategies. A wide range of technologies and approaches have been developed to manage water in agricultural systems, and there is a continuum between rainfed and irrigated systems. Agricultural Water Management (AWM) interventions fall into three broad classes: measures to reduce water use or on-farm demand; measures to control and/or increase water supply (including, but not only based on, irrigation); and enabling or accompanying measures. Water management interventions might not be designed specifically to improve yields, but directed towards diversification, with aims to improve overall production and revenues by providing biological and economic resilience. It is important to work across scales to identify where gains in production can be made most effectively. Collective smallscale interventions may be able to achieve similar outcomes to large-scale projects, but with lower costs and greater ownership and involvement. Identifying appropriate management interventions must be done in context, taking into consideration the farming system, physical environment, socioeconomic and cultural factors, and community dynamics. Effective water management should be tailored to the specific condition of each field and farmer. Consultation with local stakeholders is essential.

Water is inextricably linked to processes in the wider landscape, and the cumulative effects of multiple small-scale interventions and land-use decisions can have significant impacts on the way water is transmitted and retained at catchment scales. AWM interventions should be seen in the context of improving the overall capacity of the landscape to provide water storage, stabilize and increase production and water buffers, and strengthen resilience to climate variability.

Groundwater use for agriculture in the GMS is limited, accounting for less than $10 \%$ of total irrigated area, although there has been a rapid expansion in the number of small pumps over the last 10 or 20 years. Groundwater provides significant advantages over formal surface water irrigation systems in terms of flexibility and lower infrastructure costs. The potential for expansion of groundwater use is high, particularly in the large alluvial systems of the region's major rivers, where groundwater is seasonally recharged by the annual flood in 'underground natural irrigation systems'. In some systems, there are opportunities for enhancing groundwater availability through managed aquifer recharge. A comprehensive assessment of the options available for, and barriers to, increasing the use of groundwater is a high priority for the region.

A defining feature of the agricultural systems in the GMS is the rapid pace of change, driven by a complex mix of large-scale forces and unplanned individual land-use choices. Given the need for farmers to shift rapidly in response to external forces and adjust to new environments and conditions, strengthening the population's capacity to adapt and developing supporting institutions is a high priority. Discussions regarding sustainability need to consider how landscapes can function effectively while supporting a variety of cropping and farming systems. They must, therefore, focus on the fundamental ecosystem services that support agricultural production, such as soil fertility, nutrient cycling, water cycling and pollination services, rather than only taking into account the potential for individual crops.

To illustrate the range of issues inherent in identifying and implementing AWM interventions in different systems, six case studies are presented as follows:

- Farm ponds in northeast Thailand.

- Integrated soil and water conservation in Hoa Binh, Vietnam.

- Small reservoirs in Chamnar Krom, Tonle Sap, Cambodia. 
- Coping with drought in Yunnan, China.

- Shallow groundwater tube wells in Svay Rieng, Cambodia.

- Terraces for montane paddy in Luang Prabang, Lao PDR.

Interventions for AWM are specific to local conditions and context. In any system, a diverse range of measures may be needed to address issues at different scales, and to provide farmers with flexibility in terms of cost and production options. While many measures will be implemented on-farm, supporting actions may be required at community or watershed level, and appropriate policies and institutions are required.

At the regional scale, we have identified three priority areas to move AWM forward:

- A regional situation analysis for AWM interventions in the GMS, based on the approach developed in Africa and South Asia under the AWM Solutions Project.

- An assessment of options for different modes of irrigation development in the lowland plains of Cambodia, Myanmar and Lao PDR as a precursor to large proposed investment.

- Development of methods for landscape planning at watershed scale, to optimize integration of water management with agronomic practices and livelihood strategies. 



\section{INTRODUCTION}

The Greater Mekong Subregion (GMS) comprises the five mainland Southeast Asian nations of Cambodia, Lao PDR, Myanmar, Thailand and Vietnam; plus the southern Chinese provinces of Yunnan and Guangxi. Home to around 313 million people, rapid development over the last 20 years has made it a new frontier of Asian economic growth (ADB 2010). To keep pace with growing populations and dietary changes, food production in the GMS will need to increase by an estimated 25\% over the next 15 years (Johnston et al. 2009). The economies of the region are still essentially agricultural, at least in terms of the workforce, with the majority of employment in agriculture (Figure 1). Economic growth in agriculture is important for reducing poverty and fueling expansion of other sectors. Increasing production is required for both food security and to underpin economic development.

Figure 1: Contribution of agriculture to Gross Domestic Product (GDP) and employment in GMS countries

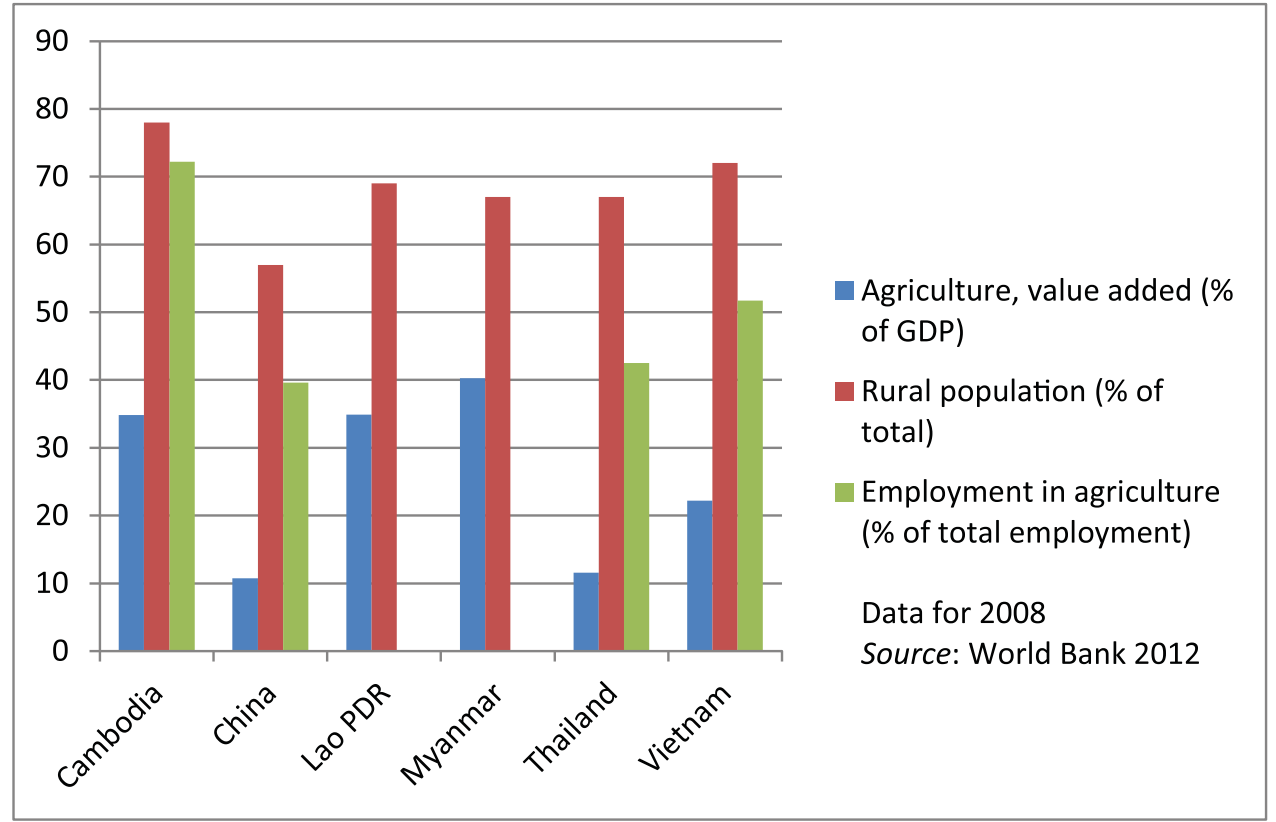

The majority of agricultural production systems in the GMS are rainfed and vulnerable to climate variability. There is great potential for improving productivity, sustainability and resilience in these systems, particularly by controlling water resources better. All national governments consider expanding irrigation an important priority. Irrigated areas are increasing but economic and physical constraints prevent full implementation in some areas. Internationally, the Comprehensive Assessment of Water Management in Agriculture (CA 2007) identified the importance of rainfed agriculture to meeting future food needs. Only $25 \%$ of the additional water required to reduce hunger in line with the 2015 target of the Millennium Development Goals can be contributed from irrigation; the remaining $75 \%$ will need to come from rainfed agriculture. Upgrading rainfed agriculture also promises large social, economic and environmental paybacks, particularly in reducing poverty and boosting economic development. 
International discussions about water for rainfed agriculture have focused on water shortages in arid and semi-arid zones, with less attention being paid to the specific challenges of rainfed agriculture in relatively water-rich humid and sub-humid systems (Pandey et al. 2007). The GMS lies within the humid to sub-humid tropics, and total annual rainfall exceeds 750 millimeters $(\mathrm{mm})$ in most areas. Absolute water shortage is not the primary issue, but yields are much lower than they could be and water stress is a significant constraint to production. The strongly seasonal nature of rainfall and flows means floods and droughts are common. Although not necessarily the only or most important constraint to increasing production, access to water is often the least manageable risk factor for smallholder farmers. Where water-related risks are reduced, farmers are more willing to invest in other yield-increasing strategies (Wani et al. 2009).

This study was commissioned by Sida to investigate opportunities to improve production in rainfed agriculture in the GMS through small-scale water management interventions. The study has seven sections:

- Part 1 reviews the agroecological context of rainfed agriculture in the GMS and describes the main farming systems.

- Part 2 analyzes patterns of climate variability across the region to identify areas where crops are most vulnerable to water-related stress.

- Part 3 examines how suitable different crops are for growing under rainfed conditions in the various climate zones across the region.

- Part 4 analyzes spatial and temporal variations in production and yield of the major rainfed crops across the region, with the aim of identifying yield gaps and opportunities for improvement.

- Part 5 identifies water management interventions with the potential to improve production in rainfed systems. Using six case studies, it explores the issues, opportunities and constraints to implementing these changes.

- Part 6 outlines issues relating to increased use of groundwater for agricultural production in the GMS.

- Part 7 provides a brief synthesis and suggests priorities for implementing changes in smallscale water management. 


\section{Definitions}

Rainfed agriculture refers to those agricultural systems that are not irrigated and rely solely on rainfall for their water supply. About $80 \%$ of the world's farmed lands are rainfed and this ratio rises up to $88 \%$ in mainland Southeast Asia (Devendra and Thomas 2002). These systems are highly sensitive to climate variability, which limits agricultural production. Often, the total amount of rainfall is more than adequate for crop growth, but the variation between years and distribution within the wet season means that unpredictable droughts and water shortages reduce production (Rockström et al. 2007). Inundation can reduce productivity or even completely destroy crops.

Drought has many definitions (Eriyagama et al. 2009). Although it is induced climatically, the impacts of drought depend on many other factors. Three commonly used definitions of drought (Pandey et al. 2007) are:

- Meteorological drought: a period where rainfall is significantly below the long-term average. A commonly used criterion is less than $80 \%$ of mean annual rainfall or rainfall during the period in question.

- Hydrological drought: depletion of surface and subsurface water resources, usually due to low rainfall, though there may be other contributing factors. Hydrological drought is an important concept in irrigated systems. Meteorological drought in the headwaters of a catchment can result in hydrological drought downstream in areas where local rainfall is normal.

- Agricultural drought: a period when soil water is insufficient to meet crop water requirements, resulting in yield losses. Since the impacts of rainfall deficits depend on soil and crop type, and cumulative addition and removal in consecutive cropping seasons, agricultural drought can be a very local phenomenon.

Agricultural systems are defined by a combination of agricultural practices within a specific ecological setting, resulting from interactions between climate, environment and social behavior.

Lowland versus upland: there are two commonly used definitions relating respectively to position in the topo-sequence, and specifically to modes of rice cultivation. Topographic lowlands are flat, low-lying areas generally inundated during the wet season (broadly approximated in this study by areas less than 250-meter (m) elevation). Uplands are at higher elevations and usually sloping, from gentle to steep. Lowland rice, whether rainfed or irrigated, is grown under inundated conditions for at least part of the crop cycle, typically in bunded paddy fields. Upland rice is grown in non-inundated fields. These two definitions, based on topography and rice cultivation, are not universally consistent. Sometimes, lowland rice grows in upland topographic areas in irrigated valleys and terraces. In this study, the term montane paddy is used for inundated rice cultivation in upland areas. Similarly, it is possible to have upland (non-inundated) areas and crops within lowland areas that are dominated by lowland, inundated rice, where the upland nature of these cropping areas results from very small differences in elevation and water management. Upland crops can also occur in topographically low areas through temporal separation from the main wet-season inundated lowland rice crop. 


\section{PART 1: RAINFED AGRICULTURE IN THE GREATER MEKONG SUBREGION}

\section{Agro-ecozones of the GMS}

The GMS region is culturally and geographically diverse, but can be divided into six broad agro-ecozones, each of which share common production systems and are subject to similar biophysical constraints and risks (modified from Johnston et al. 2009) (Figure 1.1).

Figure 1.1 Agro-ecozones of the Greater Mekong Subregion

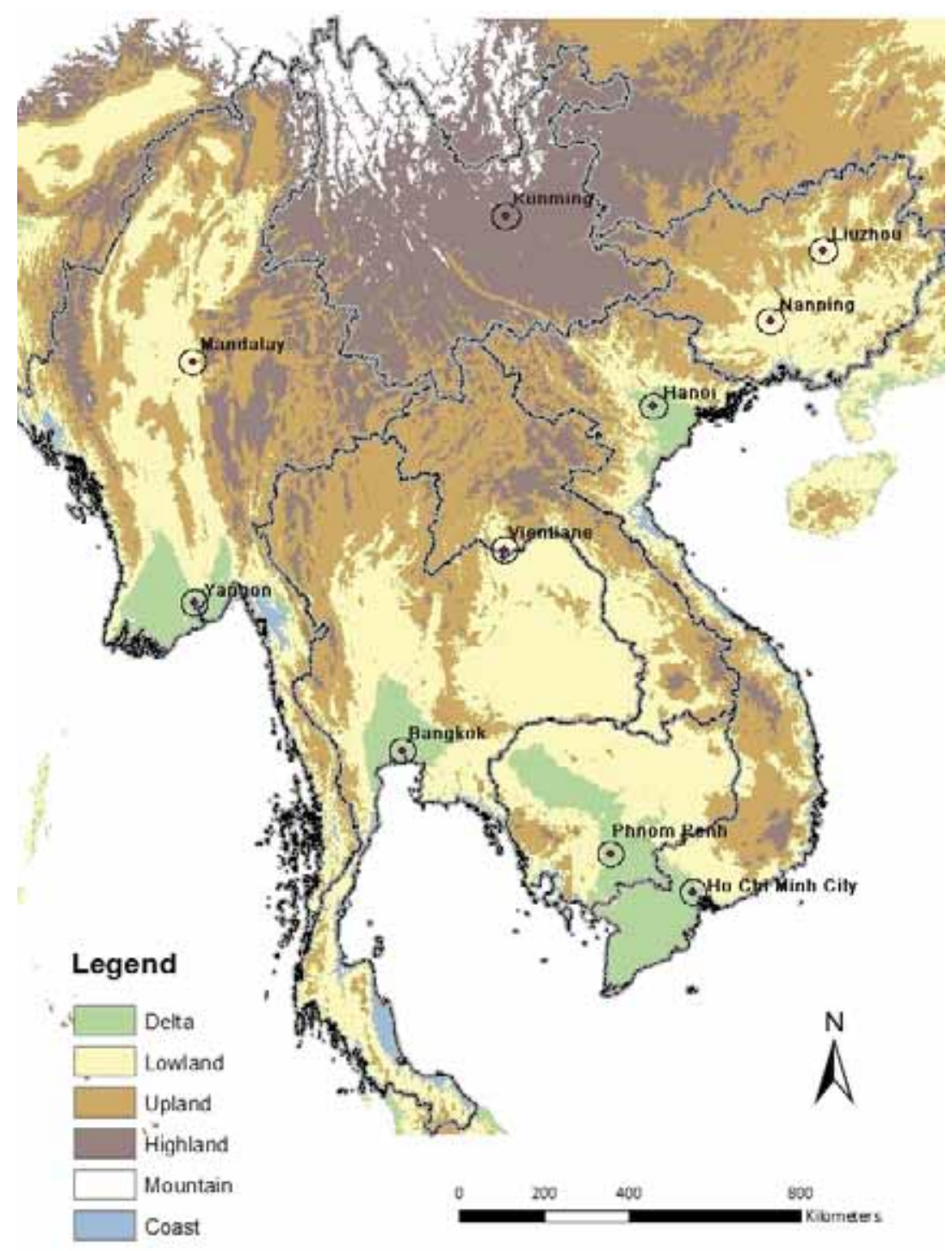

- Mega-deltas of the Red, Chao Phraya, Irrawaddy and Mekong rivers (including the Tonle Sap Floodplain).

- Lowland plains of northeast Thailand, Central Thailand, Myanmar Dry Zone, Lao Mekong floodplains, and north and northeast Cambodia. 
- Coastal zones, which comprise narrow coastal plains that rise rapidly to coastal ranges (defined as areas below $250 \mathrm{~m}$ and within 50 kilometers $(\mathrm{km})$ of the ocean in Vietnam, Cambodia, Thailand and Myanmar).

- Tropical uplands of Guangxi, northern Thailand, northern and central Lao PDR, northern and central Myanmar, and central and northern Vietnam.

- Subtropical highlands of Yunnan; eastern and western hills in Myanmar; Da Lat Plateau of Vietnam; and the Bolovens and Xiengkuang plateaux in Lao PDR.

- Peri-urban zones around the region's major cities.

These agro-ecozones are not rigidly defined areas, but provide a useful construct in which to assess the interactions and dependencies between agricultural production systems and the ecosystems that support them. Rainfall varies considerably across these zones but topography generally exerts a stronger control on farming systems than rainfall. The relative distribution of these agroecologies varies widely between the six countries of the GMS. The delta and lowland areas make up more than $80 \%$ of Cambodia and $60 \%$ of Thailand, but only $21 \%$ and $16 \%$ of Lao PDR and southern China (Yunnan and Guangxi), respectively (Figure 1.2). Populations are concentrated in the deltas, lowlands and coasts relative to the uplands and highlands.

Figure 1.2 Distribution of land area and population within agro-ecozones in the countries of the GMS

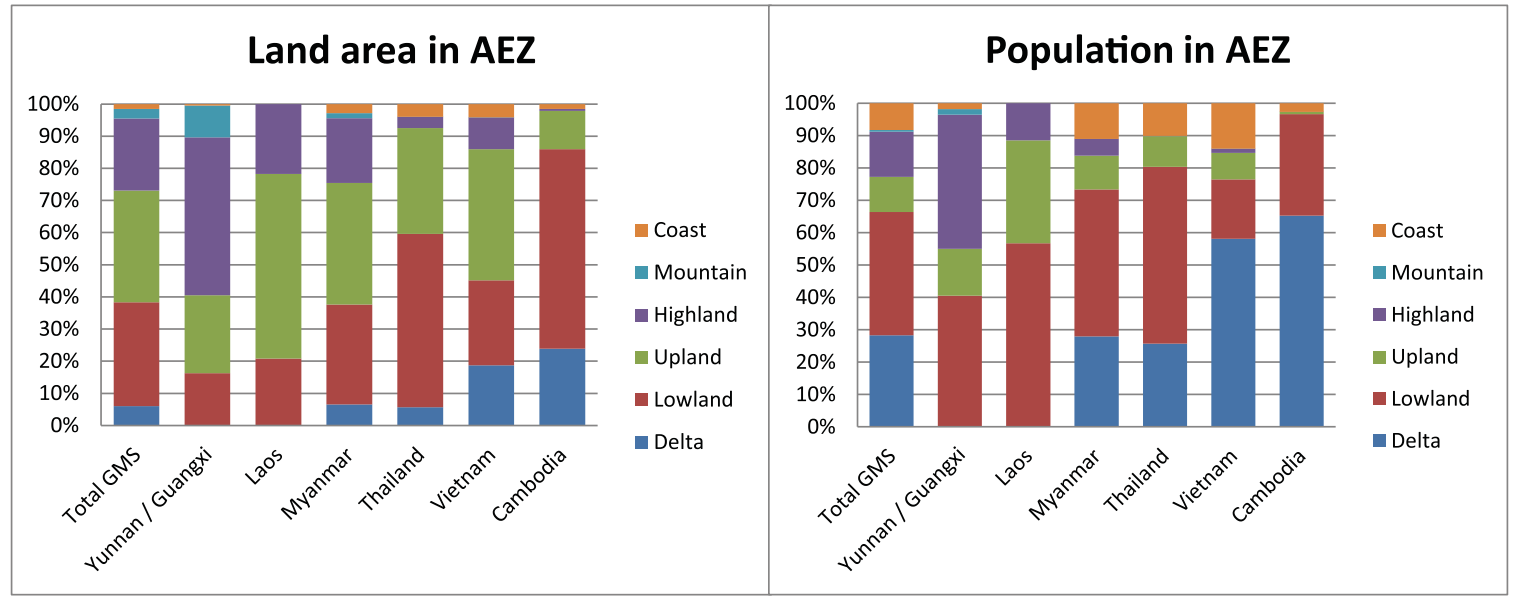

Modes of agricultural production vary according to the natural resources available and the degree of economic development. Agriculture in southeast Asia is in transition from being traditional subsistence systems to modern commercial production. The extent of travel along this trajectory varies enormously both within and between countries, but the overall direction of change is very similar: intensification, specialization, increased inputs and mechanization. Given the diverse levels of economic development within the region, farming systems have progressed to different levels within each zone in different countries. The more developed countries (such as Thailand and China) can be seen as models of where the less-developed countries may be heading.

Climatically, the GMS lies almost entirely within the humid to sub-humid tropics, with only small areas of Myanmar and northeast Thailand regarded as marginally semi-arid. Water resources are relatively abundant. The region contains four major rivers that drain from the Himalayan plateau in Yunnan (Mekong, Yangtze, Irrawaddy and Salween), plus a number of 
smaller but locally important rivers (Chao Phraya, Red and Yun Xiang). However, between $70 \%$ and $95 \%$ of rainfall occurs within the six months of the wet season and many areas have periods of three to five months without rainfall. Climate and climate variability in the GMS are described in Part 2 below.

\section{Rainfed versus irrigated agriculture}

Agriculture is an important component of the economy and livelihoods in all GMS countries. The contribution of agriculture to total GDP varies (Figure 1) and is declining over time, but in all countries agriculture accounts for more than 50\% of employment. Devendra and Thomas (2002) estimated that rainfed areas accounted for between $70 \%$ and $95 \%$ of total arable land between 1997 and 2000. The proportion of irrigated agriculture in the GMS is generally increasing over time (Figure 1.2), but is still low in comparison with world standards. World Bank (2012) reports that between $7 \%$ and 35\% of total cropland in GMS countries is irrigated. Government statistics compiled for this study (Tables $1.1-1.5$ ) indicate that the irrigated area extends to around 10 million hectares (Mha), or $20 \%$ of total cropland.

These statistics, however, mask a more complex picture. While experts acknowledge that the majority of agricultural production in the region is rainfed, it is surprisingly difficult to differentiate the relative extent and importance of rainfed production from irrigated production, for two main reasons. First, the region's dominant crop is wet-season lowland rice, grown in paddy fields under varying degrees of water management that range from fully rainfed to that requiring a significant amount of supplementary irrigation. Second, since average annual rainfall exceeds 1,000 $\mathrm{mm}$ across more than $90 \%$ of the GMS, a significant proportion of water available to crops comes from rainfall, even in areas where irrigation infrastructure is provided.

The wet-season lowland rice crop, nominally rainfed, is grown in flooded paddy fields with varying degrees of control over water inputs and often supplemented by irrigation; this can vary from formal schemes to local redistribution of the seasonal flood water and rainfall. Nesbitt (2002) estimated that over 4 Mha of the total 10 Mha cultivated with rice in the Lower Mekong Basin during the wet season receives some form of supplemental irrigation. This figure includes 750,000 hectares (ha) of nursery, which receives extra water prior to transplanting. If the redistribution of rainfall as drainage from one field to another is included, the area categorized as irrigated would be much greater.

In some locations, partially or fully irrigated crops of rice, vegetables and maize are grown during the dry season to take advantage of the high solar radiation. This is only possible where there is a large water supply that can be carefully controlled. Generally, dry-season crops are rarely fully irrigated. In most cases, they are planted to take advantage of the beginning or end of the wet-season rains, or of residual soil moisture. More than half of Cambodia's reported dry-season rice crop, harvested between April and May, is actually recession rice, watered primarily from receding floodwaters (Nesbitt 2002). Myanmar has a similarly large proportion of recession rice. In the Mekong Delta, growing two irrigated dry-season crops a year has progressively replaced planting traditional wet-season rice. However, both receive a significant amount of rainfall. Based on a water account, Kirby et al. (2010) estimated that in Cambodian and Vietnamese sub-basins of the southern Mekong Basin, more than $60 \%$ of total evapotranspiration from irrigated crops is derived from rainfall.

Statistics on the area equipped for irrigation do not accurately reflect the extent of irrigation in use. In many areas, only a small proportion of the land equipped for irrigation actually receives water in this way during the dry season; wet-season supplementary irrigation is much more widely 
used. In northeast Thailand, the dry-season cropping intensity equates to only $10 \%$ or $15 \%$ of the irrigated area (Nesbitt 2002; Molle and Floch 2008). This is attributed to poor reliability of supply and high labor costs. In Cambodia, the low uptake of dry-season irrigation is partly due to a lack of flexibility in the way irrigation water is delivered. The irrigation systems were designed primarily for rice production and do not provide appropriate water control for other higher-value dry-season crops (Thuon and Bastakoti 2010). In Laos, the 70,000 ha of irrigated area used during the dry season is only $40 \%$ of the area reported as being equipped for irrigation. Conversely, the 162,000 ha of land used with some irrigation during the wet season equates to $130 \%$ of the equipped area, indicating a much more enthusiastic uptake of wet-season supplementary irrigation than full dryseason irrigation.

Throughout the GMS, there is thus a gradation from fully irrigated to fully rainfed systems, but the lines between the two are blurred. Rainfed lowland rice systems are classed as being more or less 'favorable', based on the riskiness of producing crops without irrigation. Wani et al. (2009) argued that the division of fully irrigated to fully rainfed systems is artificial and should be discarded in favor of a more integrated approach to water management at a catchment level. A more useful distinction may be made between large-scale, formal irrigation and drainage schemes that are planned and managed by governments or corporations, and small-scale, informal water management systems managed at farm or community level. The two are not necessarily mutually exclusive, as small-scale water management efforts may complement large-scale systems, providing a degree of flexibility. The central issue is about managing risks related to water availability across the spectrum. There is, however, a clear pattern of decreasing intensity of agricultural water management moving up topographically from the mega-deltas to the lowlands and then to the uplands, with consequences for crop type and productivity.

\section{Farming systems of the GMS by agro-ecozone}

\section{Deltas}

Extent: Mega-deltas of the Irrawaddy, Chao Phraya, Red and Mekong rivers, including the Tonle Sap Floodplain, at elevations below $20 \mathrm{~m}$. Together, they represent $7 \%$ of the total area of the GMS.

Population: 94 million people, including more than $60 \%$ of the total population of Vietnam and Cambodia, and more than 25\% in Thailand and Myanmar. Each of the deltas contains major urban areas.

AEZ: The low-lying deltas and floodplains of these major rivers are inundated between three and eight months of the year, and have been extensively modified for agriculture. Annual rainfall varies from more than 3,000 $\mathrm{mm}$ annually in parts of the Irrawaddy Delta to less than 1,200 $\mathrm{mm}$ in the Chao Phraya Delta.

Farming systems: Dominantly lowland rice - both irrigated and rainfed. Some irrigated upland crops are grown in the dry season in Thailand (sugarcane, maize, cassava) and the Red River Delta (vegetables, maize). There is a high density of livestock fed on crop residues. Brackish and freshwater aquaculture are also undertaken.

Water management: All deltas have been modified with a complex of dykes, levees and canals to divert and retain water for agriculture. Water is taken directly from surface rivers and streams; only the Red and Chao Phraya deltas have significant upstream reservoirs to regulate supply. Infrastructure is least developed in the Irrawaddy Delta and on the Tonle Sap Floodplain. It is most intensively developed in the Red and Mekong deltas. 
The deltas (Table 1.1) are the rice bowls of Southeast Asia, dominated by rice production in flooded paddy and between one and three crops being cultivated a year. Production systems vary from being traditional recession and deep-water rice using the natural floods in Cambodia and Myanmar, to highly managed smallholder irrigation in the Mekong and Red deltas producing two to three crops a year, and large-scale irrigation for commercial production in the Chao Phraya delta. Production is intensive; $75 \%$ of the area is cropped. Only remnant areas of the natural vegetation of flooded forests and mangroves remain. The deltas produce 37\% of the total rice crop of the GMS from 7\% of total area. Production of upland crops is limited, except in Thailand, where farmers grow sugarcane, maize and cassava, and the Red River Delta, where vegetables and maize are planted. Horticultural crops and orchards are being developed in the Mekong Delta in Vietnam and in the Chao Praya Delta. There is a high density of livestock but low numbers of animals compared to that on the lowland plains. Brackish and freshwater aquaculture are both important sectors.

The seasonal inundation that occurs between three and eight months annually in the deltas makes water management essential for growing crops. All the deltas are flood-prone, though the upper part of the Mekong Delta and the Tonle Sap Floodplain are most at risk. Levees and dykes, vital for protecting early- and late-season crops from flooding, have substantially modified natural patterns of flooding. Flood-control systems restrict flushing of fields, and reduce the volume of sediment and nutrients deposited on land, causing soil fertility to decline and residues of pesticide and herbicides to build-up.

All deltas have at least two crops a year, although cropping intensity is lower in the Irrawaddy Delta and around Tonle Sap Floodplain. In these locations, the wet-season crop still accounts for more than $75 \%$ of plantings, which include substantial areas of recession, deep-water and floating rice. The extent of land equipped to produce irrigated dry-season rice is increasing, as infrastructure is constructed or repaired. In the Red River Delta, where there has been extensive development of polders for controlling water, plantings in the seasons of spring and winter are approximately equal. In the Mekong Delta, the traditional wet-season (тиа) crop has declined to only about $10 \%$ of total plantings (0.38 Mha). By comparison, 1.8 Mha are sown in the autumn and 1.57 Mha in spring. In the Chao Phraya Delta, dry-season planting is about half that of the wet season.

The higher degree of water management is a contributing factor in the relatively high yields reported from deltas (see Table 1.1). Yields in the Red and Mekong deltas are the highest in the region, averaging 5-6 tonnes per hectare (t/ha), and lowest in Cambodia (2.5 t/ha) and Myanmar (3.6 t/ha). There are various reasons why yields differ so much between deltas. These include the much lower use of improved crop varieties and fertilizers in Cambodia and Myanmar, pest and disease problems, and the lower incidence of dry-season cropping in certain areas. The yield potential of crops is generally higher during the dry season than the wet season because of the higher levels of solar radiation.

In the Vietnamese part of the Mekong Delta, and in the Red and Chao Phraya deltas, the majority of production now takes place in the dry season under highly controlled water conditions. This has resulted in large gains in yield. Attaining the maximum potential yield from these areas will depend more on careful management of other agronomic factors. In the Cambodian Mekong Delta and Myanmar, however, there are still significant gains to be made from reducing water-related risks. Different strategies will be required for each area. Based on experience in the Vietnamese sector of the Mekong Delta, shifting production to the dry season in the Cambodian part could bring about benefits from the greater solar radiation and reduced likelihood of flooding. Surface water and groundwater sources for irrigation should be investigated in this area. In the Irrawaddy Delta, where annual rainfall is very high, measures to mitigate flooding (such as introducing inundation-resistant crop varieties) are more important. Major gains in yield will require not only better agricultural water management but improved crop varieties and agronomic practices. 
Table 1.1: Deltas and floodplains

\begin{tabular}{|c|c|c|c|c|c|}
\hline Deltas and floodplains & GMS & Myanmar & Thailand & Vietnam & Cambodia \\
\hline Proportion of total land area & $7 \%$ & $25 \%$ & $16 \%$ & $35 \%$ & $24 \%$ \\
\hline$\%$ of country in AEZ & & $7 \%$ & $6 \%$ & $19 \%$ & $24 \%$ \\
\hline Population (millions) & 93.7 & 16.4 & 16.5 & 51.3 & 9.5 \\
\hline$\%$ of total country population & $29 \%$ & $28 \%$ & $26 \%$ & $58 \%$ & $65 \%$ \\
\hline \multicolumn{6}{|l|}{ Land cover (Globcover 2009)*\# } \\
\hline Irrigated crops & $42 \%$ & $43 \%$ & $46 \%$ & $43 \%$ & $35 \%$ \\
\hline Rainfed crops & $30 \%$ & $33 \%$ & $23 \%$ & $26 \%$ & $36 \%$ \\
\hline Crop mosaic & $15 \%$ & $13 \%$ & $21 \%$ & $16 \%$ & $12 \%$ \\
\hline Forest & $3 \%$ & $1 \%$ & $3 \%$ & $4 \%$ & $4 \%$ \\
\hline Shrub and grasslands & $5 \%$ & $3 \%$ & $3 \%$ & $7 \%$ & $4 \%$ \\
\hline Average rainfall & & 2,750 & 1,370 & 1,730 & 1,400 \\
\hline Area equipped for irrigation ('000 ha) & & 542 & 700 & 1,915 & 38 \\
\hline \multicolumn{6}{|l|}{ Agricultural statistics } \\
\hline Area WS rice ('000 ha) & & 1,812 & 800 & 466 & 1,115 \\
\hline Yield WS rice (t/ha) & & 3.4 & 4.0 & 4.1 & 2.6 \\
\hline Area DS rice ('000 ha) & & 460 & 618 & 4,658 & 255 \\
\hline Yield DS rice (t/ha) & & 3.9 & 3.9 & 5.6 & 4.2 \\
\hline Area maize ('000 ha) & & 7 & 29 & 140 & 71 \\
\hline Yield maize (t/ha) & & 3.0 & 4.0 & 4.6 & 3.5 \\
\hline Area sugarcane ('000 ha) & & 3 & 84 & 82 & 4 \\
\hline Yield sugarcane (t/ha) & & 42.5 & 69.3 & 83.4 & 21.8 \\
\hline Cattle plus buffalo ('000s) & & 3,626 & 379 & 1,793 & 1,944 \\
\hline$\%$ of country total & & $15 \%$ & $6 \%$ & $20 \%$ & $46 \%$ \\
\hline Pigs ('000s) & & 439 & 1,830 & 11,198 & 1,175 \\
\hline \multicolumn{6}{|l|}{ Farming system } \\
\hline Primary & & $\begin{array}{l}\text { Wet-season rainfed } \\
\text { rice/recession rice. } \\
\text { Livestock. Pulses as } \\
\text { un-irrigated second } \\
\text { crop }\end{array}$ & $\begin{array}{l}\text { Commercial and } \\
\text { semi-commercial } \\
\text { multiple cropping } \\
\text { of rice and other } \\
\text { crops. Mechanized, } \\
\text { high input }\end{array}$ & \begin{tabular}{|l|} 
Red: two crops \\
intensive irrigated \\
rice,vegetables and \\
maize in winter. \\
Mekong: intensive \\
irrigated rice in \\
three seasons
\end{tabular} & \begin{tabular}{|l} 
Wet-season rainfec \\
rice/recession rice. \\
Livestock graze \\
stubble in dry \\
season. Capture \\
fishery from lakes, \\
rivers, rice field
\end{tabular} \\
\hline Secondary & & $\begin{array}{l}\text { Irrigated double } \\
\text { rice cropping }\end{array}$ & $\begin{array}{l}\text { Wet-season rice, } \\
\text { dry-season } \\
\text { irrigated field } \\
\text { crops (maize, } \\
\text { sugar); } \\
\text { livestock } \\
\end{array}$ & \begin{tabular}{|l|} 
Mekong: mixed \\
gardens, fruit trees, \\
vegetables; small \\
livestock (pigs, \\
chickens)
\end{tabular} & $\begin{array}{l}\text { Irrigated/partially } \\
\text { irrigated double } \\
\text { cropping of rice; } \\
\text { early season fast- } \\
\text { growing varieties }\end{array}$ \\
\hline Other & & \begin{tabular}{|l|} 
Freshwater and \\
marine fisheries; \\
fresh and brackish \\
water aquaculture
\end{tabular} & $\begin{array}{l}\text { Intensive } \\
\text { production around } \\
\text { Bangkok: dairy, pig } \\
\text { and chicken farms; } \\
\text { vegetables; } \\
\text { horticulture intensive } \\
\text { aquaculture. }\end{array}$ & $\begin{array}{l}\text { Brackish water } \\
\text { shrimp } \\
\text { aquaculture; } \\
\text { freshwater } \\
\text { aquaculture, } \\
\text { freshwater and } \\
\text { marine fisheries }\end{array}$ & $\begin{array}{l}\text { Floating/ } \\
\text { deep-water rice } \\
\text { around Tonie Sap; } \\
\text { decreasing in area }\end{array}$ \\
\hline \multicolumn{6}{|l|}{ Water management } \\
\hline & & \begin{tabular}{|l|} 
Extensive drainage \\
and flood \\
protection works, \\
some areas \\
equipped with \\
pumps for \\
irrigation
\end{tabular} & \begin{tabular}{|l|} 
Large-scale \\
irrigation schemes \\
with upstream \\
storage; some \\
groundwater \\
irrigation. Chao \\
Phraya Basin is \\
over-allocated; dry \\
season water \\
shortages
\end{tabular} & \begin{tabular}{|l|} 
Red: extensive \\
system of polders \\
and canals, with \\
upstream storage \\
Mekong: intricate \\
system of canals \\
and dykes cover \\
most of the delta; \\
up to $80 \%$ of \\
dry-season flows \\
extracted for \\
irrigation
\end{tabular} & \begin{tabular}{|l|} 
Colmatage \\
systems south \\
of Phnom Penh; \\
limited areas of \\
formal irrigation \\
around Tonie \\
Sap, mostly only \\
partially \\
functioning
\end{tabular} \\
\hline
\end{tabular}

Notes: * Total may be $<100 \%$ since minor classes (open water, wetlands, urban, etc.) are not included.

\# There are discrepancies between estimates of irrigated area from satellite imagery and national statistics, due to difficulties in distinguishing flooded paddy and recession rice from formal irrigation; and in identifying small areas of irrigation.

WS = wet season; DS = dry season 
Tailoring water management in the deltas primarily to rice production has had repercussions for other types of farming. For example, it has limited production of other crops; it is only in the Red River and Chao Phraya deltas that significant planting of other crops, namely vegetables and sugarcane, respectively, are taking place. Increased rice production has provided the opportunity to increase the density of livestock, however, since herds of cattle and buffalo are fed on stubble and hay, while pigs and poultry eat bran. As a result, livestock densities are now very high. Traditional rice-fish systems, dependent on the natural flood pulse, decrease in importance in more intensive agricultural areas. While paddy-field capture is important for fisheries in the Cambodian part of the Mekong Delta and around the Tonle Sap Floodplain, it is less important in the Vietnamese parts of the delta, where the capture of fish from rivers and streams dominates. Brackish and freshwater aquaculture, expedited by the ability to control water inputs, is a large and growing sector across all the deltas.

\section{Lowland plains}

Extent: Lowlands, lying at an altitude between 20 and $250 \mathrm{~m}$, account for a third of the total area in the GMS. The largest areas are in Guangxi in China, Myanmar and Thailand. Lowlands make up more than half the total area of Thailand and almost two-thirds of Cambodia (Table 1.2).

Population: Lowlands are home to just over a third of the total population (38\%), with a lower population density and low-intensity agriculture than in the deltas. There are moderate population densities of 50-150 people/square kilometer $\left(\mathrm{km}^{2}\right)$ throughout the GMS, apart from Cambodia where the population density is very low with fewer than 10 people $/ \mathrm{km}^{2}$.

AEZ: The relatively flat lowland plains have been extensively cleared for agriculture. However, large areas of forest remain in the north and northeast of Cambodia, and Central Lao PDR. Annual rainfall is generally low at 1,200-1,500 mm, but can reach 2,000 mm/year in Lao PDR and Cambodia.

Farming systems: The lowlands are dominated by wet-season lowland rice, rainfed sugarcane, maize, legumes, pulses and cassava. A second irrigated rice crop is grown in some areas, and there is increasing use of irrigation for other dry-season crops. There has been a rapid expansion of commercial plantations providing sugarcane, oil crops, rubber, timber and pulpwood. Large livestock herds graze stubble in the dry season or are fed on crop residues. Combined rice-fish cultivation in lowland paddy, and capture fishery from waterways, are important contributors to livelihoods, particularly in Cambodia, Lao PDR and northeast Thailand.

Water management: Irrigation is predominantly used in the lowlands as supplementary water when growing wet-season paddy and field crops, particularly at the transition from the wet season to dry. Uptake of dry-season irrigation has so far been limited. There are large-scale irrigation projects and extensive water storage facilities in Thailand, with mainly river-pumped systems in Lao PDR and Myanmar. There has been limited irrigation development in Cambodia, but large schemes are proposed. Serious dry-season water shortages and conflicts over use occur in some areas (notably in northeast Thailand).

The dominant farming system in the lowlands is wet-season rice grown in seasonally inundated paddies. Across much of the lowlands, as with the deltas, there are relatively few cropping options other than rice. In some areas, double-cropping in the wet season is possible with fast-maturing high-yielding varieties planted early on, and then harvested in time to plant a second traditional variety (Nesbitt 2002; DAP 2011). Other rainfed crops, cultivated in areas not subject to inundation, include sugarcane, maize, vegetables, legumes, pulses, mung beans, sesame, cassava, soybeans, peanuts and kenaf. Most crops are planted early in the wet season and harvested before the floods 
Table 1.2: Lowlands

\begin{tabular}{|c|c|c|c|c|c|c|c|}
\hline Lowlands & GMS & $\begin{array}{l}\text { Yunnan / } \\
\text { Guangxi }\end{array}$ & Laos & Myanmar & Thailand & Vietnam & Cambodia \\
\hline Proportion of total land area & $32 \%$ & $13 \%$ & $6 \%$ & $25 \%$ & $33 \%$ & $10 \%$ & $13 \%$ \\
\hline$\%$ of country in AEZ & & $16 \%$ & $21 \%$ & $31 \%$ & $54 \%$ & $27 \%$ & $62 \%$ \\
\hline Population (millions) & 111.8 & 36.2 & 3.3 & 19.0 & 34.6 & 14.7 & 4.0 \\
\hline$\%$ of total country population & & $41 \%$ & $57 \%$ & $45 \%$ & $55 \%$ & $18 \%$ & $31 \%$ \\
\hline \multicolumn{8}{|l|}{ Land cover (Globcover 2009)*\# } \\
\hline Irrigated crops & $8 \%$ & $1 \%$ & $3 \%$ & $13 \%$ & $11 \%$ & $2 \%$ & $2 \%$ \\
\hline Rainfed crops & $36 \%$ & $22 \%$ & $29 \%$ & $28 \%$ & $60 \%$ & $19 \%$ & $19 \%$ \\
\hline Crop mosaic & $17 \%$ & $43 \%$ & $9 \%$ & $8 \%$ & $16 \%$ & $22 \%$ & $13 \%$ \\
\hline Forest & $20 \%$ & $21 \%$ & $29 \%$ & $22 \%$ & $6 \%$ & $31 \%$ & $34 \%$ \\
\hline Shrub and grasslands & $18 \%$ & $11 \%$ & $27 \%$ & $27 \%$ & $5 \%$ & $24 \%$ & $28 \%$ \\
\hline Average rainfall & & 1,550 & 2,070 & 1,990 & 1,540 & 1,840 & 1,800 \\
\hline \multicolumn{2}{|c|}{ Area equipped for irrigation ('000 ha) } & 652 & 61 & 874 & 1,107 & 488 & 44 \\
\hline \multicolumn{8}{|l|}{ Agricultural statistics } \\
\hline$\%$ of national rice production & $35 \%$ & $12 \%$ & $3 \%$ & $18 \%$ & $47 \%$ & $14 \%$ & $7 \%$ \\
\hline Area WS rice ('000 ha) & & 664 & 309 & 1,865 & 6,486 & 235 & 998 \\
\hline Yield WS rice (t/ha) & & 5.4 & 3.4 & 3.3 & 2.3 & 4.2 & 2.5 \\
\hline Area DS rice ('000 ha) & & 1,324 & 241 & 1,205 & 4,743 & 4,886 & 378 \\
\hline Yield DS rice (t/ha) & & 7.4 & 4.9 & 3.8 & 3.5 & 5.3 & 3.7 \\
\hline Area maize ('000 ha) & & 229 & 6 & 73 & 493 & 294 & 81 \\
\hline Yield maize (t/ha) & & 4.2 & 4.9 & 2.1 & 4.1 & 4.2 & 3.9 \\
\hline Area sugarcane ('000 ha) & & 453 & 8 & 67 & 655 & 78 & 7 \\
\hline Yield sugarcane (t/ha) & & 71 & 29 & 44 & 68 & 53 & 26 \\
\hline Cattle plus buffalo (millions) & & 1.9 & 1.0 & 10.9 & 4.3 & 2.7 & 2.0 \\
\hline$\%$ of country total & & $37 \%$ & $37 \%$ & $45 \%$ & $64 \%$ & $30 \%$ & $47 \%$ \\
\hline Pigs ('000s) & & 23.3 & 0.7 & 0.7 & 3.4 & 7.2 & 0.9 \\
\hline \multicolumn{8}{|l|}{ Farming system } \\
\hline Primary & & $\begin{array}{l}\text { Intensive } \\
\text { wet-season } \\
\text { paddy with } \\
\text { double } \\
\text { cropping or } \\
\text { cash crop; pig } \\
\text { raising on crop } \\
\text { residues }\end{array}$ & $\begin{array}{l}\text { Wet-season } \\
\text { rainfed rice, } \\
\text { plus dry-season } \\
\text { maize, } \\
\text { sugarcane, } \\
\text { cassava; } \\
\text { livestock }\end{array}$ & \begin{tabular}{|l|} 
Wet-season \\
rainfed rice, \\
single crop and \\
pulses, maize, \\
sugarcane, \\
cassava; \\
livestock
\end{tabular} & \begin{tabular}{|l|} 
Wet-season \\
rainfed rice, \\
single crop plus \\
maize, \\
sugarcane, \\
cassava; \\
livestock
\end{tabular} & \begin{tabular}{|l|} 
Double \\
cropping of \\
paddy rice; one \\
rice and one \\
upland crop
\end{tabular} & \begin{tabular}{|l} 
Wet-season \\
rainfed \\
rice-fish; \\
single rice plus \\
rainfed maize, \\
cassava, \\
sugarcane; \\
livestock
\end{tabular} \\
\hline Secondary & & & $\begin{array}{l}\text { Vegetables, } \\
\text { field crops } \\
\text { along river } \\
\text { terraces }\end{array}$ & \begin{tabular}{|l|} 
Subsistence \\
double rice or \\
rice/field crops \\
with dry-season \\
irrigation
\end{tabular} & \begin{tabular}{|l|} 
Semi- \\
commercial \\
double rice or \\
rice/field crops \\
with dry-season \\
irrigation \\
\end{tabular} & $\begin{array}{l}\text { Intensive mixed } \\
\text { field crops and } \\
\text { livestock }\end{array}$ & $\begin{array}{l}\text { Vegetables, } \\
\text { field crops } \\
\text { along river } \\
\text { terraces }\end{array}$ \\
\hline Other & & & $\begin{array}{l}\text { Plantations: } \\
\text { oil palm, } \\
\text { rubber, } \\
\text { sugarcane, } \\
\text { biofuels }\end{array}$ & $\begin{array}{l}\text { Plantation } \\
\text { rubber, } \\
\text { sugarcane, } \\
\text { timber }\end{array}$ & \begin{tabular}{|l|} 
Commercial \\
plantation \\
sugarcane, \\
cassava, maize, \\
eucalyptus
\end{tabular} & $\begin{array}{l}\text { Rice-fish; fruit } \\
\text { crops, } \\
\text { commercial } \\
\text { plantation of } \\
\text { sugarcane, } \\
\text { cassava } \\
\end{array}$ & $\begin{array}{l}\text { Plantation: oil } \\
\text { palm, rubber }\end{array}$ \\
\hline \multicolumn{8}{|l|}{ Water management } \\
\hline & & $\begin{array}{l}\text { Irrigation } \\
\text { available for } \\
36 \% \text { of } \\
\text { cultivated land } \\
\text { in Guangxi }\end{array}$ & $\begin{array}{l}\text { Small to } \\
\text { medium } \\
\text { irrigation } \\
\text { schemes } \\
\text { pumped from } \\
\text { rivers }\end{array}$ & $\begin{array}{l}\text { Large-scale } \\
\text { surface water } \\
\text { irrigation } \\
\text { around } \\
\text { Mandalay, } \\
\text { Sagaing; some } \\
\text { groundwater } \\
\text { irrigation }\end{array}$ & \begin{tabular}{|l|} 
Large-scale \\
irrigation on \\
Central Plain \\
and Isan; farm \\
dams; limited \\
groundwater \\
irrigation
\end{tabular} & $\begin{array}{l}\text { Small to } \\
\text { medium } \\
\text { irrigation } \\
\text { schemes } \\
\text { pumped from } \\
\text { rivers }\end{array}$ & $\begin{array}{l}\text { Some formal } \\
\text { irrigation, } \\
\text { mainly } \\
\text { supplementary } \\
\text { wet season; } \\
\text { new irrigation } \\
\text { developments } \\
\text { around } \\
\text { Battambang }\end{array}$ \\
\hline
\end{tabular}


arrive during August to September. Sugarcane and cassava are harvested later, between December and April. Some crops are grown using residual water left over after the lowland rice crop. These crops also receive water from small rainfall events in November, December and January, and in some cases from irrigation. In the dry season, large livestock herds graze the leftover stubble. Where access to irrigation is available, irrigated dry-season rice may be grown, or, increasingly, crops such as sugarcane, maize, cassava or vegetables may be grown. Commercial plantations cultivating oil palm, eucalyptus, cassava or sugarcane are common in Thailand, and are becoming more widespread in other countries.

The capture and culture of freshwater fish are important components of livelihoods in lowland rice systems, with a gradation from managed pond aquaculture to the capture of wild fish entering paddy fields with the floodwaters. Hortle et al. (2008) demonstrated that in some areas of Cambodia, the value of fish from paddy fields is as high as that of rice. When production is intensified, fish are often lost from the system, because of pesticide use or changes to the water regime.

The predominance of wet-season paddy requires water control through bunding and canals. Supplementary irrigation of the wet-season crop is widespread; this ranges from small systems working directly from diverted streams or farm ponds to large-scale schemes with purpose-built water storage. Large irrigation schemes have been developed in the lowlands of Thailand and Myanmar, and to a lesser extent in Lao PDR and Cambodia, but the uptake of dry-season irrigation has been limited. The actual irrigated area during the dry season is generally much smaller than the area that could be irrigated. Less than $15 \%$ of rice production takes place in the dry season. Small-scale irrigation of vegetables and other cash crops is common in some areas, particularly alongside rivers. In Lao PDR and Cambodia, riverbank production is an important component of dry-season production. Small on-farm storage facilities were traditionally used for growing dryseason crops in Thailand; this practice is now reappearing and has been included as part of the nation's New Theory of Agriculture.

Annual rainfall on the lowland plains varies from less than $500 \mathrm{~mm}$ in central Myanmar to more than 2,000 $\mathrm{mm}$ in northeast Cambodia and Lao PDR. In Myanmar's dry zone and central Thailand, conditions are sub-humid to semi-arid, with a long dry season. Water-related risks are higher than in the other AEZs, and crop losses due to dry spells are a significant problem (see Part 3, Assessing crop suitability).

Yield gaps for all crops are large. Rice yields are low in Isan and northeast Cambodia $(\sim 2 \mathrm{t} /$ ha), moderate on the Thai central plain (2.8 t/ha) and higher in Myanmar and Lao PDR ( 3.5 t/ha). Yields in the dry season are higher (3.5-4.5 t/ha), but are still significantly below those achieved in the deltas. Analyses by Singh et al. (2009) and Banterng et al. (2008) indicated that yields of soybean, peanut and maize under rainfed conditions in northeast Thailand are less than half the potential yields, and that very large gains could be achieved by improving water management, fertilizing crops more, and controlling pests and diseases better. Potential gains in yield for upland rice were lower (around 20\%); significant increases in rice yield may require a shift to irrigated cropping.

Across much of the lowland plains, poor soils constrain the production of crops. Interventions to improve soil water-holding capacity and nutrient retention have successfully increased yields. Modest and sustainable increases have been achieved in the sandy soils of northeast Thailand (Whitbread et al. 2003) through improved management of crop residues and other organic inputs. Noble and Suzuki (2005) reported larger yield increases, of between 30 and 100\%, in rainfed, lowland and organically grown rice crops in northeast Thailand when soils were treated with bentonite clays in farmer-initiated field studies. 
The lowland plains of northeast Cambodia, Myanmar and Lao PDR are prospective areas for opening up new agricultural land, but three constraining factors must be taken into account. Much of the area has poor soils, access to water is limited and the remaining forests have significant conservation value (WWF 2009). In Myanmar, 40\% of arable farming land (7.2 Mha), mainly in the Dry Zone, is classified as 'cultivatable wasteland'. It is not clear how much of this is suitable for conversion to permanent agriculture, but there is potential to bring at least some of this area into production. Low use of irrigation across much of the plains suggests that there is potential to increase production by expanding and improving irrigation, but raises concerns over current irrigation methods and management.

\section{Tropical uplands}

Extent: Extending upwards from $250 \mathrm{~m}$ to $1,000 \mathrm{~m}$ above sea level, uplands constitute $36 \%$ of the GMS, including more than a third of Thailand, Vietnam and Myanmar, plus half of Guangxi and Laos (Table 1.3).

Population: Some 35 million people inhabit the uplands. In Guangxi, population density is moderate to high; elsewhere, the uplands are relatively sparsely populated, containing between 5\% and $15 \%$ of national populations. In Cambodia, fewer than 100,000 people live in mountainous areas. Ethnic minorities have traditionally settled in uplands, and poverty rates in these regions are high.

AEZ: The uplands comprise steeply sloping hills interspersed with small fertile river valleys. Large areas were originally forested, but more than half of this land has since been cleared for agriculture. Permanent cropping occupies around $15 \%$ to $20 \%$ of the land area; there are also large areas of shifting cultivation and degraded forest. Rainfall varies from less than 1,200 $\mathrm{mm}$ in the hills on the border between Thailand and Myanmar to more than 2,500 mm in Central Laos.

Farming systems: Paddy rice cultivation and small-scale irrigation are the norm in the valleys. Upland crops such as maize, cassava and soybeans are grown under rainfed conditions. Shifting cultivation is widespread and extensive grazing takes place in the forests. There is a high dependence on timber and non-timber forest products. Plantations growing commodities such as rubber and coffee are expanding in Lao PDR, Vietnam and Myanmar.

Water management: There has been limited development of irrigation. Existing infrastructure mainly comprises small-scale gravity-fed systems for growing paddy rice in the river valleys. Conservation agriculture approaches have been applied to increase water retention and decrease soil erosion.

Swidden (shifting cultivation) systems are common in the uplands of the GMS (Table 1.3), both pioneering swidden (slash and burn) with clearing for mono-cropping of cereals and legumes; and established swidden, with rotational cultivation of trees, annual crops, cereals and legumes. Farming is predominantly subsistence and semi-subsistence, with limited cash cropping. A shortening of the fallow period and an extension of the cropping period has been observed in shifting cultivation in most areas as population density has increased. This has reduced the capacity of the land to recover during fallow periods, due to a decline in soil fertility, an increase in weed pressure, and, in some cases, very high rates of soil erosion (Yamamoto et al. 2009). Traditional swidden systems have low-to-moderate overall soil loss (high in cultivated years, low in fallow years) but decreasing fallow periods, and changing cropping systems can result in very serious erosion. Valentin et al. (2008) reported a 600\% increase in soil loss at study sites in northern Lao PDR. High erosion rates are also associated with plantation crops such as teak, rubber and coffee, unless an understory is maintained or intercrops are grown. Many of the production systems in the uplands are considered dangerously unsustainable, resulting not only in low productivity, but also long-term degradation of the soil and off-site impacts from erosion. 
Table 1.3: Tropical uplands

\begin{tabular}{|c|c|c|c|c|c|c|c|}
\hline Uplands & GMS & $\begin{array}{l}\text { Yunnan / } \\
\text { Guangxi }\end{array}$ & Laos & Myanmar & Thailand & Vietnam & Cambodia \\
\hline Proportion of total land area & $35 \%$ & $18 \%$ & $15 \%$ & $30 \%$ & $19 \%$ & $15 \%$ & $2 \%$ \\
\hline$\%$ of country in AEZ & & $24 \%$ & $57 \%$ & $38 \%$ & $33 \%$ & $41 \%$ & $12 \%$ \\
\hline Population (millions) & 34.6 & 13.1 & 1.9 & 6.1 & 6.1 & 7.2 & 0.1 \\
\hline$\%$ of total country population & $11 \%$ & $14 \%$ & $32 \%$ & $10 \%$ & $10 \%$ & $8 \%$ & $1 \%$ \\
\hline \multicolumn{8}{|l|}{ Land cover (Globcover 2009)*\# } \\
\hline Irrigated crops & $1 \%$ & $0 \%$ & $0 \%$ & $2 \%$ & $2 \%$ & $1 \%$ & $0 \%$ \\
\hline Rainfed crops & $9 \%$ & $13 \%$ & $1 \%$ & $8 \%$ & $16 \%$ & $7 \%$ & $0 \%$ \\
\hline Crop mosaic & $8 \%$ & $15 \%$ & $2 \%$ & $6 \%$ & $10 \%$ & $11 \%$ & $1 \%$ \\
\hline Forest & $43 \%$ & $52 \%$ & $49 \%$ & $39 \%$ & $35 \%$ & $44 \%$ & $60 \%$ \\
\hline Shrub and grasslands & $38 \%$ & $20 \%$ & $47 \%$ & $45 \%$ & $38 \%$ & $38 \%$ & $38 \%$ \\
\hline Average rainfall & & 1,250 & 1,850 & 1,840 & 1,390 & 1,750 & 2,260 \\
\hline \multicolumn{2}{|c|}{ Area equipped for irrigation ('000 ha) } & 897 & 82 & 360 & 422 & 348 & 3 \\
\hline \multicolumn{8}{|l|}{ Agricultural statistics } \\
\hline \multicolumn{8}{|l|}{ Proportion of total rice production } \\
\hline Area WS rice ('000 ha) & & 846 & 399 & 982 & 1,709 & 222 & 116 \\
\hline Yield WS rice $(\mathrm{t} / \mathrm{ha})$ & & 5.4 & 3.3 & 3.2 & 2.7 & 4.1 & 2.5 \\
\hline Area DS rice ('000 ha) & & 228 & 39 & 111 & 420 & 714 & 4 \\
\hline Yield DS rice (t/ha) & & 7.5 & 4.8 & 3.7 & 3.7 & 5.0 & 3.6 \\
\hline Area maize ('000 ha) & & 381 & 129 & 89 & 564 & 519 & 10 \\
\hline Yield maize (t/ha) & & 4.2 & 4.8 & 2.1 & 4.1 & 4.0 & 4.2 \\
\hline Area sugarcane ('000 ha) & & 560 & 5 & 46 & 232 & 79 & 2 \\
\hline Yield sugarcane (t/ha) & & 70.3 & 23.1 & 44.7 & 67.4 & 52.4 & 46.7 \\
\hline Cattle plus buffalo (millions) & & 2,324 & 1,276 & 6,853 & 1,721 & 3,386 & 233 \\
\hline$\%$ of country total & & $45 \%$ & $49 \%$ & $28 \%$ & $26 \%$ & $38 \%$ & $6 \%$ \\
\hline Pigs ('000s) & & 32.1 & 1.6 & 0.7 & 1.5 & 7.1 & 0.1 \\
\hline \multicolumn{8}{|l|}{ Farming system } \\
\hline Primary & & $\begin{array}{l}\text { Mixed rainfed } \\
\text { farming. } \\
\text { Double rice } \\
\text { crop, or rice } \\
\text { plus cash crop }\end{array}$ & \begin{tabular}{|l|} 
Shifting \\
cultivation; \\
grazing; forest \\
products \\
\end{tabular} & $\begin{array}{l}\text { Mixed rainfed } \\
\text { farms: upland } \\
\text { rice, cash or } \\
\text { subsistence } \\
\text { food crops; } \\
\text { livestock }\end{array}$ & \begin{tabular}{|l|} 
Intensive \\
mixed farming \\
-commercial, \\
irrigated, \\
high-value \\
crops
\end{tabular} & \begin{tabular}{|l|} 
Mixed rainfed \\
farming: \\
upland rice, \\
cash crops; \\
livestock
\end{tabular} & $\begin{array}{l}\text { Subsistence } \\
\text { mixed farming, } \\
\text { upland rice and } \\
\text { food crops }\end{array}$ \\
\hline Secondary & & $\begin{array}{l}\text { Shifting } \\
\text { cultivation: } \\
\text { fallow land } \\
\text { grows tea, } \\
\text { rubber, fruit }\end{array}$ & \begin{tabular}{|l|} 
Montane \\
paddy and \\
mixed farming; \\
livestock
\end{tabular} & $\begin{array}{l}\text { Shifting } \\
\text { cultivation: } \\
\text { upland rice, } \\
\text { maize, } \\
\text { vegetables }\end{array}$ & \begin{tabular}{|l|} 
Mixed rainfed \\
farming: \\
upland rice, \\
cash crops; \\
livestock
\end{tabular} & \begin{tabular}{|l|} 
Upland \\
plantations \\
(coffee, rubber, \\
timber); fruit \\
crops
\end{tabular} & $\begin{array}{l}\text { Plantations: } \\
\text { e.g., rubber, } \\
\text { cassava, coffee; } \\
\text { smallholders } \\
\text { and commercial }\end{array}$ \\
\hline Other & & $\begin{array}{l}\text { Private rubber } \\
\text { and tea } \\
\text { plantations }\end{array}$ & \begin{tabular}{|l|} 
Upland \\
plantation: \\
rubber, coffee
\end{tabular} & $\begin{array}{l}\text { Upland } \\
\text { plantation: } \\
\text { rubber, coffee }\end{array}$ & \begin{tabular}{|l|} 
Remnant \\
shifting \\
cultivation, \\
non-timber \\
forest products; \\
cattle grazing. \\
\end{tabular} & \begin{tabular}{|l|} 
Remnant \\
shifting \\
cultivation, \\
non-timber \\
forest products; \\
cattle grazing. \\
\end{tabular} & \\
\hline \multicolumn{8}{|l|}{ Water management } \\
\hline & & $\begin{array}{l}\text { Terracing for } \\
\text { montane paddy, } \\
\text { small to } \\
\text { medium } \\
\text { irrigation } \\
\text { schemes for > } \\
30 \% \text { of land }\end{array}$ & $\begin{array}{l}\text { Irrigation of } \\
\text { small areas } \\
\text { from rivers/ } \\
\text { streams }\end{array}$ & $\begin{array}{l}\text { Irrigation of } \\
\text { small areas } \\
\text { from rivers/ } \\
\text { streams }\end{array}$ & \begin{tabular}{|l|} 
Small to \\
medium \\
irrigation \\
schemes
\end{tabular} & \begin{tabular}{|l|} 
Terracing \\
for montane \\
paddy, small to \\
medium \\
irrigation \\
schemes; \\
groundwater \\
pumping
\end{tabular} & \\
\hline
\end{tabular}

* Total may be < $100 \%$ since minor classes (open water, wetlands, urban, etc.) are not included.

\# There are discrepancies between estimates of irrigated area from satellite imagery and national statistics, due to difficulties in distinguishing flooded paddy and recession rice from formal irrigation; and in identifying small areas of irrigation.

$\mathrm{WS}=$ wet season; DS = dry season 
Upland farming systems often have low productivity. Yields from upland rice, for example, are significantly lower than that for lowland crops. In Lao PDR, the only country to record statistics for upland rice separately, the average yield is $1.7 \mathrm{t} / \mathrm{ha}$, which is less than half that of lowland wet-season rice (3.6 t/ha) and a third of the irrigated dry-season crop (4.8 t/ha). Singh et al. (2009) found large differences between actual and potential yields for field crops in rainfed upland systems in Northern Vietnam; studies indicate that yields for groundnut and soybean could be doubled. Large yield gaps are attributed to a range of causes, including water stress.

Water management in the uplands falls under two main approaches: small-scale irrigation in relatively flat upland valleys; and conservation farming to improve water retention and decrease soil erosion on steeply sloping areas. Depending on topography, the scale of irrigation in river valleys can vary from a few hectares, as is common in Lao PDR, to developments of several thousand hectares. In northern Thailand, around Chiang Mai, intensive irrigated horticultural production has been developed in upland valleys. Small areas of irrigation are usually gravity-fed directly from streams, sometimes with the construction of a small weir. Larger areas may be fed directly from the river, or from small local reservoirs.

Conservation farming approaches have been introduced in upland areas to increase productivity, reduce erosion and protect catchment flows. These include agroforestry, banks and vegetation strips to reduce erosion, and on-farm water storage facilities and cut-and-carry fodder systems for livestock. Traditionally, terracing to allow cultivation of paddy rice on hillsides has been used, but was not widespread outside of China. Recently, terracing has being introduced as a means of increasing the area available for planting permanent crops and reducing shifting cultivation (Linquist et al. 2007).

Moves in all countries to eradicate shifting cultivation from steep lands have placed increasing pressure on the remaining agricultural land; finding sustainable production systems for sloping lands is a high priority. The accompanying shift from upland to paddy rice is a major transitional pathway from swidden systems, but this requires better water management, with potential for conflicts between users in upland river valleys. This shift, if well-managed, provides a long-term solution for maintaining livelihoods of marginalized upland farmers.

As increasing livestock herds exert pressure on grazing lands, primarily in forests, there is a move towards improving pastures and introducing cut-and-carry forage systems. If well-managed, these can be highly productive systems that can take the pressure off collapsing upland rice production systems. Improving livestock production so that it provides a regular income, instead of simply being an insurance policy, is an important transitional pathway out of swidden agriculture, especially for farmers without the option of moving from producing upland rice to lowland paddy.

A move away from shifting agriculture dominated by upland rice can involve a transition to more stabilized, perennial agricultural systems based on tree crops, but this must be done with great care. The recent rapid shift to planting tree crops such as rubber, timber and coffee has resulted in significant deforestation in some places, with impacts on water supplies downstream.

\section{Subtropical highlands}

Extent: Highlands between 1,000 and 2,500 m, constitute 22\% of the GMS (Table 1.4), mainly in Yunnan and Myanmar (Shan Plateau including the Inle Lake region; Western Hills), with smaller areas in Lao PDR (Bolovens Plateau and Xiengkhuoang Plateau and northern uplands) and Vietnam (Central Highlands, Da Lat Plateau). The distinction between uplands and highlands reflects the transition from tropical to subtropical climate with altitude. In reality, there is a transition between the two, with no clear demarcation. The delineation from $1,000 \mathrm{~m}$ altitude corresponds approximately to the zone where mean annual temperature drops below $18{ }^{\circ} \mathrm{C}$ (according to the 
Table 1.4: Subtropical highlands

\begin{tabular}{|c|c|c|c|c|c|c|}
\hline Highlands & GMS & $\begin{array}{l}\text { Yunnan/ } \\
\text { Guangxi }\end{array}$ & Laos & Myanmar & Thailand & Vietnam \\
\hline Proportion of total land area & $22 \%$ & $57 \%$ & $9 \%$ & $25 \%$ & $3 \%$ & $6 \%$ \\
\hline$\%$ of country in AEZ & & $49 \%$ & $22 \%$ & $20 \%$ & $3 \%$ & $10 \%$ \\
\hline Population (millions) & 42.6 & 37.6 & 0.7 & 3.0 & 0.06 & 1.2 \\
\hline$\%$ of total country population & $13 \%$ & $41 \%$ & $11 \%$ & $5 \%$ & - & $1 \%$ \\
\hline \multicolumn{7}{|l|}{ Land cover (Globcover 2009)*\# } \\
\hline Irrigated crops & $2 \%$ & $2 \%$ & $0 \%$ & $1 \%$ & $0 \%$ & $0 \%$ \\
\hline Rainfed crops & $13 \%$ & $21 \%$ & $1 \%$ & $4 \%$ & $0 \%$ & $4 \%$ \\
\hline Crop mosaic & $12 \%$ & $18 \%$ & $1 \%$ & $6 \%$ & $1 \%$ & $5 \%$ \\
\hline Forest & $40 \%$ & $33 \%$ & $52 \%$ & $47 \%$ & $57 \%$ & $53 \%$ \\
\hline Shrub and grasslands & $33 \%$ & $25 \%$ & $46 \%$ & $43 \%$ & $42 \%$ & $38 \%$ \\
\hline Average rainfall & & 1,160 & 1,830 & 1,770 & 1,200 & 1,880 \\
\hline Area equipped for irrigation (' 00 & ha)\# & 1,270 & 19 & 72 & 28 & 54 \\
\hline \multicolumn{7}{|l|}{ Agricultural statistics } \\
\hline Area WS rice ('000 ha) & & 660 & 101 & 307 & 95 & 33 \\
\hline Yield WS rice (t/ha) & & 6.0 & 3.2 & 3.0 & 3.2 & 3.8 \\
\hline Area DS rice ('000 ha) & & 178 & 5 & 25 & 27 & 126 \\
\hline Yield DS rice (t/ha) & & 8.3 & 4.5 & 3.7 & 3.7 & 4.4 \\
\hline Area maize ('000 ha) & & 1,056 & 41 & 76 & 48 & 123 \\
\hline Yield maize (t/ha) & & 4.0 & 4.7 & 2.0 & 4.1 & 3.5 \\
\hline Area sugarcane ('000 ha) & & 282 & 1 & 15 & 10 & 10 \\
\hline Yield sugarcane (t/ha) & & 62 & 10 & 48 & 69 & 51 \\
\hline Cattle plus buffalo (millions) & & 795 & 371 & 1,985 & 118 & 659 \\
\hline$\%$ of country total & & $15 \%$ & $14 \%$ & $8 \%$ & $2 \%$ & $7 \%$ \\
\hline Pigs ('000s) & & 45.1 & 0.6 & 0.4 & 0.1 & 1.3 \\
\hline \multicolumn{7}{|l|}{ Farming system } \\
\hline Primary & & $\begin{array}{l}\text { Mixed rainfed } \\
\text { farming. Double } \\
\text { rice crop, or rice } \\
\text { plus cash crop. }\end{array}$ & \begin{tabular}{|l|} 
Shifting \\
cultivation; \\
grazing; forest \\
products
\end{tabular} & $\begin{array}{l}\text { Shifting } \\
\text { cultivation: } \\
\text { upland rice, } \\
\text { maize, } \\
\text { vegetables }\end{array}$ & $\begin{array}{l}\text { Upland intensive } \\
\text { mixed farming - } \\
\text { commercial, } \\
\text { irrigated, } \\
\text { high-value crops } \\
\text { (e.g., vegetables) }\end{array}$ & $\begin{array}{l}\text { Upland intensive } \\
\text { mixed farming - } \\
\text { commercial, } \\
\text { irrigated, } \\
\text { high-value crops }\end{array}$ \\
\hline \multirow[t]{2}{*}{ Secondary } & & $\begin{array}{l}\text { Shifting } \\
\text { cultivation: } \\
\text { fallow land } \\
\text { grows tea, } \\
\text { rubber, fruit }\end{array}$ & \begin{tabular}{|l|} 
Montane paddy \\
and mixed \\
farming; livestock
\end{tabular} & $\begin{array}{l}\text { Mixed rainfed } \\
\text { farming: upland } \\
\text { rice, cash or } \\
\text { subsistence food } \\
\text { crop. Livestock. }\end{array}$ & $\begin{array}{l}\text { Mixed rainfed } \\
\text { farming: upland } \\
\text { rice, cash crops; } \\
\text { livestock. }\end{array}$ & $\begin{array}{l}\text { Upland } \\
\text { plantations } \\
\text { (coffee, rubber, } \\
\text { timber) }\end{array}$ \\
\hline & & $\begin{array}{l}\text { Private rubber } \\
\text { and tea } \\
\text { plantations }\end{array}$ & $\begin{array}{l}\text { Upland plantation: } \\
\text { rubber, coffee }\end{array}$ & $\begin{array}{l}\text { Upland plantation: } \\
\text { rubber, coffee }\end{array}$ & $\begin{array}{l}\text { Remnant shifting } \\
\text { cultivation, } \\
\text { non-timber forest } \\
\text { products; cattle } \\
\text { grazing. }\end{array}$ & \\
\hline \multicolumn{7}{|l|}{\begin{tabular}{|l|} 
Water management \\
\end{tabular}} \\
\hline & & $\begin{array}{l}\text { Terracing for } \\
\text { montane paddy, } \\
\text { small to } \\
\text { medium irrigation } \\
\text { schemes for }> \\
25 \% \text { of land }\end{array}$ & \begin{tabular}{|l|} 
Irrigation of small \\
areas from rivers/ \\
streams
\end{tabular} & $\begin{array}{l}\text { Irrigation of small } \\
\text { areas from rivers/ } \\
\text { streams }\end{array}$ & $\begin{array}{l}\text { Small irrigation } \\
\text { schemes }\end{array}$ & $\begin{array}{l}\text { Irrigation of } \\
\text { small areas from } \\
\text { rivers/streams; } \\
\text { groundwater } \\
\text { pumping in } \\
\text { Central } \\
\text { Highlands }\end{array}$ \\
\hline
\end{tabular}

Notes: * Total may be $<100 \%$ since minor classes (open water, wetlands, urban, etc.) are not included.

\# There are discrepancies between estimates of irrigated area from satellite imagery and national statistics, due to difficulties in distinguishing flooded paddy and recession rice from formal irrigation; and in identifying small areas of irrigation.

WS = wet season; DS = dry season 
Köppen definition of subtropical). It also corresponds to a shift from lower intensity farming on slopes (mainly shifting cultivation) to more intensive farming concentrated in highland valleys and plateaus.

Population: Some 43 million people inhabit the highlands; this includes $90 \%$ of Yunnan's population but less than $10 \%$ of Gunagxi's. The total highland population in other countries is less than five million. Levels of poverty are generally lower than in the adjoining uplands.

AEZ: The highlands have a subtropical climate. Rainfall varies from less than 1,000 $\mathrm{mm} / \mathrm{year}$ in northern Yunnan to more than 2,500 mm/year in southern Laos. Yunnan, west Guangxi and Myanmar have steep mountainous areas within the foothills of the Himalaya. In Lao PDR and Vietnam, the highlands are mainly volcanic plateaus with fertile soils. Some of the plateau areas in the Central Highlands are at lower elevations of between 500 and $800 \mathrm{~m}$ but share similar farming systems.

Farming systems: The subtropical climate enables farmers to cultivate a wide range of crops, including paddy rice, wheat, potatoes, vegetables, flowers (Yunnan, Chiang Mai), tobacco (Yunnan), coffee (Central Highlands, Bolovens Plateau), sugarcane, tea, rubber, pepper, fruit trees, cocoa and mulberry. Similar intensive production systems are found in Northern Thailand around Chiang Mai, though at a lower altitude. Rice is cultivated as montane paddy, upland rice or as irrigated aerobic rice, the latter being upland rice grown under highly favorable conditions of water management.

Water management: There is intensive irrigation of high-value horticultural crops, and partial irrigation of some cash crops, such as tobacco, vegetables and coffee. Water sources include rivers, small storages and groundwater. In Yunnan, there has been development of terracing for montane paddy. Intensive horticulture employs methods such as drip irrigation and plastic mulches.

Yunnan's highlands represent a major population and agricultural zone, with both being concentrated mainly in highland valleys. Only about 5\% of Yunnan's land area is cultivable. Cultivation is forbidden by law on slopes steeper than 25 degrees, and over the last 20 years there has been a concerted effort to reduce farming on sloping lands. Rice production is split between irrigated or rainfed paddy in flat river valleys and on terraced slopes, and shifting cultivation of upland rice in sloping areas. Over $75 \%$ of rice is grown in the wet season, usually supplemented by a non-rice dry-season crop, such as faba bean, wheat, oil rap or sugarcane. Livestock are raised semi-intensively using fodder from stubble, crop by-products and fodder crops including cassava and maize. In the north of Yunnan, highland grasslands are used extensively for grazing.

During the 1970s to 1990s, Chinese government programs in Yunnan provided technical and financial assistance for farmers to return steep land to forest, plant commercial agroforestry cash crops (mainly rubber and tea) and construct terraces for permanent montane paddy rice, irrigated upland rice and other crops (UNEP and TEI 2007). The aim behind these schemes was to improve the sustainability of land use in steep areas and encourage a move away from shifting cultivation. The adoption of improved rice technologies during the 1990s has resulted in significant yield increases. For example, yields in Simao Province have risen from less than $2 \mathrm{t} / \mathrm{ha}$ in 1990 to more than $3 \mathrm{t} / \mathrm{ha}$ in 2003 (Pandey et al. 2007). As a result, there has been a decrease in the area planted with rice, while overall production has increased. This has enabled farmers to diversify to cash crops with higher returns. The largest crops in terms of areas planted are now maize, rice and tubers, but a wide variety of other crops are grown, including wheat, vegetables, oilseeds and tobacco. Tree crops, such as rubber, tea and orchards, account for $17 \%$ of the total cultivated area. 
Outside of Yunnan and Guangxi, the highlands are still predominantly forested, although the quality of this woodland has become significantly degraded due to shifting cultivation and logging. In Lao PDR and Vietnam, the highland plateaus have been very important areas for developing commercial agriculture, particularly coffee and vegetables; over $90 \%$ of Vietnam's coffee production takes place in the Central Highland provinces. Here, unrestricted groundwater pumping by smallholders to irrigate coffee has resulted in a dramatic decline in groundwater levels and periodic water shortages (Cheesman and Bennett 2005).

The following stages define a trend towards intensification of agriculture in highland areas:

- Establishment of small-scale irrigation from rivers, streams and lakes. In Thailand and Yunnan, particularly, there is considerable investment in irrigation for horticulture.

- Development of terracing for upland rice.

- Increased use of chemical fertilizers, pesticides and herbicides.

- Introduction of improved varieties and hybrids.

- Commercialization and diversification, with increased cash cropping, especially of perennial crops.

- More intensively managed livestock systems.

\section{Coastal zones}

Extent: The coastal zones lie at an elevation of less than $250 \mathrm{~m}$ above mean sea level (amsl) within $50 \mathrm{~km}$ of the coast, outside of the mega-deltas. They include the eastern coast of Vietnam, peninsular Thailand and Myanmar, and the coasts of Cambodia and Guangxi. Coastal zones constitute only $3 \%$ of the total GMS area, but are heavily populated and agriculturally important (Table 1.5).

Population: Around 9 million people live in the coastal zones. This equates to between $10 \%$ and $14 \%$ of national populations, except in Guangxi (with small coastal population), Yunnan and Lao PDR (with no coastal regions). The coastal areas have a high population density of more than 100 persons $/ \mathrm{km}^{2}$, except for the Andaman Coast of Myanmar.

AEZ: The coastal plains are less than $25-\mathrm{km}$ wide and rise rapidly to coastal ranges between 500 $\mathrm{m}$ and 2,000 $\mathrm{m}$ elevation. Average rainfall exceeds $2 \mathrm{~m}$ (and is more than $4 \mathrm{~m}$ in Myanmar). Those coastal zones that face west have higher rainfall; the coasts of Guangxi and Vietnam are drier, with $1,800 \mathrm{~mm}$ to $2,000 \mathrm{~mm}$ of rain falling each year.

Farming systems: The varied production systems along the coasts include: lowland rice; rainfed field crops; combined crop and livestock systems; and agro-industrial and tree crops, such as rubber, oil palm, eucalypt and other pulpwood. Many people depend on marine fisheries for their livelihoods. Marine/brackish water aquaculture is limited in non-delta coastal areas.

Water management: There is small-scale irrigation of rice and vegetables from rivers and groundwater, plus limited irrigation of oil palm in Thailand. Lowland areas are prone to flash flooding, due to short, steep catchments.

The coastal zones are densely populated and agriculturally diverse, with a heavy dependence on artisanal fisheries for generating income. Rainfall varies across the region but is generally high. The topography of small coastal plains adjoining steep catchments means that streams are abundant. As a result, water availability is generally not limiting except in some areas of coastal Vietnam; AWM interventions may not be the highest priority in this zone. Other important constraints to production include the small size of farms, sandy soils with low and declining 
Table 1.5: Coastal zones (excluding mega-deltas)\#

\begin{tabular}{|c|c|c|c|c|c|}
\hline Coastal zone & GMS & Myanmar & Thailand & Vietnam & Cambodia \\
\hline Proportion of total land area & $2 \%$ & $33 \%$ & $35 \%$ & $23 \%$ & $5 \%$ \\
\hline$\%$ of country in AEZ & & $3 \%$ & $4 \%$ & $4 \%$ & $2 \%$ \\
\hline Population (millions) & 27.5 & 6.5 & 6.5 & 12.4 & 0.4 \\
\hline$\%$ of total country population & $9 \%$ & $11 \%$ & $10 \%$ & $14 \%$ & $3 \%$ \\
\hline Average rainfall & & 3,280 & 2,164 & 1,930 & 3,010 \\
\hline \multicolumn{6}{|l|}{ Land cover (Globcover 2009)* } \\
\hline Irrigated crops & $7 \%$ & $8 \%$ & $2 \%$ & $14 \%$ & $1 \%$ \\
\hline Rainfed crops & $38 \%$ & $37 \%$ & $40 \%$ & $40 \%$ & $22 \%$ \\
\hline Crop mosaic & $29 \%$ & $21 \%$ & $36 \%$ & $28 \%$ & $15 \%$ \\
\hline Forest & $9 \%$ & $12 \%$ & $8 \%$ & $5 \%$ & $23 \%$ \\
\hline Shrub and grasslands & $11 \%$ & $15 \%$ & $6 \%$ & $8 \%$ & $34 \%$ \\
\hline \multicolumn{6}{|l|}{ Farming system } \\
\hline Primary & & $\begin{array}{l}\text { Plantation rubber, } \\
\text { coconut, palm oil, } \\
\text { pineapple, banana }\end{array}$ & $\begin{array}{l}\text { Plantation rubber, } \\
\text { coconut, palm oil, } \\
\text { pineapple, banana }\end{array}$ & $\begin{array}{l}\text { Mixed farming, } \\
\text { increasingly } \\
\text { intensive; } \\
\text { semi-commercial } \\
\text { fisheries }\end{array}$ & $\begin{array}{l}\text { Mixed subsistence } \\
\text { farming, artisanal } \\
\text { fisheries. }\end{array}$ \\
\hline Secondary & & $\begin{array}{l}\text { Mixed subsistence } \\
\text { farming, artisanal } \\
\text { fisheries. }\end{array}$ & $\begin{array}{l}\text { Mixed farming, } \\
\text { increasingly } \\
\text { intensive; } \\
\text { semi-commercial } \\
\text { fisheries } \\
\end{array}$ & $\begin{array}{l}\text { Mixed subsistence } \\
\text { farming, artisanal } \\
\text { fisheries. }\end{array}$ & $\begin{array}{l}\text { Plantation rubber, } \\
\text { palm oil }\end{array}$ \\
\hline \multicolumn{6}{|l|}{ Water management } \\
\hline & & Limited & $\begin{array}{l}\text { Small to medium } \\
\text { irrigation schemes }\end{array}$ & $\begin{array}{l}\text { Small-scale } \\
\text { irrigation from } \\
\text { streams }\end{array}$ & Limited \\
\hline
\end{tabular}

Notes: ${ }^{*}$ Agricultural production statistics at provincial level are not meaningful for such small areas.

* Total may be $<100 \%$ since minor classes (open water, wetlands, urban, etc.) are not included.

fertility, the high incidence of erosion in coastal uplands, and urban and agricultural pollution affecting water quality. These areas are also at risk from storms, as evidenced by the devastation from Cyclone Nargis in Myanmar in 2008 which killed over 130,000 people, and Typhoon Ketsana in Vietnam in 2009 which resulted in evacuation of 170,000 people, 163 deaths and USD 785 million in damages.

The coastal zones are important areas for plantation agroforestry. Over $80 \%$ of Thailand and Myanmar's rubber production comes from the southern coastal provinces of the peninsula. Coconut and palm oil are also grown extensively. Horticulture to supply tourism is an important sector in southern Thailand's coastal zone. As Vietnam's population has risen over the last 20 years, there has been significant intensification of agriculture on its coastal plains, including a move from extensive grazing to intensive raising of livestock using stubble and by-products from field crops. These are the areas that are most at risk from climate change, through sea-level rise and exposure to extreme storms and storm surges. Protecting low-lying areas by developing infrastructure and reestablishing mangroves is a high priority.

\section{Peri-urban zones}

Extent: These intensively farmed areas rim each of the region's major cities (Table 1.6). There are seven cities in the GMS with a population of more than one million (see Figure 1.1).

Population: The total population in urban and peri-urban zones exceeds 50 million. These zones have very high population densities. 
Table 1.6: Peri-urban zones

\begin{tabular}{|c|c|c|c|c|c|c|c|}
\hline Peri-urban zone & GMS & $\begin{array}{l}\text { Yunnan / } \\
\text { Guangxi }\end{array}$ & Laos & Myanmar & Thailand & Vietnam & Cambodia \\
\hline Cities & & $\begin{array}{r}\text { Kunming, } \\
\text { Nanning, } \\
\text { Liuzhou }\end{array}$ & Vientiane & $\begin{array}{r}\text { Yangon, } \\
\text { Mandalay }\end{array}$ & Bangkok & $\begin{array}{r}\text { Hanoi, Ho } \\
\text { Chi Minh City }\end{array}$ & Phnom Penh \\
\hline $\begin{array}{l}\text { Population (millions) in } \\
\text { greater urban areas }\end{array}$ & 64 & $\begin{array}{l}\text { K } 6.4 \\
\text { N } 6.6 \\
\text { L } 3.8\end{array}$ & 0.75 & 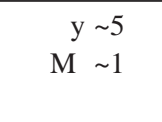 & 12 & $\begin{array}{r}\text { H } 6.5 \\
\text { HCMC } 20\end{array}$ & 2.0 \\
\hline $\begin{array}{c}\% \text { of national population } \\
\text { in greater urban areas }\end{array}$ & $20 \%$ & $19 \%$ & $12 \%$ & $10 \%$ & $19 \%$ & $30 \%$ & $14 \%$ \\
\hline Average rainfall & & $\begin{array}{l}\text { K } 1000 \\
\text { N } 1370 \\
\text { L } 1400\end{array}$ & V 1700 & $\begin{array}{l}\text { Y } 2400 \\
\text { M } 800\end{array}$ & B 1500 & $\begin{array}{r}\text { H } 1700 \\
\text { HCMC } 1900\end{array}$ & PP 1400 \\
\hline \multicolumn{8}{|l|}{ Farming system } \\
\hline Primary & & $\begin{array}{l}\text { Intensive } \\
\text { horticulture } \\
\text { (vegetables, } \\
\text { flowers), } \\
\text { chicken and } \\
\text { pig raising }\end{array}$ & $\begin{array}{l}\text { Riverbank } \\
\text { vegetable } \\
\text { cultivation, } \\
\text { fruit trees }\end{array}$ & $\begin{array}{l}\text { Intensive } \\
\text { horticulture } \\
\text { (vegetables, } \\
\text { fruit), chicken } \\
\text { and ducks, } \\
\text { dairy. Brackish } \\
\text { water and } \\
\text { freshwater } \\
\text { aquaculture } \\
\text { near Yangon } \\
\end{array}$ & 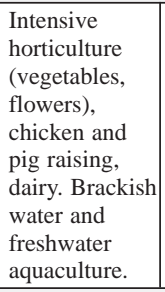 & \begin{tabular}{|l|} 
Intensive \\
horticulture \\
(vegetables, \\
flowers), chicken \\
and pig raising, \\
dairy. Brackish \\
water and \\
freshwater \\
aquaculture near \\
HCMC \\
\end{tabular} & $\begin{array}{l}\text { Riverbank } \\
\text { vegetable } \\
\text { cultivation, fruit } \\
\text { trees. Freshwater } \\
\text { aquaculture }\end{array}$ \\
\hline
\end{tabular}

Agroecosystem: The five biggest cities (Bangkok, Yangon, Hanoi, Ho Chi Minh City and Phnom Penh) are in deltas. Vientiane, Mandalay and Nanning lie on lowland riverine plains, while Kunming is located in the uplands. Rainfall varies from around $800 \mathrm{~mm}$ annually at Mandalay to more than 2,400 $\mathrm{mm}$ at Yangon.

Farming systems: These include intensive horticulture and orchards, with irrigation from rivers. There is also intensive livestock production of chicken, pigs and dairy cattle. Intensive aquaculture has developed around Ho Chi Minh City, Bangkok, Yangon and Phnom Penh.

Water management: Water for irrigating horticultural crops comes mainly from small-scale pumping from rivers and groundwater. There are potential problems with surface water and groundwater contamination by urban and agricultural pollution.

Peri-urban farming systems are characterized by intensive commercial production of mainly food crops for the adjoining urban areas. In terms of water management, they have two distinctive characteristics. First, the level of irrigation is high, to ensure production of high-value crops. However, agriculture must compete with urban demands for water, prompting some conflicts during the dry season. Second, most peri-urban zones have significant water-quality problems. This is due to sewage, industrial effluents and high levels of agricultural chemicals, such as fertilizers and pesticides. Peri-urban zones face unique challenges in managing nutrient streams, from the urban sewage and intensive livestock raising. While not covering a large area, agriculture in peri-urban 
zones is expanding rapidly. Its impacts are felt directly within urban areas in terms of the quality and availability of food, and environmental quality.

Internationally, the reuse of urban wastewater for agriculture is expanding, in response to water shortages and to take advantage of the nutrients in wastewater. Water is treated to varying degrees. In some cases, such as around Bangkok, water is provided from wastewater treatment plants (Visvanathan and Shapkota 2006). Elsewhere, untreated effluent is used and agriculture constitutes a form of primary treatment. Such examples are the cultivation of vegetables in the wetlands downstream of Phnom Penh and wastewater use in fishponds. The significant benefits of using wastewater for irrigation include security of water supply and the reduced need for fertilizer, but there are risks to human health and the environment in using wastewater. There are options to improve wastewater management for irrigation through policies, standards and financial mechanisms to reduce risks (Qadir et al. 2010). Wastewater reuse in peri-urban areas represents a significant opportunity for 'win-win' outcomes for production and the environment. 


\section{PART 2: IMPACTS OF CLIMATE CHANGE ON AGRICULTURE IN THE GMS}

The Southeast Asian monsoon controls climate in the GMS, bringing very marked wet and dry seasons. Spatial and temporal variations in the monsoon define the patterns of rainfed agriculture. A study of climate variability in the region explored these climatic controls in detail. First, climate variables relating to crop growth were analyzed for two locations representative of lowland and upland conditions to determine which factors exercised the strongest controls on crop growth. Second, these factors were then analyzed and mapped for the entire region.

\section{Key climate variables affecting crop growth}

Variability in key climate parameters relating to crop growth were analyzed for two locations: Ubon Ratchathani in Thailand, representative of the lowland plains; and Luang Prabang in Lao PDR, representative of the upland regions. In order to estimate the temporal distribution of dry and wet years and their impact on crops, a frequency analysis, using Franquin's method (Franquin 1969), was performed at Ubon Ratchathani and Luang Prabang stations, using potential evaporation values derived from pan evaporation data measured from 1962 to 2004 and rainfall time series recorded at the two stations from 1953 to 2004. The frequency analysis involves sorting cumulative rainfall amounts for each five-day period of the year and then separating the series into five groups. The maximal value of each group, or quintile, defines five categories of years corresponding to very dry, dry, normal, wet and very wet situations. The non-exceedence frequencies corresponding to the first, second, third, fourth and fifth quintiles are equal to $20 \%, 40 \%, 60 \%, 80 \%$ and $100 \%$, respectively.

Figure 2.1 illustrates the important inter- and intra-annual rainfall variability and the possibility of heavy rainfall (greater than $50 \mathrm{~mm} /$ five-day period) occurring at the beginning (March-April) or end (October-November) of the rainy season. Each of the five quintiles displayed in Figure 2.1 is compared to mean potential evapotranspiration (PET) and PET/2 at each station. This comparison allows the definition of four types of seasons: very dry, dry, humid and very humid, as well as representing the multi-annual variability of their occurrence (Figure 2.2).

In parallel to the different types of season and their occurrence, two typical cropping calendars are drawn in order to assess the occurrence of droughts, depending on the cropping calendar stages. In lowland rice areas, the theoretical sowing period occurs during a dry period in $20 \%$ of years. Thus, the transplanting and crop establishment phase, which benefits greatly from maintenance of a saturated paddy field, may not be possible at the desired time in one year out of five because of

Figure 2.1. Frequential distribution of rainfall in Ubon Ratchathani and Luang Prabang.
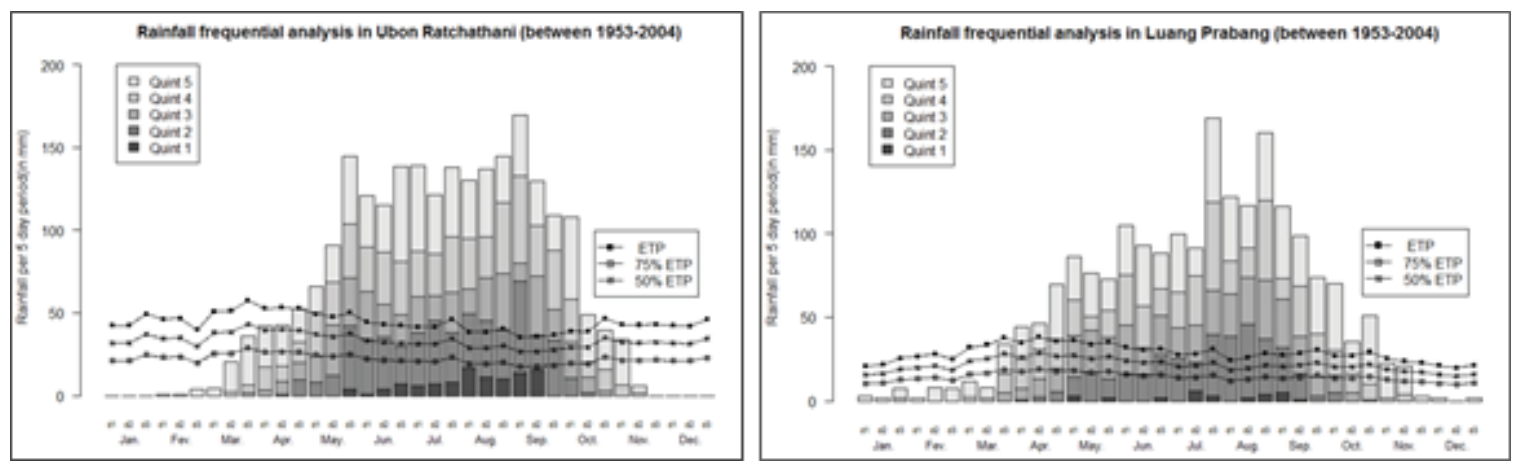
Figure 2.2 Multi-annual variability of the seasonal cycle, according to Franquin's method (Franquin 1969).

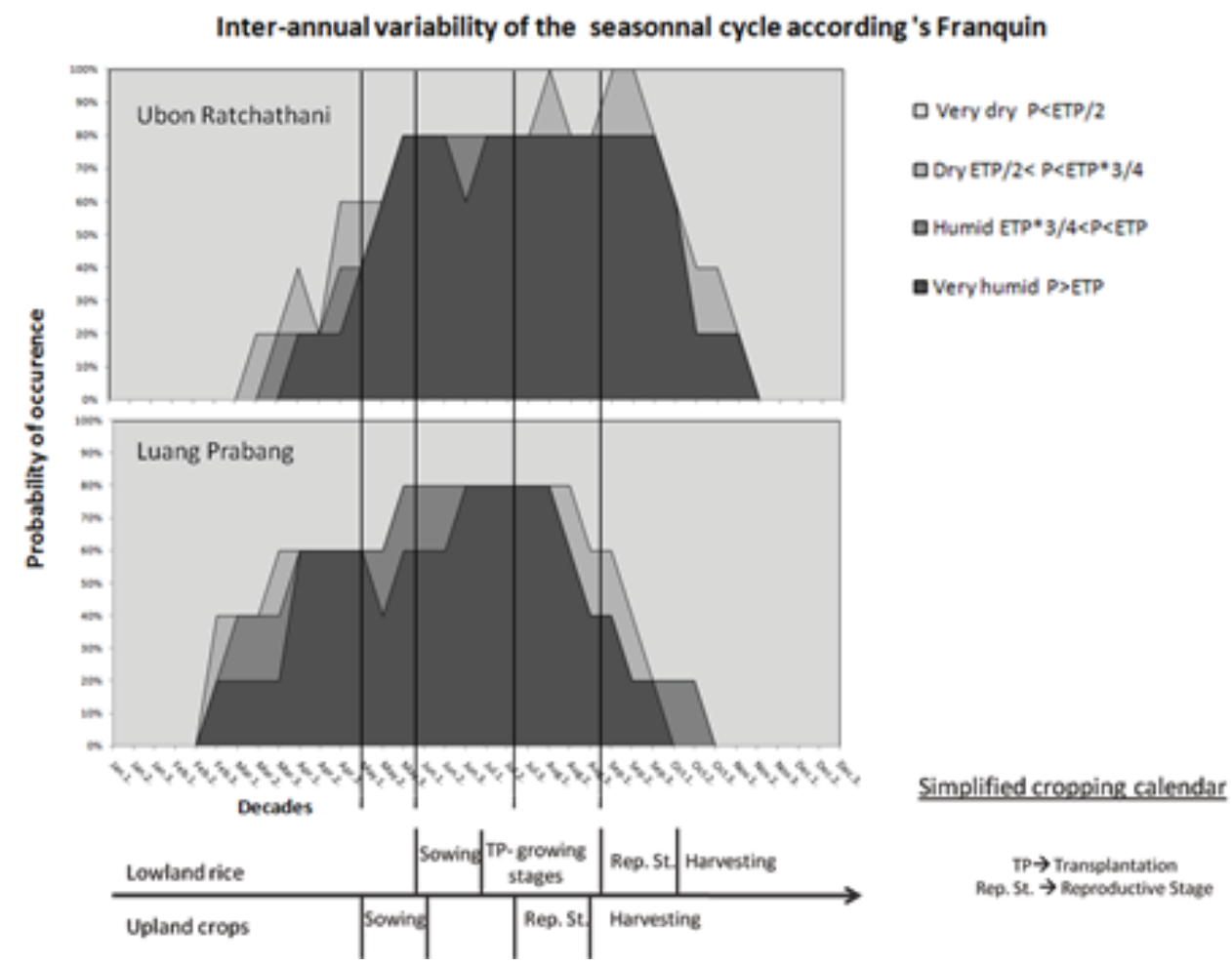

insufficient rainfall. The reproductive stage, which is perhaps the most sensitive to water stress, may also include dry periods with the same frequency. This stage is more exposed to water stress in Luang Prabang than in Ubon Ratchathani. As the probability of having a dry period sharply increases after August in Luang Prabang, and after September in Ubon Ratchathani, late-maturing crop varieties will be more exposed to droughts. However, late-maturing crop varieties usually have a deeper root system, thus alleviating the drought effects on crops. Just before and during harvesting time, crops need a dry environment to mature. One year out of five will be very humid, thus damaging crops.

For rice in upland areas, the theoretical sowing period occurred during a dry period in $40 \%$ of the years. The reproductive stage was less exposed to droughts (20\% probability) in Ubon Ratchathani than in Luang Prabang. However, the risk of drought increased if the productive stage was delayed. The work showed that the harvesting time would rarely be humid in Luang Prabang but will more likely be humid in Ubon Ratchathani, possibly causing yield decreases.

In addition to using Franquin's method, the length of the growing period (LGP) was computed to assess adaptation of local cultivars to climate patterns. The growing period is the span of time when supplied moisture and rainfall can generate crop growth. Rainfall amounts to greater than half and three-quarters of the potential evapotranspiration that is necessary to generate crop growth in upland and lowland areas, respectively (FAO 1978). The higher water demand in lowland areas is due to the volumes required for successful rice cultivation. The LGP is defined so as not to include any periods exceeding 15 consecutive days with those conditions not being satisfied. Figure 2.3 displays the statistical distribution of the beginning, end and length of the growing period at the two study sites. The range of variations of the beginning of the growing period is much greater than that of the end of the growing period, illustrating the higher variability of the rainy season 
Figure 2.3. Statistical distribution of the starting date, ending date and length of the growing periods for upland (rainfall $>50 \%{ }^{*}$ ETP) and lowland (rainfall $>75 \%{ }^{*}$ ETP) areas.

\section{Growing period characteristics in the study area}
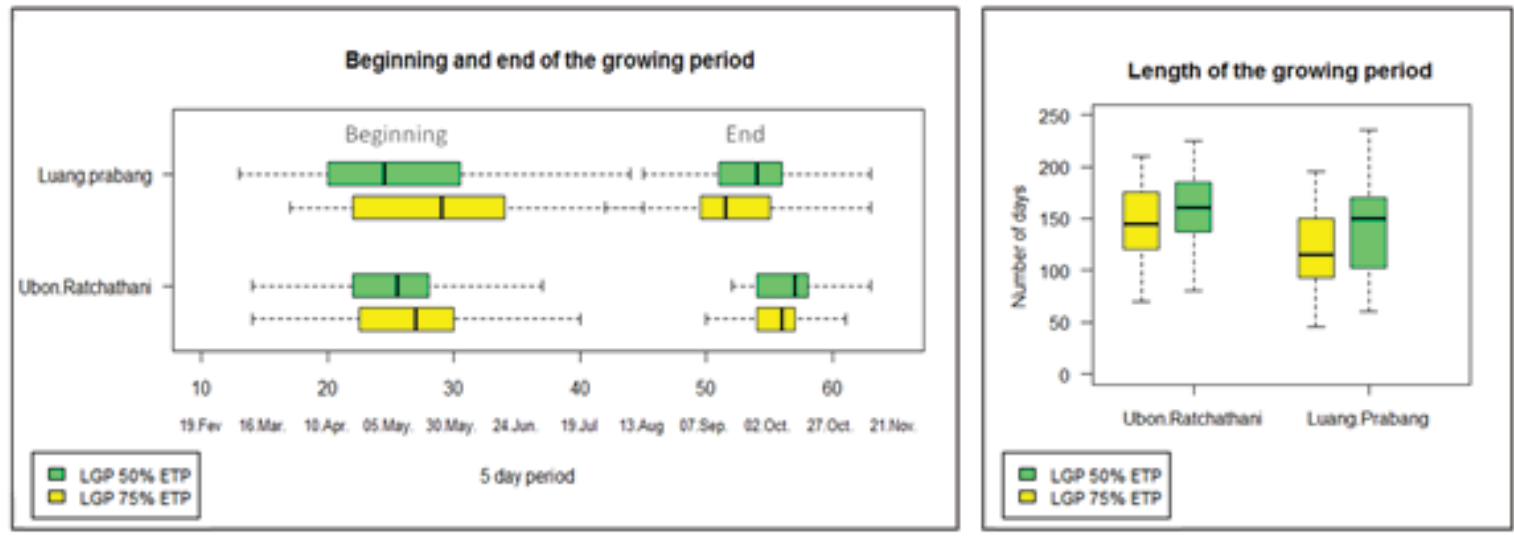

onset, in comparison with its end. This also reflects the difficulty for the farmers to decide on an appropriate date to start growing crops and the risks associated with drought problems during this early stage of the cropping calendar. Because of a higher water demand, the LGP in lowland areas is shorter than in upper areas. The duration of the LPG (between 150 and 160 days) is similar to the length of actual cropping calendar. However, one year out of four, the growing season is shorter because of inappropriate climate conditions.

\section{Agro-climate analysis for the GMS}

In order to generalize this analysis to the whole GMS, climate variables were derived and mapped, using a dataset of monthly rainfall and PET data provided by the Climate Research Unit (CRU) of the University of East Anglia and covering the period 1901-2009 with a $0.5^{\circ} \times 0.5^{\circ}$ spatial resolution (Mitchell and Jones 2005). The analysis focused on variables relating to timing and duration of water availability (rainfall and PET) associated with the monsoon. The Southeast Asian monsoon is influenced by the East and South Asian Monsoon as well as atmospheric and oceanic processes, conferring important inter- and intra-annual variability. In general, temperature is not an important constraint for crop growth in the GMS, except in the highlands of Yunnan (see Part 3, Assessing crop suitability). Unlike rainfall, temperature variation from year to year is not pronounced.

Patterns of annual rainfall distribution are shown in Figure 2.4 for 5\%, 50\% and 95\% percentiles of annual rainfall, which correspond to one-in-20-year extreme dry, normal and extreme wet years, respectively. The driest areas are in central, northern and northeastern regions of Thailand, Yunnan and central Myanmar, with mean annual rainfall ranging between $700 \mathrm{~mm}$ and $1,250 \mathrm{~mm}$. The wettest areas, with mean annual rainfall varying between $2,250 \mathrm{~mm} / \mathrm{year}$ and $5,000 \mathrm{~mm} / \mathrm{year}$, include the coastal areas along the Andaman Sea, the eastern coast of the Gulf of Thailand, and central parts of Lao PDR and Vietnam. During the extreme dry and wet years, the spatial distribution of annual rainfall is similar to that of mean annual rainfall. Areas with the highest rainfall variability include the high rainfall areas along the southern coast of Myanmar, and the lower rainfall areas in central and northeastern Thailand, northern Vietnam and Yunnan. Areas with lowest multi-annual rainfall variability are located in southern Vietnam. Areas with high rainfall variability are exposed to rainstorms originating from the Indian Ocean, although the variability in northeast Thailand may be due, in part, to storms coming from the South China Sea across north and central Vietnam. 
Figure 2.4. Frequency distribution and coefficient of variation of annual rainfall (1901-2009).
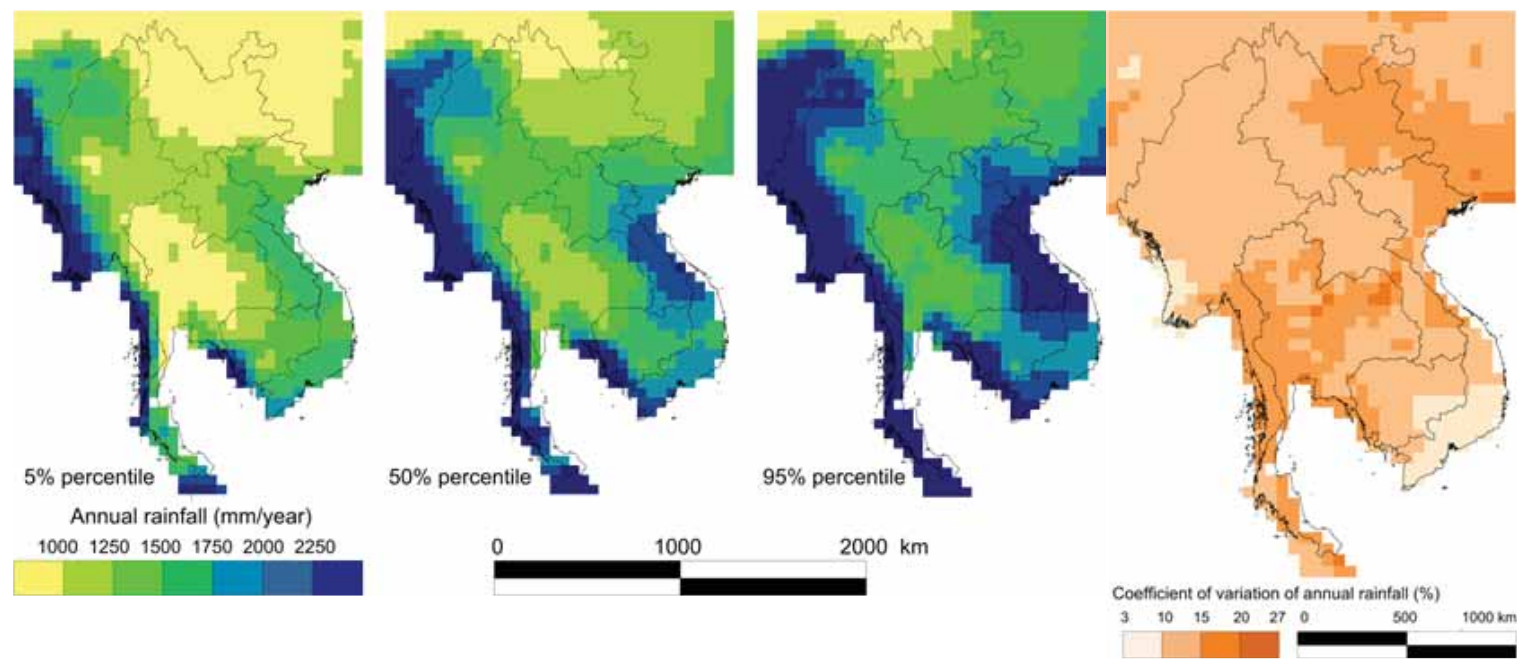

The start and end of the rainy season was assumed to correspond to the first and last months of the year, respectively, when actual monthly rainfall exceeds $1 / 12$ of total rainfall of the current year. Averaging results obtained for each year over the period 1901-2009 resulted in decimal values translated to 10-day periods as shown in Figure 2.5. The monsoon starts first in the central part of the GMS (Vientiane Plain and central Thailand) in mid-April. It starts later in southern Thailand, southern Lao PDR and central Vietnam (late May). The monsoon ends first in northeast Thailand (mid-August) and lasts until early October in Cambodia, southern Vietnam and northern Myanmar.

The driest months first occur in December in the central part of the GMS and are delayed to January in central Thailand and Cambodia, to February in southern Vietnam, southern Lao PDR and southern Thailand, and then to March along the northern Myanmar coast (Figure 2.6). Months with the highest rainfall first occur in the northern parts of the GMS (July in Northern Myanmar and Yunnan) and later in Lao PDR (August), central Thailand (September) and central Vietnam (October). The time lag in the arrival of the wettest month between central and coastal areas indicates

Figure 2.5. Occurrence of the monsoon. Numbers 1, 2 and 3 correspond to the first, second and third 10-day period of the month.

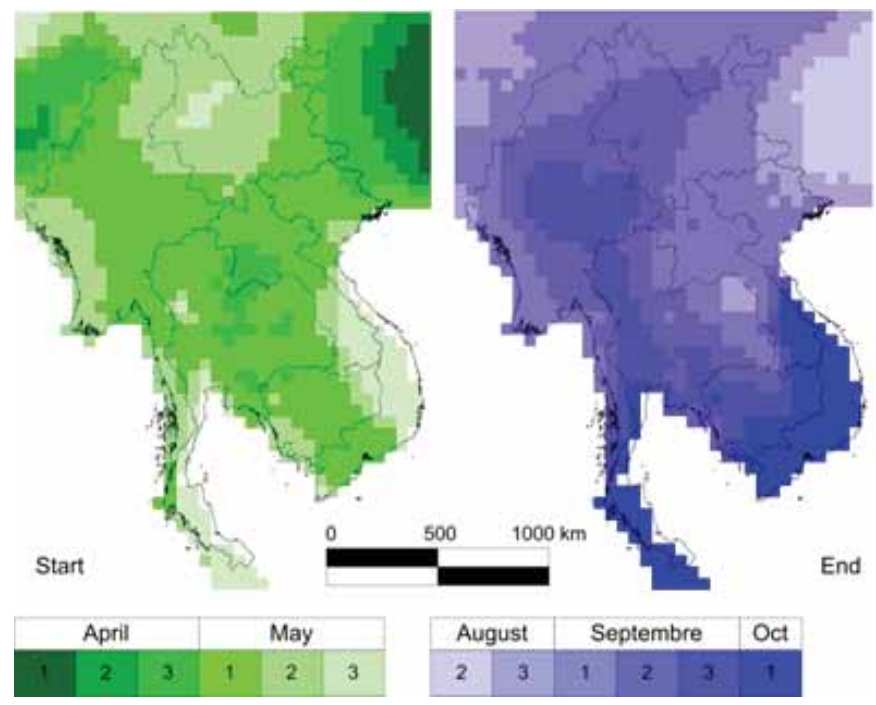


Figure 2.6 Months with lowest and highest rainfall.
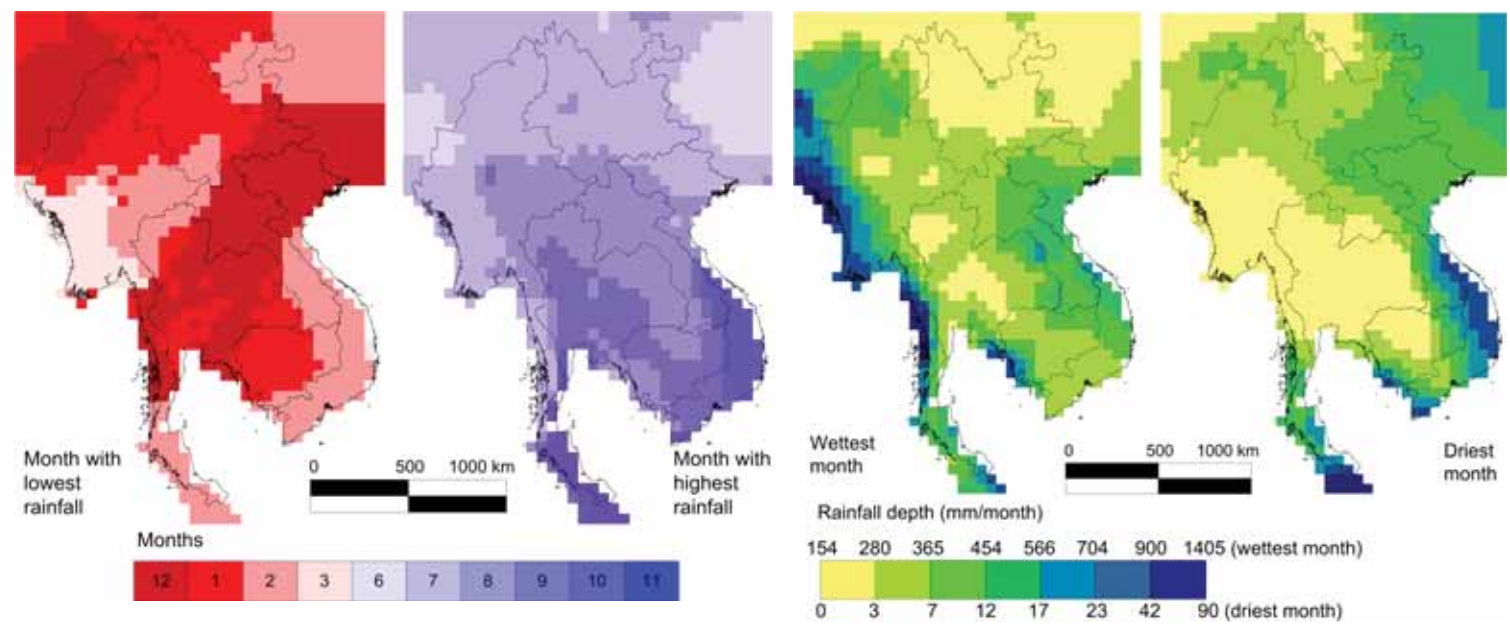

that growing periods can be distributed over a long time frame in the GMS. In most areas, the dry season is clearly marked with rainfall of less than $20 \mathrm{~mm} / \mathrm{month}$. However, central Vietnam still receives some rainfall during the driest period, as a result of the wet winds brought on by the northeast monsoon. The Myanmar coast receives the highest monthly rainfall.

The contrast between the wet and the dry season was captured by computing cumulative rainfall over the six wettest months of the year divided by the total rainfall of the year (Figure 2.7A). The length of the growing season was mapped based on the number of consecutive months when monthly rainfall exceeded PET/2 (Figure 2.7B). Comparing maps A and B shows that those areas with the highest seasonal contrast also experience the shortest growing season. The growing season lasts six months in northeast and northern Thailand, seven months in most other parts of the GMS and eight to nine months in Vietnam. Consistently, the contrast between wet and dry seasons is highest in northeast Thailand, as the six wettest months contribute more than $90 \%$ of the total annual rainfall. According to Figure 2.5, this short wet season is mainly caused by an earlier end to the monsoon in comparison with other areas. The combination of short wet season,

Figure 2.7: (A) Contribution of the six wettest months to annual rainfall, and (B) length of the growing period (rainfall $>\mathrm{PET} / 2$ ).

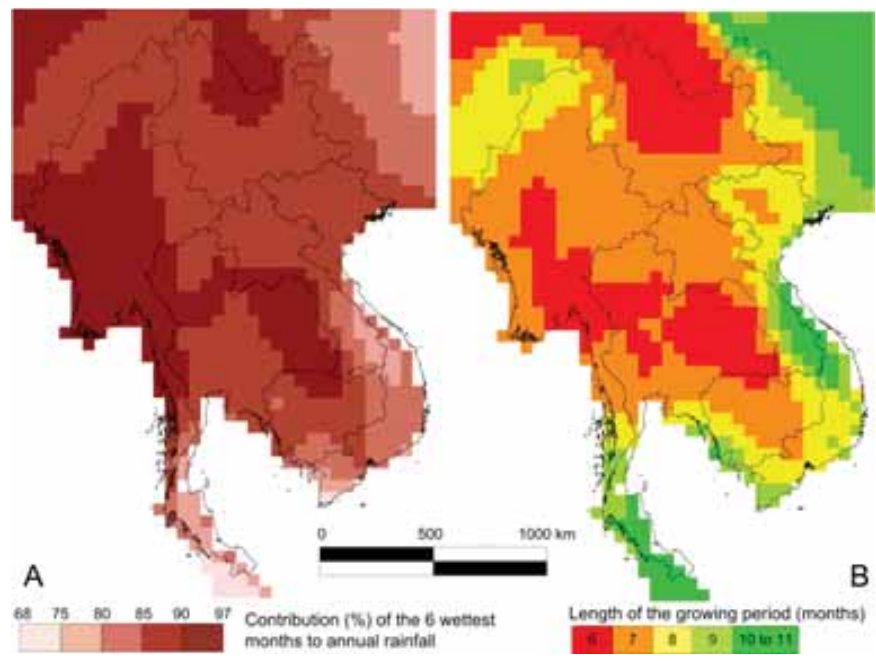


variable onset, and high year-to-year variability in total rainfall (cf. Figure 2.4), make agricultural conditions particularly uncertain in northeast Thailand.

Figure 2.8 represents, for each month of the year, the likelihood that rainfall exceeds PET, which equates to available water and the possibility of cropping. Cropping can start in April in Northern Laos in about one or two years out of four. Most areas of the GMS, except the most eastern part of Vietnam, become suitable for cropping in June. However, even during the wettest months of the year between July and September, parts of central, north and northeast Thailand occasionally experience droughts with a frequency varying between 5\% and 25\%. From October, northeast Thailand and northern Vietnam are the first areas where climate conditions become unsuitable for cropping, confirming the particularly adverse climate conditions of northeast Thailand for growing crops. Cropping remains possible along the Thai peninsula and in southern Vietnam until December.

Figure 2.8. Occurrence frequency of growing period (Rainfall $>$ PET).

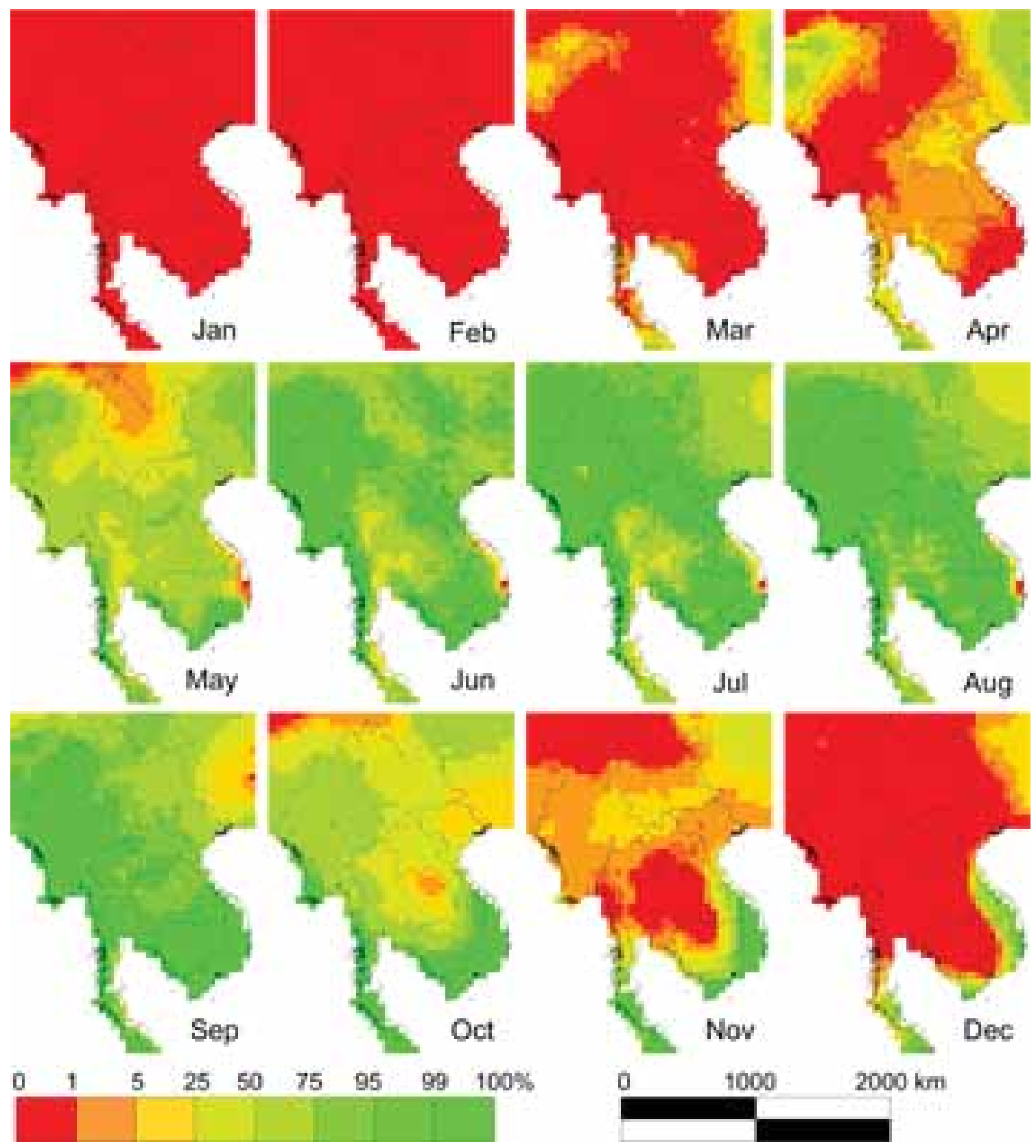




\section{Drought in the GMS}

Although total annual rainfall across most of the region is high by global standards, drought and water stress are common. There are four main causes of water stress. First, the very strong seasonal influence on rainfall; more than $80 \%$ of rain falls during the six months of the wet season and there are correspondingly large moisture deficits during the dry season. Figure 2.8 shows the length of the growing season (period for which rainfall > PET/2). Without irrigation, agriculture in the dry season is significantly constrained. Second, the inter-annual variability of rainfall. Using the definition of a dry year as being one with less than $80 \%$ of mean annual rainfall, drought conditions can be expected between one year in five and one year in 10 over much of the basin. Figure 2.9 shows the distribution of dry years since 1995, indicating that drought is quite localized, and does not affect the whole region in a single year.

Third, and the most common, cause of water stress is changes in the timing of rainfall. For example, drought affected large areas of Thailand and Cambodia in 2004, even though total annual rainfall was close to the long-term average. Almost no rain fell in the last three months of the year, a period that is critical for rainfed rice, resulting in a $30 \%$ fall in farm output (Adamson and Bird 2010). Thus, very severe agricultural drought can occur in years where meteorological drought is not evident.

In the deltas and floodplains, wet- and dry-season cropping depend on the annual flood pulse. In the wet season, overbank flow is needed to inundate the rice crop and in the dry season water is needed for pumped irrigation. Low flows in the river can result in hydrological drought and losses. Flow conditions usually bear little relationship to local rainfall, since the majority of flow originates upstream. For example, low flows in the Mekong in 1998, 2004 and 2009 had significant impacts on production in Cambodia and the Vietnamese delta (Adamson and Bird 2010).

\section{Long-term climate variability}

The analysis above is based on long-term averages. In the context of climate change, an important question is how or whether these conditions have changed over time, and whether conditions will be significantly different in the future.

Lacombe et al. (Forthcoming) analyzed trends in rainfall patterns at 17 stations in the central Mekong Basin over the period 1953-2004. A modified version of the Mann-Kendall test, accounting for the long-term persistence phenomenon usually exhibited by climate time series, was applied to 31 variables derived from daily rainfall. These variables included: the amount of rain and number of rainy days per season and per range of daily rainfall, the occurrence of the wet season, the frequency and magnitude of extreme rain events, and the duration of extreme droughts. The field significance of each variable was assessed using a permutation methodology accounting for the spatial correlation structure of the data. The results indicated that less than $10 \%$ of trends are significant and correspond to increases in medium and high daily rainfall during both dry and wet seasons. Virtually no trend was detected in the occurrence of the wet season or in the frequency and magnitude of extreme events. None of the variables were found to be field significant, indicating that the few trends observed at specific locations reflect localized stochastic processes rather than any deterministic phenomenon such as human-induced impacts on climate expected to homogeneously alter rainfall patterns over the region (Lacombe et al. Forthcoming; Lacombe et al. 2012).

Previous investigations of rainfall trends undertaken in Southeast Asia concluded that rainfall either remained stable (Kripalani and Kulkarni 1997; Boochabun et al. 2004) or decreased (Kwanyuen 2008; Manton et al. 2001; Sharma et al. 2006) over the second half of the twentieth century. 
Figure 2.9. Occurrence of dry years 1995-2009.

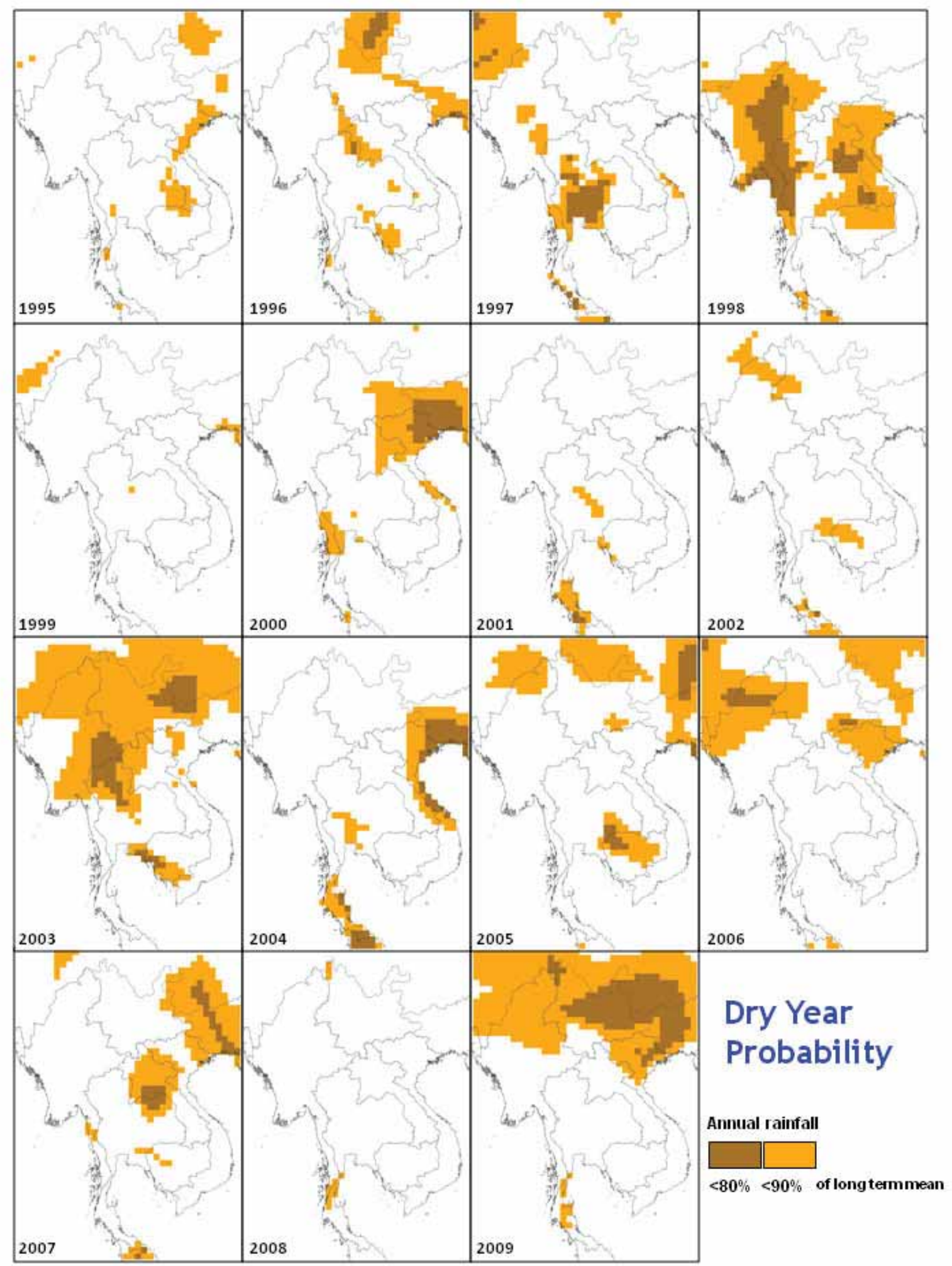

In contrast, the few significant trends detected by Lacombe et al. (Forthcoming) and Lefroy et al. (2010) mainly exhibit positive slopes, corresponding to rainfall increases. Although it is not possible to precisely explain such discrepancies as the likely causes are numerous (geographical discrepancies, 
differences of statistical tests and confidence levels, for example), variations in the lengths of study periods is likely to partly explain the differing results (Lacombe et al. Forthcoming). In all cases, the variability of rainfall is deemed a greater problem than the trends in rainfall.

\section{Climate change}

Lacombe et al. (Forthcoming) characterized climate change in the GMS, using daily rainfall and temperature time series produced by the regional climate model, Providing REgional Climates for Impacts Studies (PRECIS), and forced by the global climate model, European Centre Hamburg Model, version 4 (ECHAM4), under the SRES scenarios A2 and B2 over the period 1960-2049. Results indicate a temperature increase over the full GMS during the period 1960-2049, either during cold or warm seasons, at around $0.023 \%$ year. The highest rates of temperature increase $\left(+0.035^{\circ} \mathrm{C} /\right.$ year $)$ are localized in the northern parts of the GMS around north Myanmar and north Yunnan. The lowest rates occur over the seas.

Changes in annual rainfall are expected over about one-third of the total surface area of the region; but the magnitude of change is generally small. Significant trends detected in rainfall time series indicate an increase in annual rainfall in Myanmar and the Gulf of Thailand. Rainfall decreases are concentrated on both sides of the Gulf of Thailand below the 14th north parallel. In general, rainfall rises are due to increases in heavy rainfall during the rainy season and rainfall decreases are explained by a reduction of light rains during the dry season. Time lags in the climate seasonal patterns mostly result in a very slight delay in the onset, the peak and the end of the rainy season (Lacombe et al. Forthcoming).

Most regional studies (e.g., Eastham et al. 2008; Snidvongs et al. 2003; ADB 2009) envisage limited change to the overall amount of rain or length of the wet season, but forecast some shifts in the seasonal distribution of rainfall, with drier and/or longer dry seasons and shorter, more intense wet seasons, or a delay in the wet season, with the latter impacting highly on photoperiodic crop varieties. Even with no change in annual rainfall, the availability of water for agriculture may differ, with increases in the incidence of droughts and floods. There is a high degree of uncertainty around projections of future climate in the GMS, but, at least for the next 50 years, it is unlikely that conditions for agriculture will move much outside the current envelope of variability. The most effective approach to 'no-regrets' adaptation is to work towards greater resilience within the current situation of a highly variable climate, specifically variable rainfall. This will help to improve current livelihoods and at the same time prepare for the predicted effects of climate change. 


\section{PART 3: ASSESSING CROP SUITABILITY}

\section{Background and methodologies}

There are many factors that affect the suitability of crops that can be grown in particular locations. Of these factors, the bioclimatic suitability - the suitability to temperature and rainfall regimes is perhaps the major driver, although other factors, particularly soils, also have a major impact. Of course, there are further differences between the suitability of crops that can be grown and which crops are grown by farmers, depending on the requirements and preferences of the farmer, the availability and nature of markets, and the suitability of other crops. It is quite common that a crop that is highly suited to a particular area is not grown because other crops that have a higher demand, and not necessarily higher suitability, are grown. Similarly, crops may be grown in areas where they do not have particularly high suitability, but their combined suitability and demand are greater than the suitability and demand of other crops.

There are three possible approaches to modeling the likely differences in plant productivity under different bioclimatic conditions. The first approach is to develop full mechanistic models of plant and crop growth. These have to be complex otherwise they cannot be expected to mimic the complex behavior of the crop. Although the quality of mechanistic models is improving, there are several major drawbacks in using this approach when estimating the broad suitability of a range of crops. First, mechanistic models have not been developed for a wide range of crops, although they do exist for the main staple crops. Second, the degree of parameterization required to run these models effectively is very large and this requires a lot of site-specific data that either does not exist or is too difficult or expensive to collect.

The second approach is more empirical. This does not require detailed understanding of the mechanisms by which different plants respond to, and are adapted for, different temperature and rainfall regimes, but it does require a great deal of data on plant growth under a very wide range of conditions, and in most cases this data does not exist.

The third approach is partially mechanistic, based on understanding the specific bioclimatic niches in which a plant species grows and being able to set the limits and responses to different conditions. The International Center for Tropical Agriculture (CIAT), with the support of Bioversity International and the International Potato Center (CIP), has developed a simple mechanistic niche model based on the Food and Agriculture Organization of the United Nations (FAO) database of crop ecological requirements, Ecocrop (http://ecocrop.fao.org/ecocrop/). The model, which has the same name as the database, Ecocrop, is mechanistic in terms of the climatic niches to which a species is suited or less-well suited. The various temperature and precipitation thresholds from the Ecocrop database are used, or modified by the user, to evaluate the suitability of a certain place for a particular crop species by using the WorldClim database of global climate data (Hijmans et al. 2005a). The model was developed to run from within the DIVA-GIS software (Hijmans et al. 2005b). The main use has been to predict the suitability of various crops under different climatic conditions, and thus at different locations. The aim is to assess suitability, rather than productivity or yield per se, although in situations where there is a great deal of information about yields under different conditions and locations, then the suitability assessment can be interpreted in terms more closely related to yield.

The model uses 11 parameters (Figure 3.1):

- Tkill (the temperature at which the crop will die)

- Tmin (the minimum temperature at which the crop will grow)

- Topmin (the minimum temperature for optimal growth) 
- Topmax (the maximum temperature for optimal growth)

- Tmax (the maximum temperature at which the crop will grow)

- Rmin (the minimum amount of rain required for the crop to grow)

- Ropmin (the minimum amount of rain required for optimal growth)

- Ropmax (the maximum amount of rain for optimal growth)

- Rmax (the maximum amount of rain below which the crop grows)

- Gmin (the minimum length of the growing season)

- Gmax (the maximum length of the growing season)

Measurements of temperature, rainfall and growing season are given in degrees centigrade, millimeters and days, respectively. Using these parameters, the Ecocrop model computes separate suitability indices for temperature and rainfall and then multiplies the two indices to generate a combined suitability rating.

Figure 3.1. The use of climatic parameters to set the suitability of plant species to particular climates in the Ecocrop model.

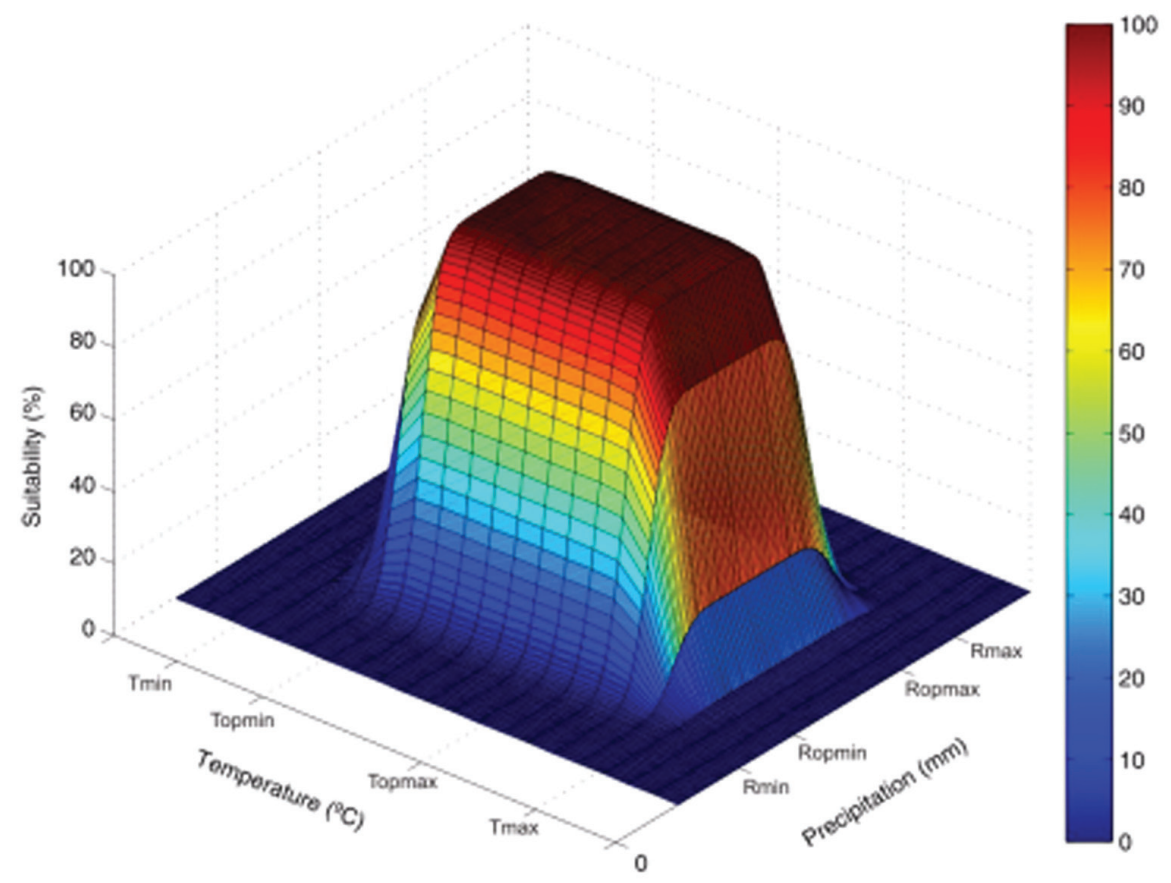

The Ecocrop model provides a very convenient way to assess the suitability of a plant species to a particular location or environment, although the results must be interpreted carefully. The main limitations are that it is based purely on bioclimatic variables. Although these are extremely important for plant growth and productivity, such a suitability rating ignores specific soil requirements, problems of pests and diseases, and how these factors interact with climate. Soils requirements and the presence of pests and diseases modify suitability relatively simply, but both have important interactions with climate. For example, the upper and lower limits for rainfall are affected by soil type in terms of the soil water-holding capacity at the dry end of the scale, and 
infiltration rates when waterlogging is a risk; both of these are further affected by topography. Another issue with the model is that the parameters come from the FAO dataset, and specific varieties or accessions may have slightly different climatic requirements. The Ecocrop database has been developed and modified over many years and the user can further modify the parameters if they have better information concerning species and varieties.

CIAT has developed several other tools that can be used to assess crop suitability. Homologue (http://gisweb.ciat.cgiar.org/homologue/index.htm) assesses the homology of location, primarily in climate and geoposition, but also in soils. It is possible to compare and contrast a site or sites where a particular crop is known to grow well and a site in question. The greater the homology, the better the plant is suited to the new location. A particular feature of Homologue is that it does not require a large amount of data. The spatial decision support system, Crop Niche Selection for Tropical Agriculture (CaNaSTA), takes a more complex approach. Based on Bayesian statistics, it combines data from trial sites, with expert knowledge and biophysical and socioeconomic data, to predict where different crops may be successful. It not only forecasts where a crop may grow or not but maps the probability of success of variables such as yield and, perhaps most interestingly, product quality. Although this study used the Ecocrop approach, Homologue and CaNaSTA could be useful for conducting further, more detailed studies.

\section{Crop suitability maps}

The Ecocrop model was used for a wide range of annual and perennial crops. The parameters were taken from the FAO Ecocrop database, although some modifications were made based on local and expert experience. The crops evaluated include: paddy and upland rice, maize, cassava, kenaf, sugarcane, rubber, oil palm, Arabica and Robusta coffee, peanut, soybean, common bean, cabbage, chili, garlic, mung bean, coconut, banana, pineapple and sweet potato.

A suitability map for each crop was created, along with the separate maps showing suitability to temperature and precipitation. Doing so enabled assessments to be made showing the comparative sensitivity to these two factors. While the temperature regime varies minimally from year to year at any site, there are significant intra-year and inter-year variations in rainfall, both in terms of the overall amount of rainfall received and how precipitation is distributed throughout during the year. Variations in rain falling during the main wet season, particularly at either end of this period, presents a great challenge to rainfed agriculture in the GMS. By consulting the maps showing overall suitability and suitability to precipitation, it is possible to assess the likely sensitivity of a specific crop to these intra- and inter-annual variations in rainfall. The maps showing frequency distribution of annual rainfall and the coefficient of variation (Figure 2.4) are particularly relevant when assessing the potential sensitivity, as well as the maps showing lengths and intensities of the growing season, monthly variations in rainfall and the distribution of drought in space and time. If an area appears to be marginal in terms of suitability to the rainfall regime, then it is important to take great care in assessing the suitability under the 'real' conditions of a variable rainfall regime.

The map of the suitability of Indica-type paddy rice (Figure 3.2) indicates that most of the GMS is not suited to cultivation of paddy rice, which is clearly not true. While there is no problem with the temperature suitability, there is a major problem with suitability in terms of rainfall. This apparent lack of suitability is because the Ecocrop model cannot take into account all of the water management practices involved in paddy rice production, which include the location of fields within the topo-sequence, bunding of fields, development of a hardpan to reduce percolation, direction of water flow into and between bunded fields, thus effectively increasing the rainfall, and anything from supplementary to full irrigation. The lack of suitability to the precipitation regime, 
Figure 3.2. Suitability of Indica-type paddy rice.

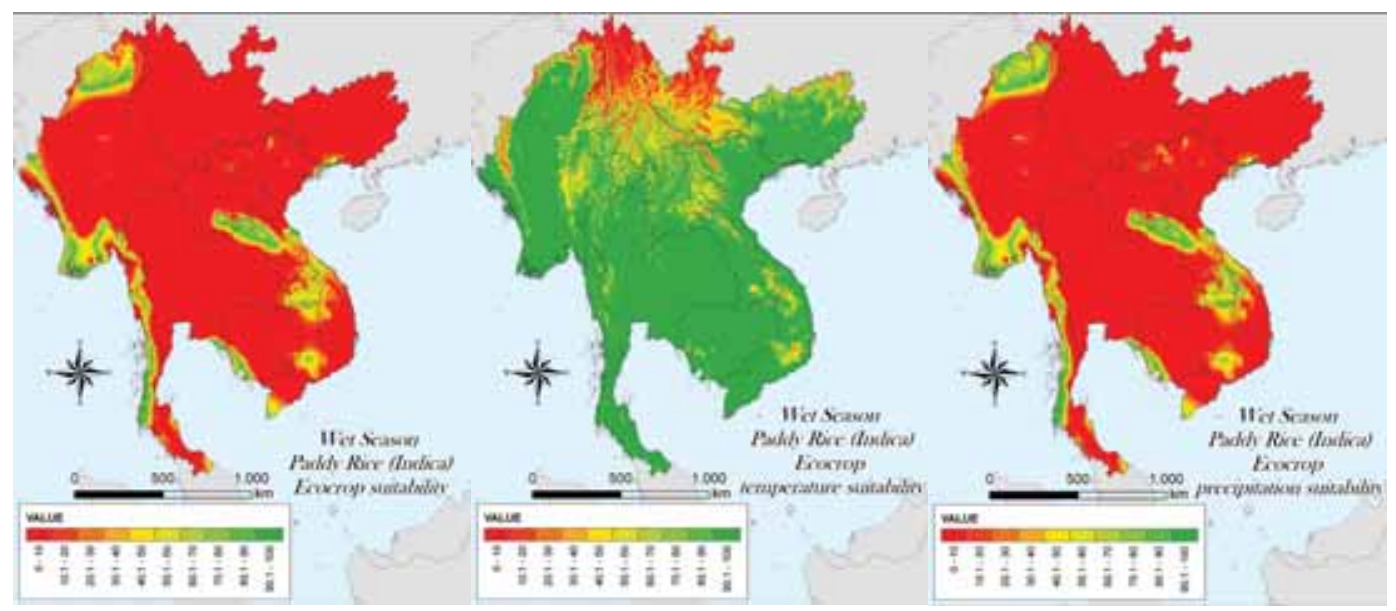

while being clearly wrong, as these water management methods are not included, does indicate the high sensitivity to water management and highlights the need for good water management, which is something that many farmers in the region are not able to achieve. While there are some very productive lowland rice systems that are assured of good water supply throughout the season from either rainfall or irrigation, there are many marginal rainfed lowland rice systems facing a high risk and as a result there will be insufficient or too much water for a good yield (see Figure 4.2).

The relatively small amount of upland rice grown in mountainous areas of the region is primarily a Japonica or tropical Japonica-type rice. Clearly there is no issue with this plant's suitability to the temperature regime, but it appears to be extremely sensitive to precipitation (Figure 3.3). The productivity of these systems is not very high, even though upland rice has been the mainstay of upland communities in swidden agriculture for generations, in places such as the northern hills of Lao PDR. The suitability assessment may, therefore, be a little harsh. Under cycles of long fallow and short cropping cycles these systems are suitable, but as cropping intensity has increased and fallow periods have shortened, productivity has declined and sensitivity to rainfall patterns has increased. An important reason for these changes can be a decline in the soil fertility.

Figure 3.3. Suitability of Japonica-type upland rice.

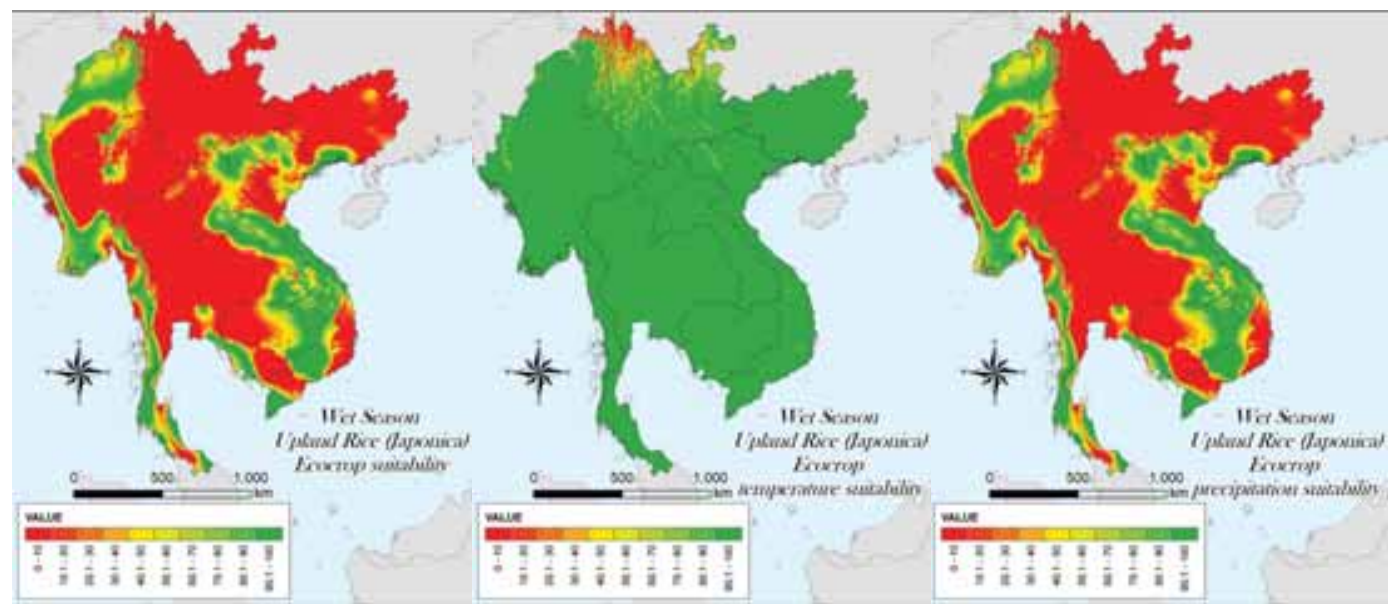


Other crops that are quite nutrient-demanding, such as maize, continue to be reasonably productive under these systems. This is partially explained by the weaker root system of rice, which means that it cannot penetrate the soil as well or compete with weeds for nutrients and, perhaps more critically, water. The decline in soil organic matter, with a major impact on soil physical fertility and water-holding capacity, plus the huge increase in weed pressure resulting from shorter fallows and longer cropping cycles, therefore have a greater impact on upland rice than other crops. Good soil, land and water management is paramount to maintaining the productivity of these systems. The only other major areas of upland rice in the GMS are the more productive, higher-input systems in parts of Yunnan. One of the inputs is water; the crop is irrigated but not flooded as for paddy rice. In both these case, the productivity of these systems relies on the quality of direct (irrigation) or indirect (management of soils and fallow/cropping cycles) water management. The situation for upland Indica-type rice, which is cultivated even less than the upland Japonica-type varieties, is much the same as for the Japonica rice, although with slightly greater sensitivity to temperature in the higher latitudes and altitudes (Figure 3.4).

Figure 3.4. Suitability of Indica-type upland rice.

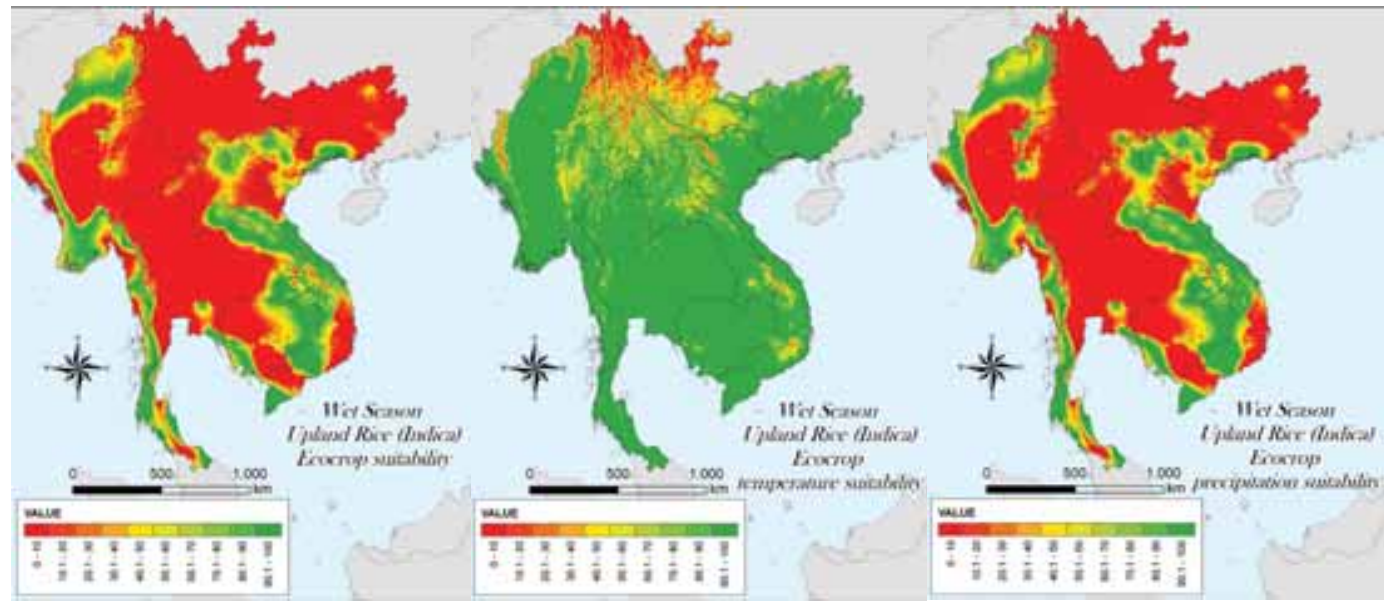

The suitability of maize is also driven by the suitability to the precipitation regime. Here, the map of suitability is closer to, but still does not match, the areas of production on the ground (Figure 3.5). In Lao PDR, the major maize production belt across the north of the country, in Xayaburi, Houaphanh, Oudomxay, and Luang Prabang, matches the suitability well. However, in parts of Thailand, where the rainfall is more variable, maize appears less suitable according to the maps of rainfall and coefficient of variation in rainfall (Figure 2.4). This matches the production areas. When information on soils is included, the suitability declines on the sandier soils of the northeast in comparison to areas with better soils in the central and north zones of the country. Clearly, management of soils, especially soil organic-matter management, and the possibilities for supplementary irrigation, are important factors in maintaining the productivity of maize under variable rainfall regimes.

In contrast to rice and maize, the suitability of cassava is driven by both temperature and precipitation, although in different regions (Figure 3.6). Comparing the overall suitability and temperature suitability maps indicate that temperature is the main restriction in the northern areas, especially in Yunnan and Guangxi, and in certain higher altitudes, such as in the areas of northeast Lao PDR. Selection of cool-tolerant varieties is under way in Lao PDR, with some improvement 
Figure 3.5. Suitability of maize.

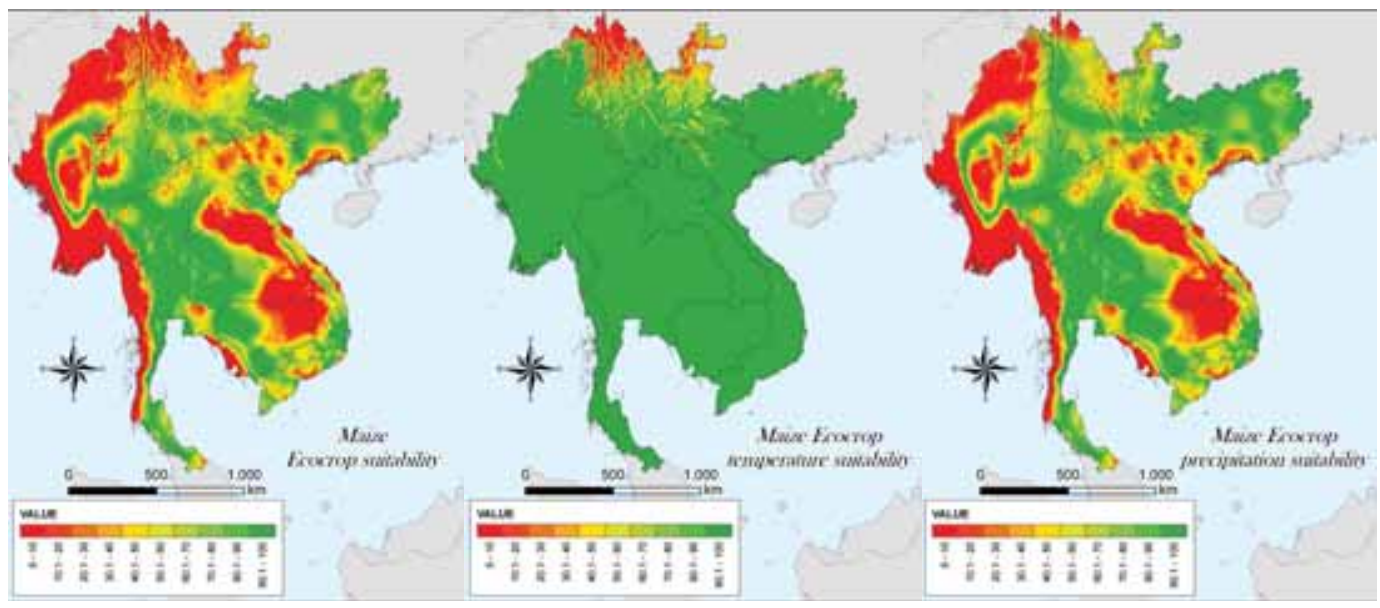

Figure 3.6. Suitability of cassava.

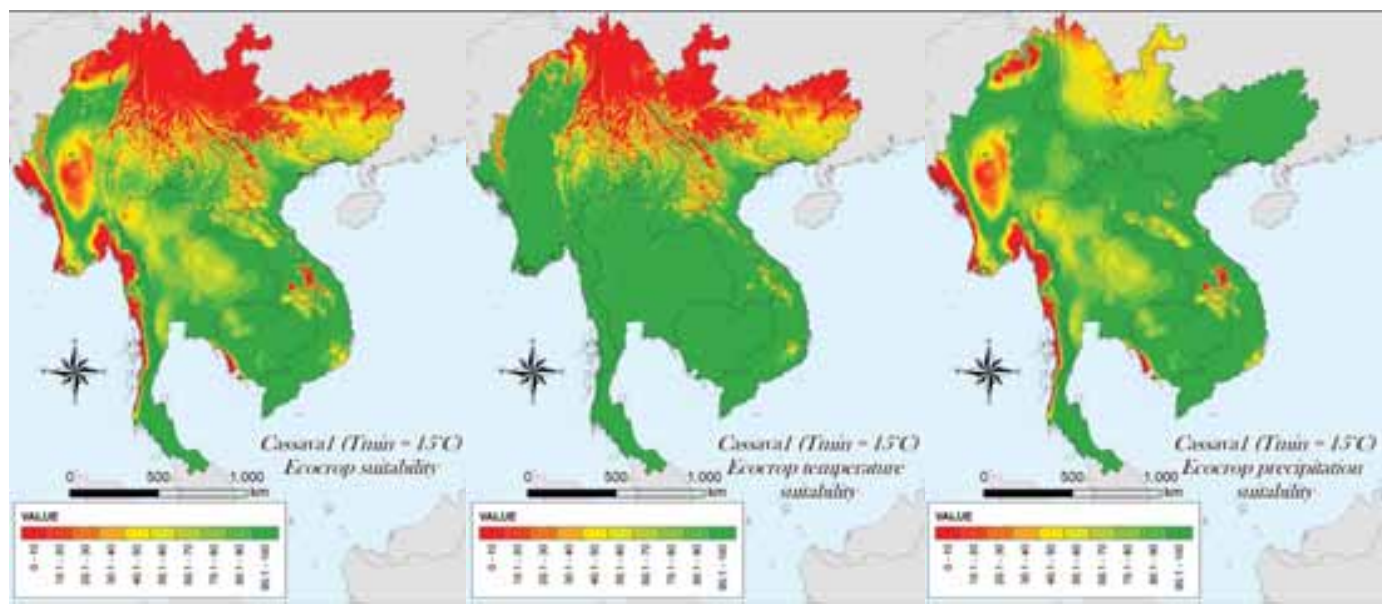

found over the current best varieties. However, yields remain quite low. There is much interest in advancing a breeding programme for cold tolerance of cassava in China, where currently at least $60 \%$ of production is in Guangxi, mostly in southern Guangxi. Tolerance of cold could allow significant increases of production into northern Guangxi and other provinces. Recalculating suitability to include greater tolerance of cold expands favorable areas for growing cassava into higher altitudes and latitudes (Figure 3.7).

The overall suitability of cassava to particular regions is also driven by characteristics of the rainfall regime with too much rain and low rainfall making certain areas unsuitable (Figure 3.6). Suitability is low, for example, in coastal Myanmar due to the high rainfall, and suitability is reduced markedly in the dry zone of central Myanmar and parts of north and northeast Thailand due to low rainfall. The observed reduced suitability in the southwest part of northeast Thailand coincides with an area that has highly variable rainfall (Figure 2.4). However, this area, especially around Nakhon Ratchasima, is one of the major cassava-producing areas (see Figure 4.2). Here, although the suitability of cassava is not very high, it is more suitable than many other crops, especially when the high variability of rainfall and sandy soils are considered. The predicted bioclimatic suitability of maize is greater than cassava in these areas, but the lower fertility of the soils and the higher 
Figure 3.7. Suitability of cassava with greater cold tolerance.

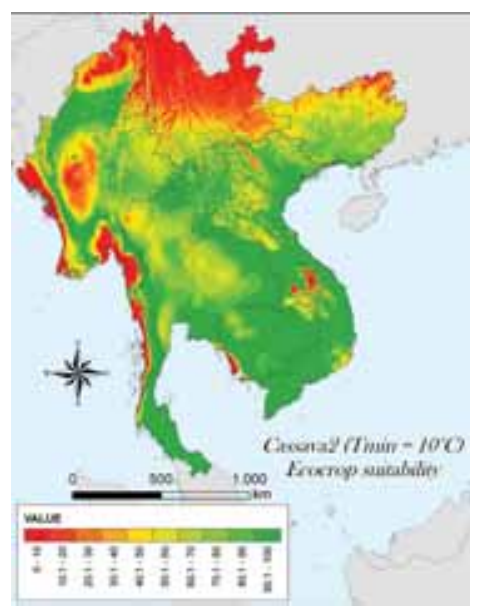

risk of drought mean that cassava is a more favorable option. This example demonstrates that the Ecocrop database is useful for predicting crop suitability, but the findings need to be modified using local knowledge of rainfall patterns and characteristics of soils.

Kenaf is a minor crop in the GMS, but it used to be cultivated widely in northeast Thailand until the 1970s. According to Ecocrop, kenaf is better suited than many crops to conditions across much of the GMS. In northeast Thailand, kenaf is more suitable than cassava, the main crop that replaced it (Figure 3.8). Kenaf production declined in northeast Thailand, not because it was poorly suited to the climate or soils, but because the market declined and there were increasing problems in managing the wet-retting process (soaking in stagnant water to break down the vegetable matter). The processing, rather than production, had a high water demand and the retting ponds became a significant source of pollution. Today, a method of dry processing has been developed, obviating the need for large volumes of water, and the market for kenaf, albeit small, is improving. It is possible that kenaf production will increase to become a reasonably small, niche market.

Although sugarcane production is relatively poorly suited to conditions across much of the GMS, it is quite widely grown, particularly as a snack crop. Thailand is a major producer of sugarcane, with the main area for production shifting in recent years primarily to the northeast part

Figure 3.8. Suitability of kenaf.

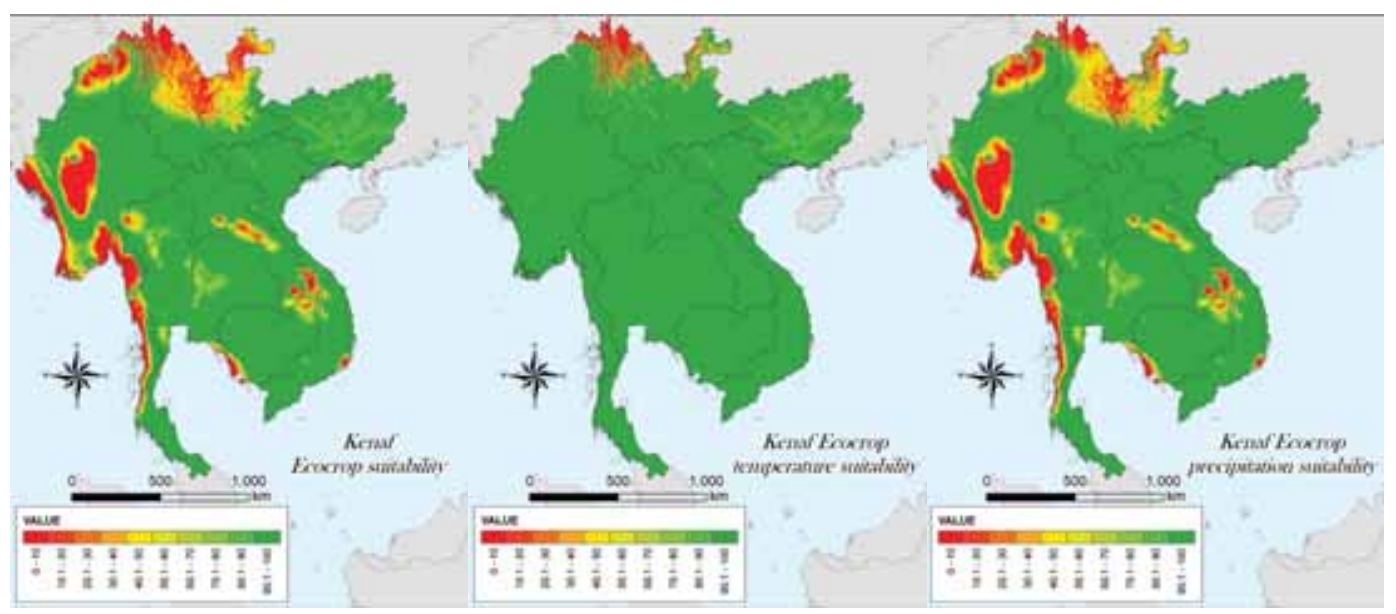


of the region. Ecocrop indicates that this is far from being an ideal area for production because of water shortages, but the value of the crop is sufficient to compensate for any reductions due to water limitations (Figure 3.9). Water availability is controlled by careful management of soils and the whole cropping system, with irrigation used in some areas. The other controlling factor when locating sugarcane production is access to a processing facility.

Figure 3.9. Suitability of sugarcane.

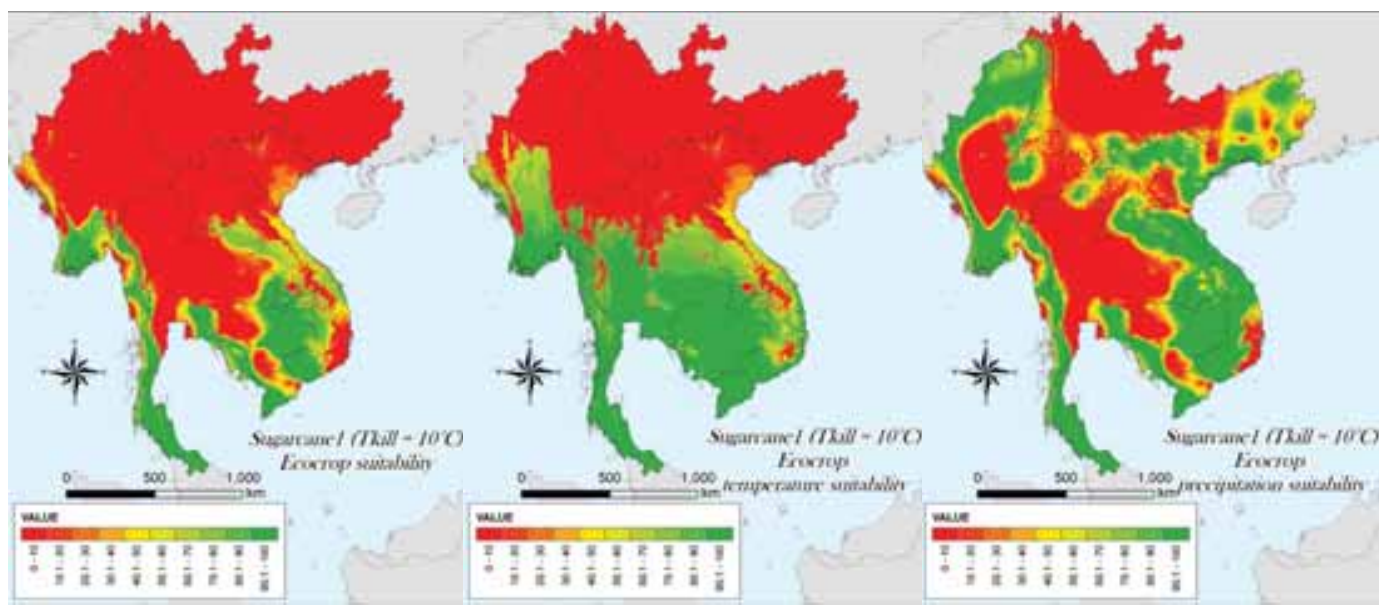

The traditional areas of rubber production, in southern Thailand and along the south and coastal areas of Myanmar, are indicated by Ecocrop to be highly suitable (Figure 3.10). Recently, however, rubber-producing areas have shifted. In Myanmar, rubber has expanded north into Kayah State and Magway Division, and even into Kachin State. In Thailand, rubber has moved from the south to the northeast. Meanwhile, rubber planting has increased in eastern Cambodia, southern and northern Laos, and Yunnan. The newer areas of production in Thailand and Myanmar are more marginal on the basis of the rainfall regime, so yields are lower and soil management becomes more critical. However, these disadvantages are compensated for by high local demand. Similarly, some new areas of rubber production in Cambodia and Lao PDR are marginal in terms of rainfall. The major constraint in northern Laos and Yunnan, meanwhile, is low temperature. New cool- tolerant clones

Figure 3.10. Suitability of rubber.

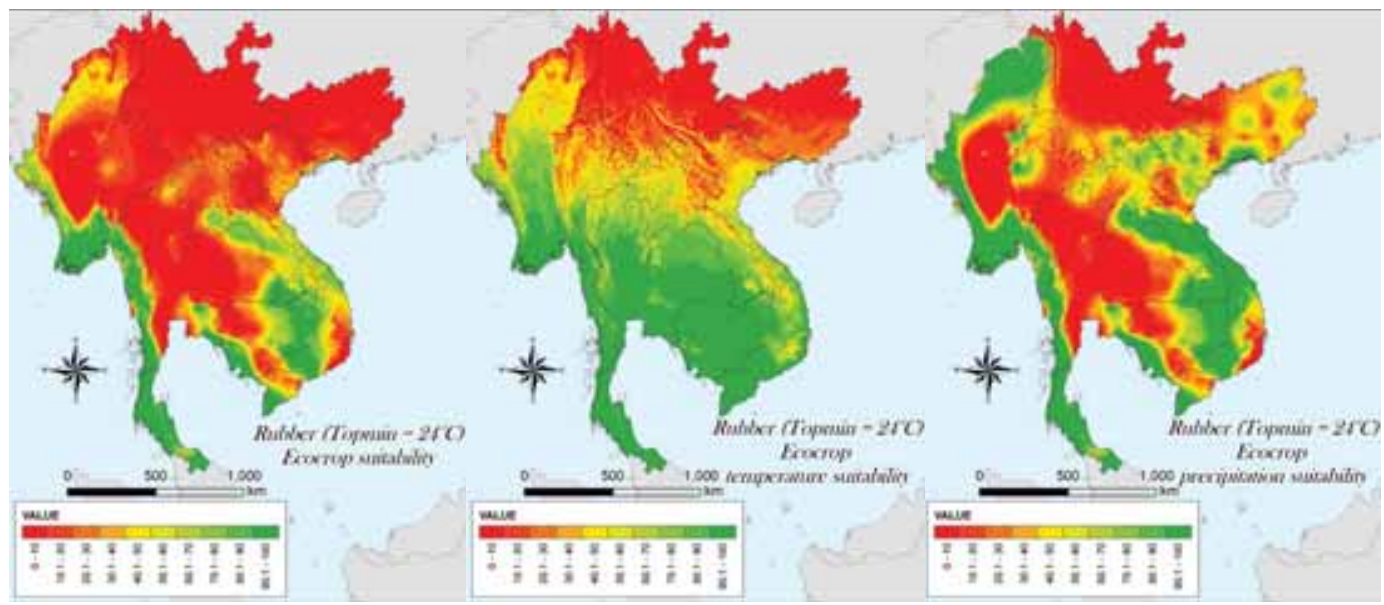


have been developed for these areas. Decreasing the minimum optimum temperature in Ecocrop from $24^{\circ}$ to $20^{\circ}$ has some impact on expanding suitability (Figure 3.11), but either these newer areas can be expected to have quite low yields or there is higher tolerance to low temperatures than used in the modified run.

Flgure 3.11. Suitability of rubber with more cold tolerance.

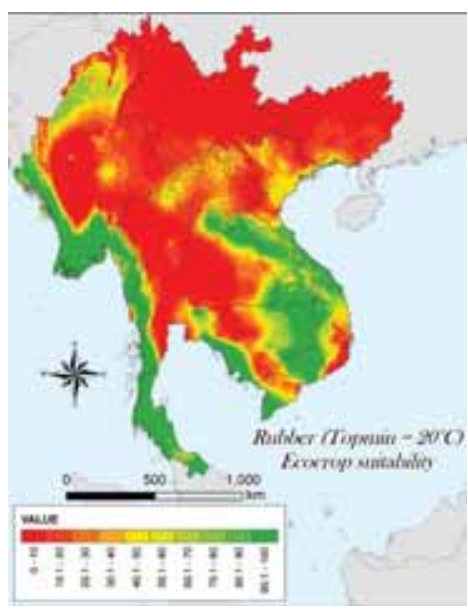

The suitability of oil palm is highest in tropical areas with high rainfall (Figure 3.12). When rubber was moved from the south to the northeast of Thailand, much of this area was replaced by oil palm. In addition to reasonably high rainfall, oil palm benefits from a more even distribution of rainfall, so production is further constrained to those areas with a more moderate dry season (Figures 2.4 and 2.7). The oil palm also requires a large amount of sulphur. While this can be added in fertilizer, there are sufficiently large amounts of sulphur in rainfall at locations with prevailing winds coming relatively short distances from the sea. These factors combine to refine the suitability and more accurately define most of the major production areas.

While Arabica coffee does not grow well in markedly dry environments or where topography and soil type combine with rainfall to result in any degree of waterlogging, the main constraint for Arabica coffee is temperature (Figure 3.13). High-quality Arabica coffee is only grown in

Figure 3.12. Suitability of oil palm.

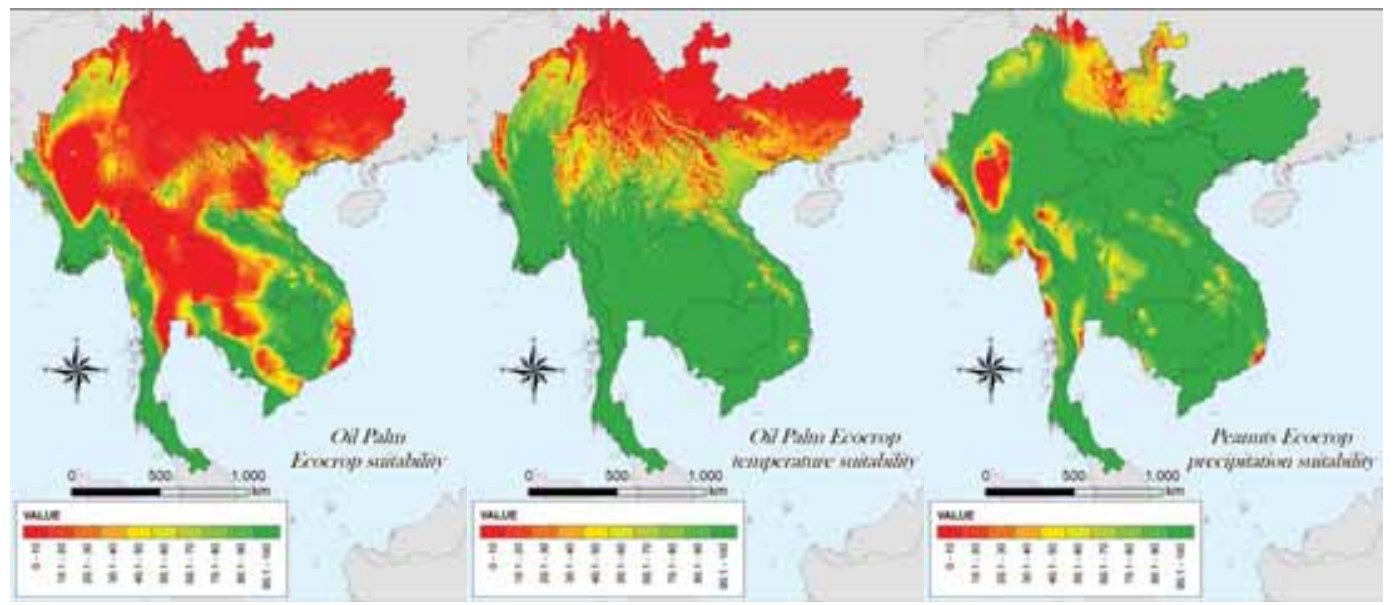


Figure 3.13 Suitability of Arabica coffee.

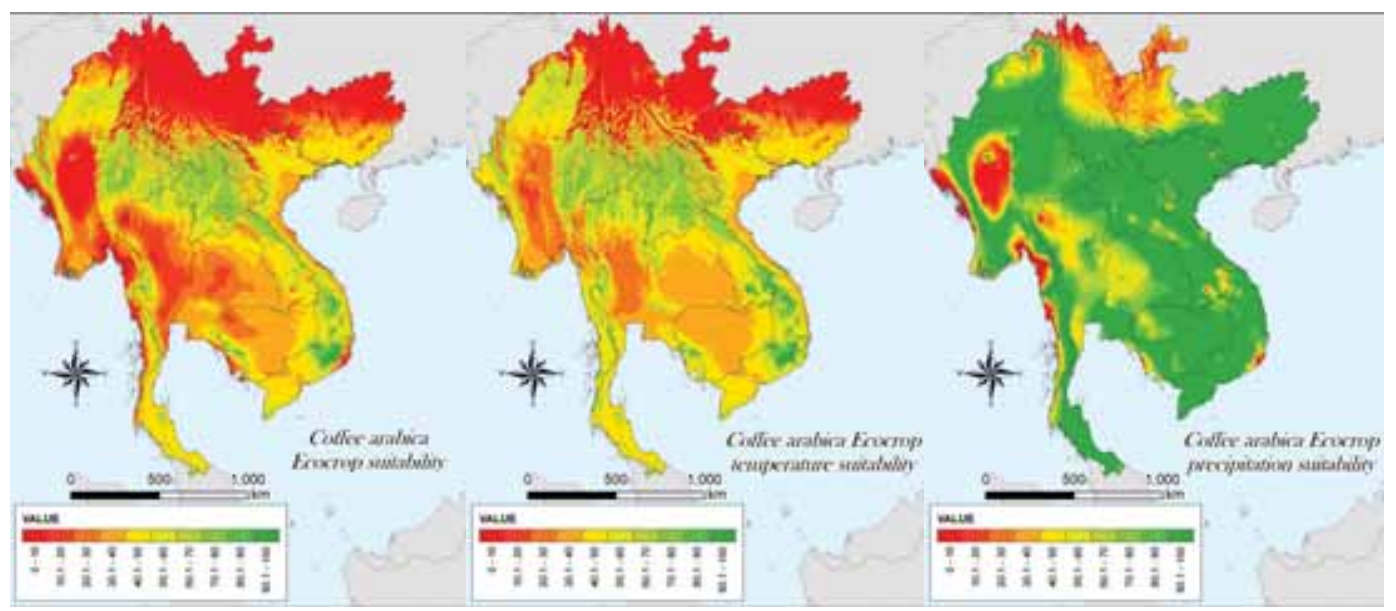

cooler areas such as the higher altitudes in south-central Vietnam, southern Lao PDR and northern Thailand, which pretty much matches the Ecocrop suitability map. The suitability of Robusta coffee is also driven by water and temperature, although as its suitability to temperatures across the GMS is much higher, the overall suitability appears greater (Figure 3.14). This suitability assessment matches the large areas of production in southern Laos and, more particularly, in south and central Vietnam, which has become a major global exporter of Robusta coffee.

Figure 3.14. Suitability of Robusta coffee.

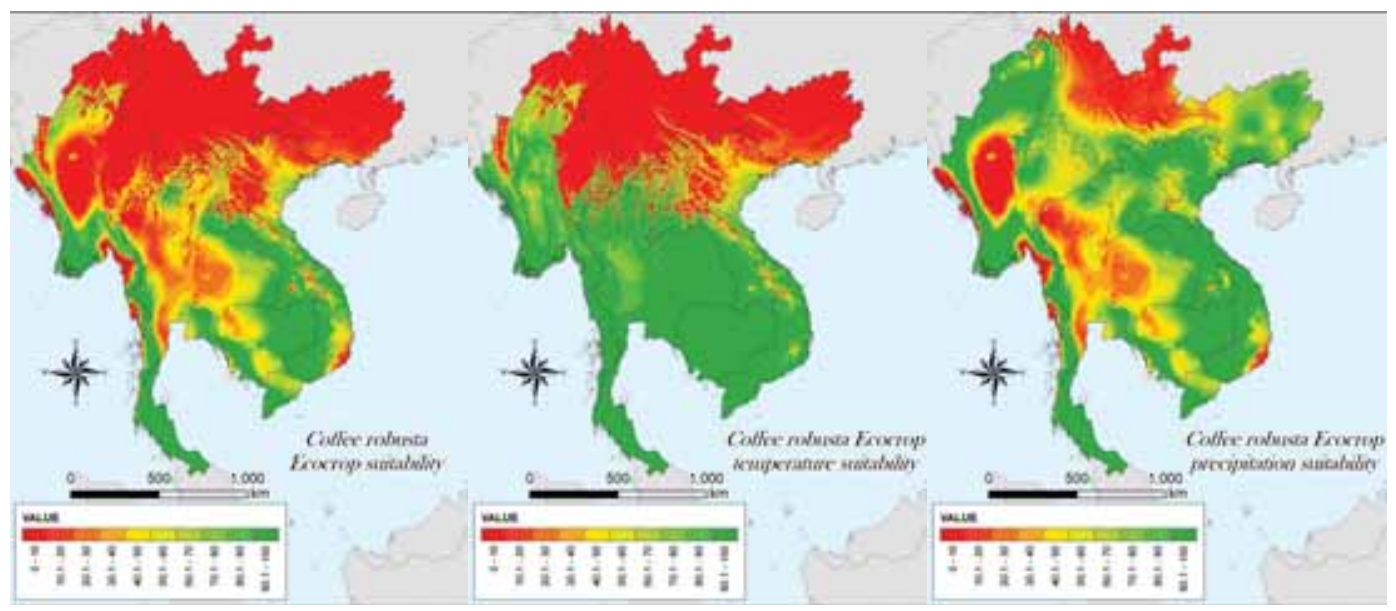

The bioclimatic suitability of peanuts is high throughout much of the GMS, with reduced suitability being due to excessive rainfall on the Myanmar coast and dry conditions in parts of Myanmar and Thailand (Figure 3.15). The main deciding factors in whether to grow peanuts are, therefore, soils, markets, farmer preferences, and the comparative suitability and demand for other crops. Very heavy soils would normally be avoided for cultivating peanuts, or at least preferentially used for growing other crops, while some of the lighter textured soils, although physically well suited, may have significant fertility constraints. Peanuts may be preferable to other crops on low-fertility soils if the fertility can be carefully managed. Using macronutrient fertilizers has helped some farmers increase production; using boron, and in some cases, 
Figure 3.15 Suitability of peanuts.

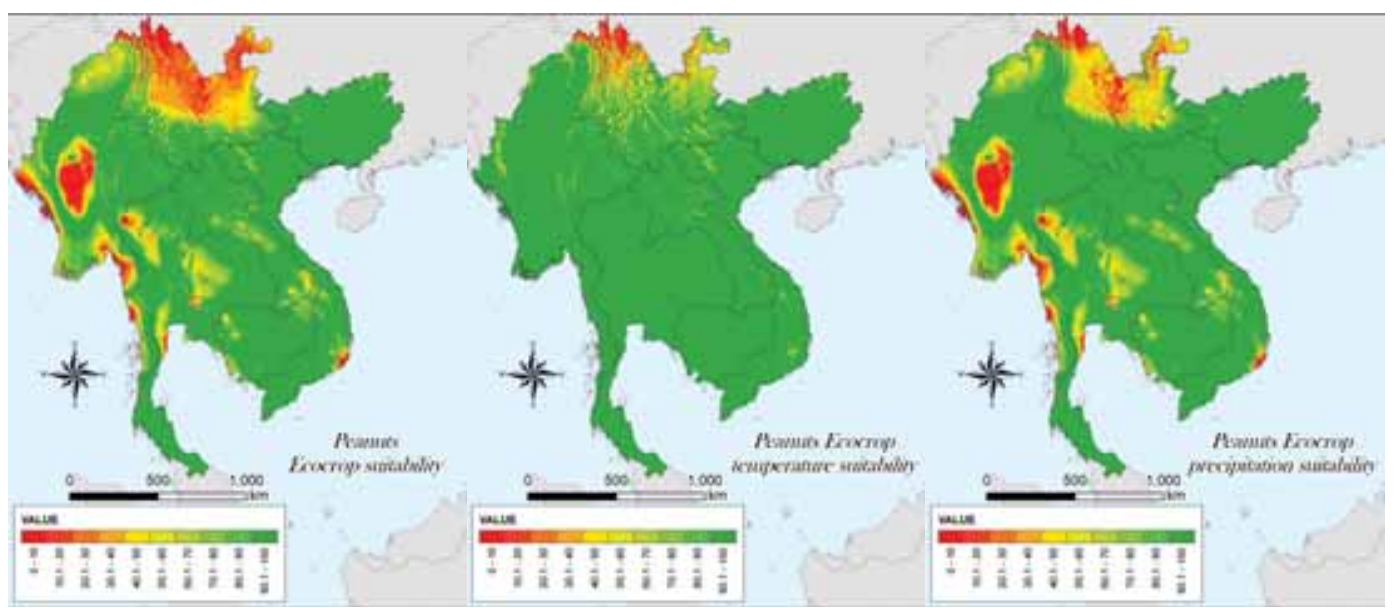

molybdenum, has significantly increased production and quality of peanuts in parts of northeast Thailand.

Soybean is widely adapted to the temperature regimes of the GMS, although it is much less suitable to rainfall patterns in some areas. There is too much rain in places such as the Myanmar coast and southern Lao PDR, and too little in parts of Thailand, Myanmar and Yunnan (Figure 3.16). While soybean is not grown to any great extent across the most favorable areas, it is grown quite widely in some of these areas and is also cultivated in what appear to be less suitable areas of Yunnan. However, different varieties of soybean have been selected in Yunnan for a range of carefully developed cropping patterns at different times of the year to produce successful soybean systems.

Figure 3.16. Suitability of soybean.

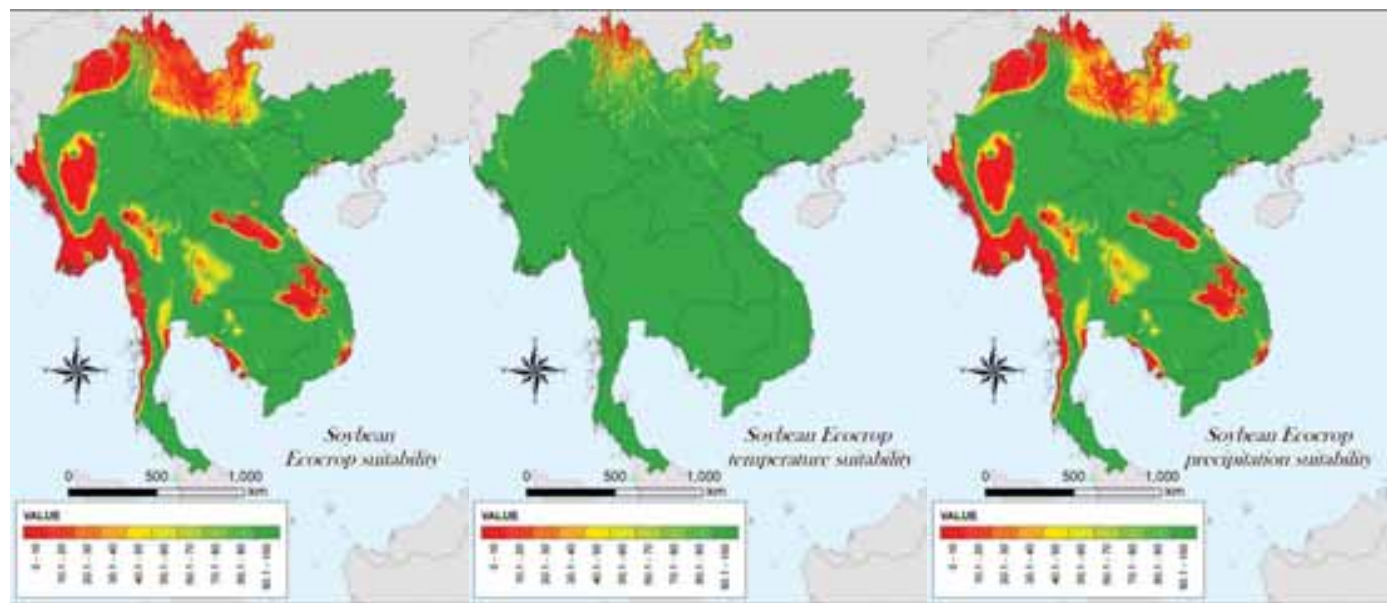

Suitability maps were created for a range of other crops. The common bean, which is an important food crop in parts of Africa and Latin America but of limited interest in the GMS, appears to be quite broadly adapted to much of the region (Figure 3.17). It may be possible to introduce it for smallholder production with the aim of improving nutrition or increasing revenue. Cabbages are grown primarily in the upland and montane areas of the region, in areas indicated 
Figure 3.17. Suitability of common beans.

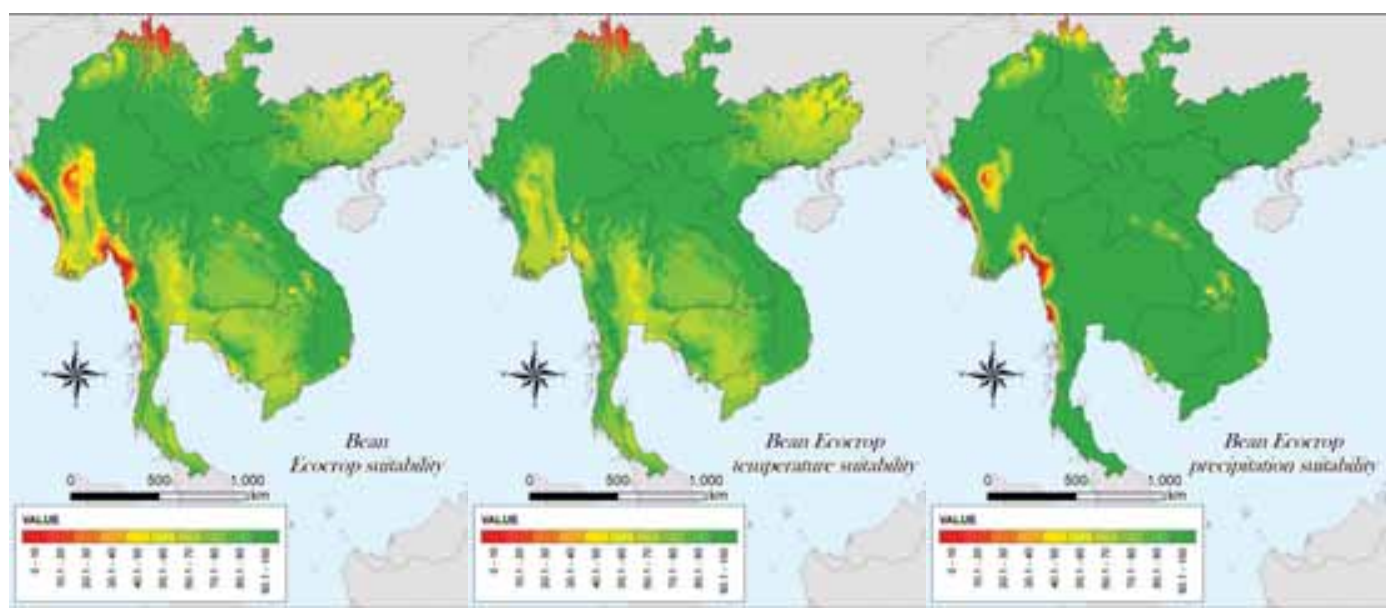

by Ecocrop as being suitable, with more limited production where the suitability is deemed to be low (Figure 3.18). While there are large areas of suitable land for growing cabbages, production is not so widespread due to alternative crops and the size of the markets.

Like the soybean, chilli is very broadly adapted (Figure 3.19) and yet is not widely produced in the GMS. The suitability for garlic production is driven by rainfall regimes, with suitability reduced due to too much rain in some areas and too little rain in others (Figure 3.20). Similar assessments are possible using the Ecocrop suitability maps of other crops, such as mung bean (Figure 3.21), coconut (Figure 3.22), banana (Figure 3.23), pineapple (Figure 3.24) and cotton (Figure 3.25). It is almost certain that product quality and access to markets will be the major drivers for production levels of these crops in different locations, rather than bioclimatic drivers alone.

Assessing the suitability of crops using Ecocrop, as presented in the examples above, can help agriculturalists better understand and plan well-managed cropping and farming systems. By assessing the overall bioclimatic suitability, and the separate suitability to temperature and rainfall regimes, the results can be used to improve farming systems. The examples above strongly indicate that bioclimatic suitability, especially as assessed by Ecocrop, cannot be interpreted alone. The major weakness of Ecocrop is that it cannot include all aspects of intraseasonal variations in climate or important interactions between climate, especially rainfall, and topography, soil type and management systems. However, no such niche model will ever include all factors, so planners should assess these and other relevant characteristics locally. The main 'missing' factors are the direct impacts of soil type (as opposed to the impact of the interaction between soil type and rainfall), especially the soil fertility and texture, the pest and disease status and risk, the relative suitability of other crops (as assessed by Ecocrop and further modified with additional and local information), the preferences of the farmer and the market demands, in quantity, quality and timing of delivery. All these factors are critical to developing improved integrated rainfed agricultural systems. This is especially so in the more marginal and biophysically and socioeconomically heterogeneous uplands of the GMS, which house a large proportion of the region's poor people. 
Figure 3.18. Suitability of cabbage.

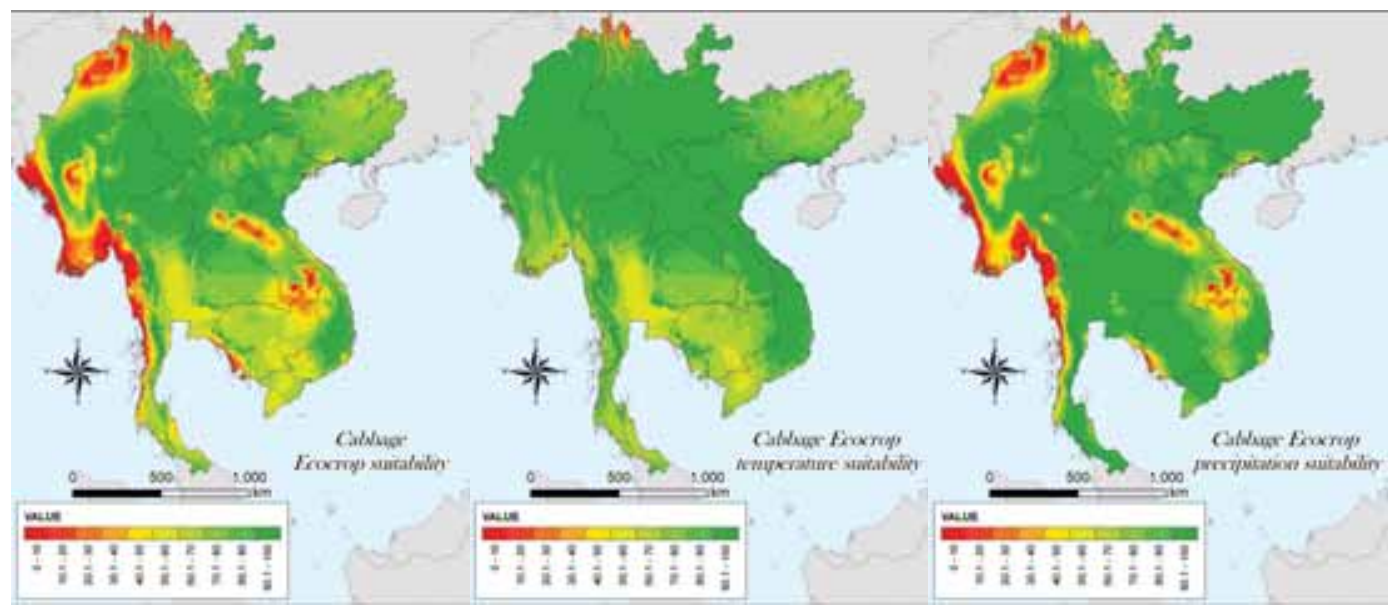

Figure 3.19. Suitability of chilli.

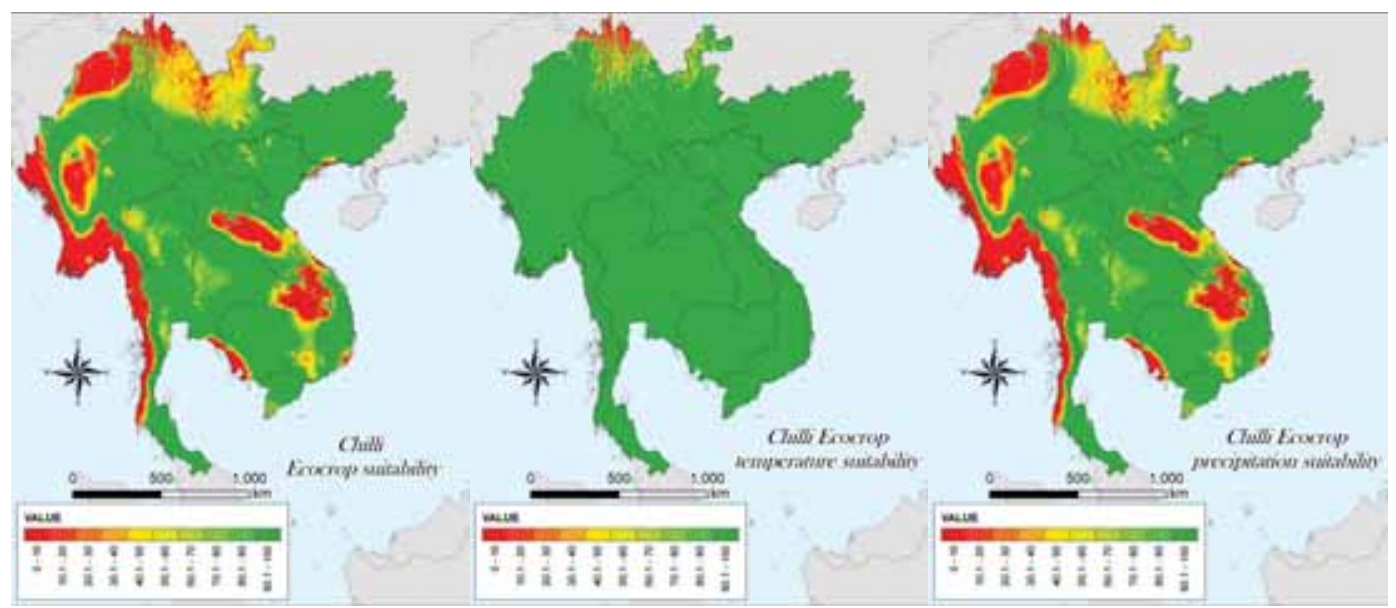

Figure 3.20. Suitability of garlic.

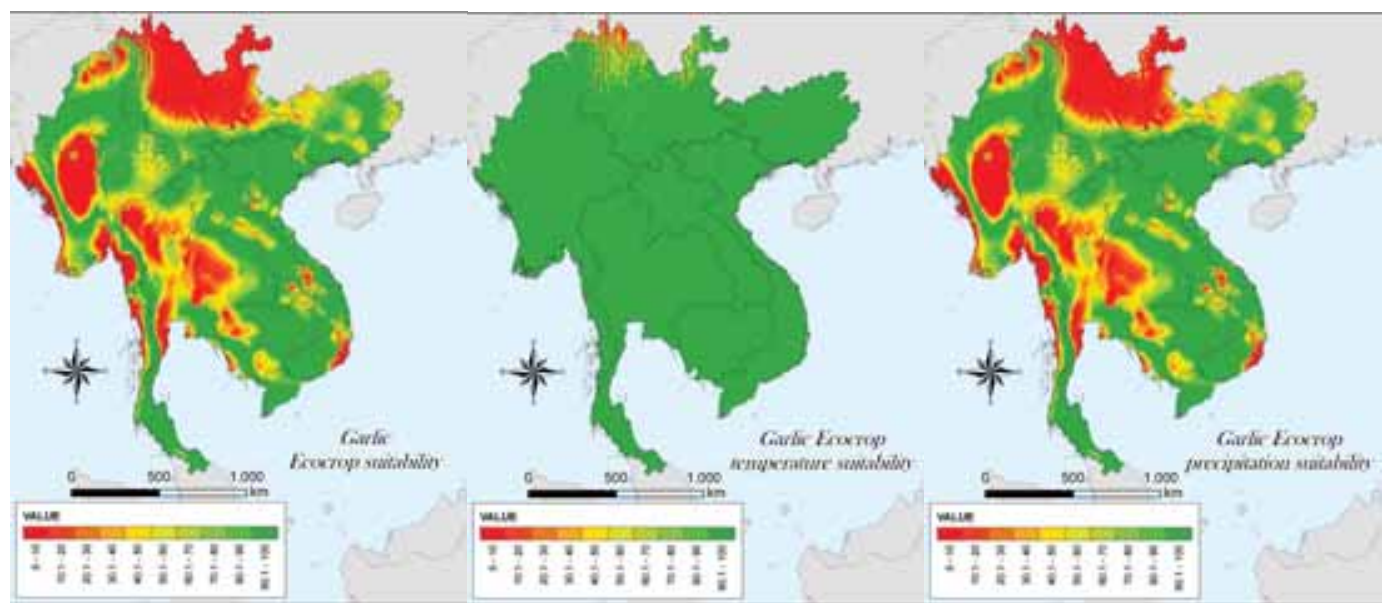


Figure 3.21. Suitability of mung bean.

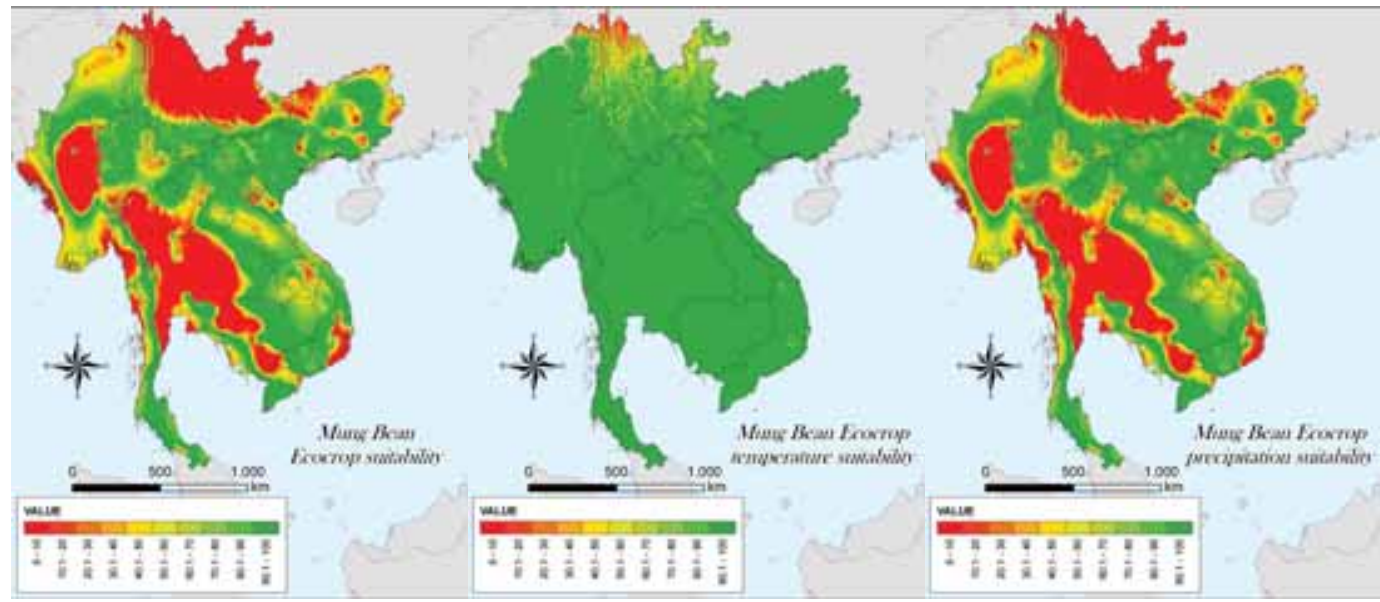

Figure 3.22. Suitability of coconut.

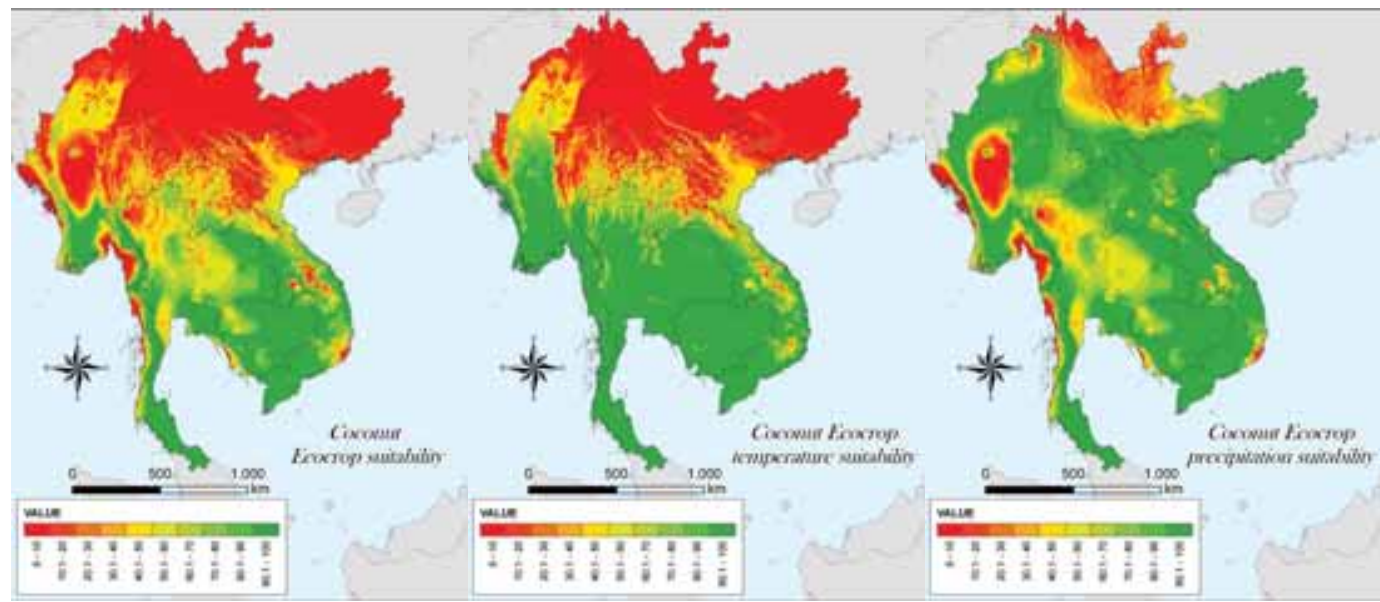

Figure 3.23. Suitability of banana.

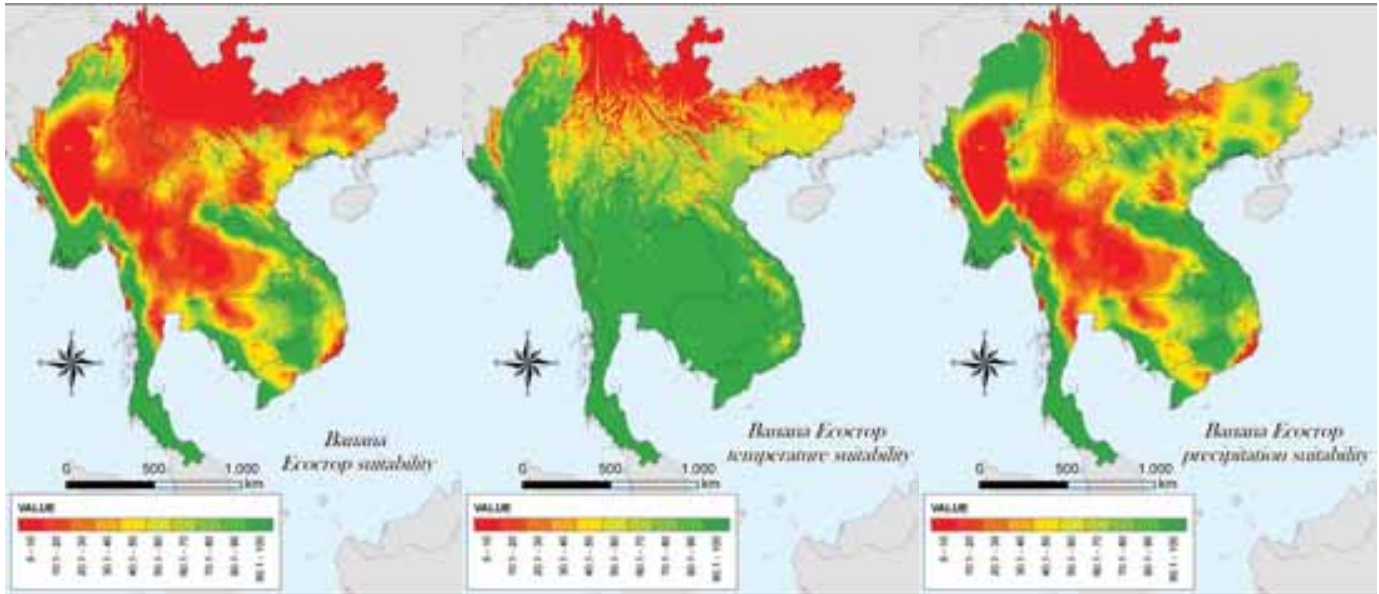


Figure 3.24. Suitability of pineapple.

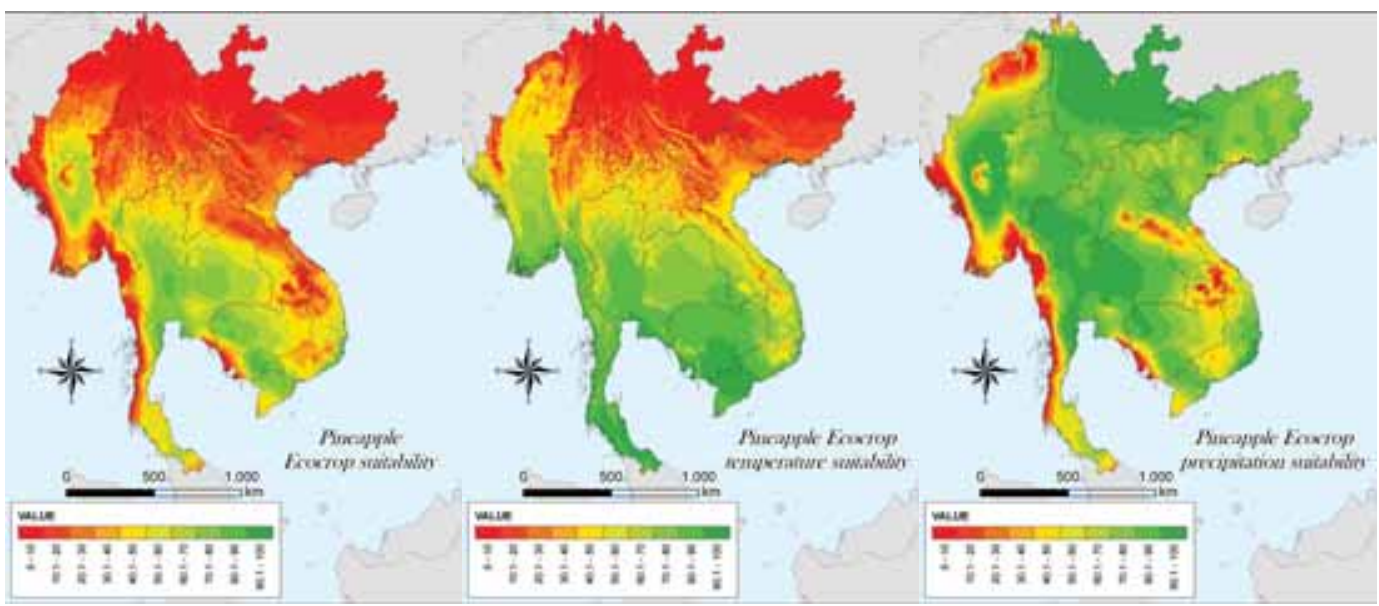

Figure 3.25. Suitability of cotton.

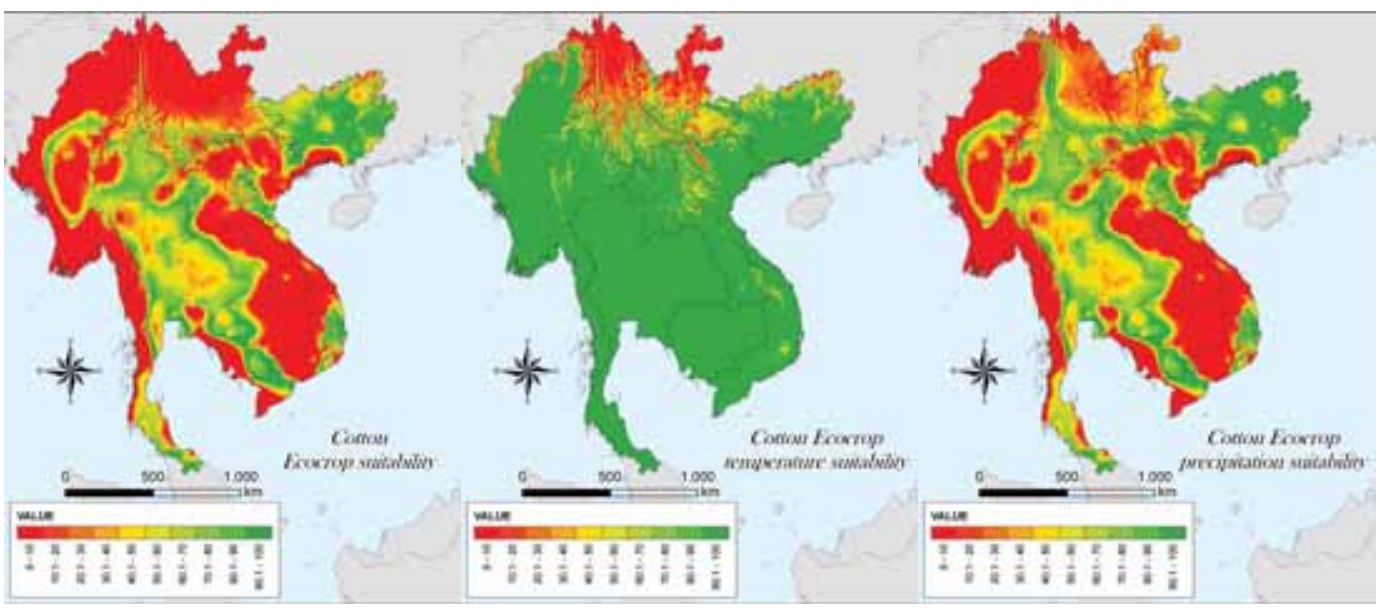




\section{PART 4: YIELD GAP ANALYSIS}

Spatial and temporal variations in production and yields were analyzed for the major crops of rice, maize, sugarcane and cassava across the GMS to assess factors affecting yields, and to explore opportunities to improve yields in rainfed systems across the region. The aim was to examine:

- long-term yield trends at country level over the period 1990-2009 (using data reported by FAO 2011; FAO 2008);

- spatial variability in yields at provincial level for the entire region, using data for the most recent year available (usually 2009; 2005 for Myanmar and 2008 for Cambodia) collated from government statistics for each country. This included remapping yield statistics to AEZs using GIS techniques (assuming constant yield across provinces); and

- $\quad$ spatial and temporal variability in yields at provincial level for Cambodia (1993-2005; MAFF 2009) and Vietnam (1995-2009; VN GSO 2011), and compare yield information with annual rainfall data (CRU dataset). Time series of annual rainfall for the grid cell (or cells) falling within each province were averaged and compared with average annual yield for that province.

\section{Potential yields and yield gap}

'Yield gap' is the difference between the actual yield achieved on farm and the maximum attainable (potential) yield: that is, the yield achievable under the best known management practices. Various physical, economic and social constraints mean that potential yields are rarely achieved under farm conditions. Factors contributing to yield gaps can be biophysical (climate, water stress, soil, pests), technical (tillage, crop varieties, nutrients), socioeconomic (farmer traditions and knowledge, ability to invest), institutional (relating to land tenure, credit, markets) or technology transfer (Tran 2004). Reducing yield gaps effectively may require strategies that address several or all of these factors.

Estimates for potential yields of the major regional crops are given in Table 4.1. These represent approximate maxima that can be achieved under experimental conditions, and are provided to give a sense of where GMS production currently lies, and where the largest potential gains could be made. Actual potential yields vary between regions depending on soil type, climate and ecology. In some systems, water availability is a dominant constraint on production; but water stress is obviously only one factor contributing to yield gaps. The timing and severity of water stress dictate how severe the impact is on yield. Water stress during the vegetative stage has a minor impact if time and water supply permit the plant to recover before flowering (Yoshida 1981). Water stress has a more severe impact when it falls during the reproductive stage (Heisey and Edmeades 1999).

Since the release of improved varieties in the 1960s, the potential yield for irrigated rice in tropical systems is generally assumed to be around 10 t/ha (Peng et al. 1999); the highest reported yields in the region are above $7 \mathrm{t} / \mathrm{ha}$ in Thai Binh in the Red Delta and An Giang in the Mekong Delta in Vietnam. Nesbitt (2002) reports that yields up to $9 \mathrm{t} / \mathrm{ha}$ were achieved in small experimental plots in the Cambodian Delta. To achieve these very high yields requires not only full management of water, but also careful management of other agronomic factors, particularly fertilizers.

Potential yields for dry (upland) rice are significantly lower. Singh et al. (2009) report that, the yield under controlled experimental conditions for upland rice in northeast Thailand was only $1.5 \mathrm{t} /$ ha. However, Saito et al. (2006) and Linquist et al. (2007) report yields of up to 3-4 t/ha for upland rice in northern Lao PDR under shifting cultivation systems. Such high yields could only be achieved after long fallow periods, as yields are very sensitive to the length of the fallow period and cropping cycle. The reported yield decreased to $1.5 \mathrm{t} / \mathrm{ha}$ or less when the period of fallow was shortened to 
Table 4.1: Comparison of country average yields (FAO 2011) with potential yield for major crops.

\begin{tabular}{|c|c|c|c|c|c|c|c|c|c|c|}
\hline & \multicolumn{10}{|c|}{ Yield (t/ha) } \\
\hline & \multicolumn{2}{|c|}{ Rice } & \multicolumn{2}{|c|}{ Maize } & \multicolumn{2}{|c|}{ Sugarcane } & \multicolumn{2}{|c|}{ Soybean } & \multicolumn{2}{|c|}{ Cassava } \\
\hline & 2009 & 1990 & 2009 & 1990 & 2009 & 1990 & 2009 & 1990 & 2009 & 1990 \\
\hline Cambodia & 2.8 & 1.3 & 4.3 & 2.0 & 27 & 43 & 1.5 & 1.5 & 22 & 5.5 \\
\hline China (all) & 6.6 & 5.7 & 5.3 & 4.5 & 68 & 59 & 1.6 & 1.5 & 16 & 13.9 \\
\hline Lao PDR & 3.6 & 2.3 & 4.8 & 1.8 & 31 & 27 & 1.5 & 0.8 & 14 & 12.8 \\
\hline Myanmar (FAO) & 4.1 & 2.9 & 3.6 & 1.5 & 47 & 40 & 1.5 & 0.8 & 13 & 9.6 \\
\hline Myanmar (USDA) & 2.4 & & & & & & & & & \\
\hline Thailand & 2.9 & 2.0 & 4.2 & 2.4 & 72 & 49 & 1.6 & 1.3 & 22 & 13.9 \\
\hline Vietnam & 5.2 & 3.2 & 4.0 & 1.6 & 59 & 41 & 1.5 & 0.8 & 16 & 8.9 \\
\hline World & 4.3 & 3.5 & 5.2 & 3.7 & 70 & 62 & 2.2 & 1.9 & 12 & 10 \\
\hline Asia & 4.3 & 3.6 & 4.4 & 3.3 & 63 & 60 & 1.3 & 1.3 & 20 & 12.9 \\
\hline Southeast Asia & 4.1 & 3.0 & 3.7 & 1.8 & 62 & 62 & 1.6 & 1.1 & 19 & 12.4 \\
\hline East Asia & 6.6 & 5.7 & 5.2 & 4.6 & 68 & 59 & 1.4 & 1.5 & 16 & 13.9 \\
\hline $\begin{array}{l}\text { Potential yield in } \\
\text { tropical systems }\end{array}$ & \multicolumn{2}{|c|}{$>10$} & \multicolumn{2}{|c|}{$>20$} & \multicolumn{2}{|c|}{$>140$} & \multicolumn{2}{|c|}{-} & \multicolumn{2}{|c|}{$>35$} \\
\hline Reference & \multicolumn{2}{|c|}{$\begin{array}{l}\text { Peng et al. } \\
\text { (1999) }\end{array}$} & \multicolumn{2}{|c|}{$\begin{array}{l}\text { Pixley et al. } \\
\text { (2006) }\end{array}$} & \multicolumn{2}{|c|}{$\begin{array}{l}\text { Inman-Bamber } \\
\text { et al. } 1998\end{array}$} & & & \multicolumn{2}{|c|}{ CIAT } \\
\hline
\end{tabular}

three years through a combination of soil fertility decline and increased weed pressure. The researchers demonstrated, however, that significant gains could be made in yields of upland rice, even without irrigation, by carefully controlling soil fertility, weeds and water in well- managed rotations. With a shift from dry rice to montane paddy, yields can more than double (Linquist et al. 2007; Pandey 2005).

Potential yields for some field crops display similar room for improvement. For sugarcane, the theoretical maximum in tropical systems is around 150-160 t/ha (Inman-Bamber et al. 1998). Across much of the GMS, yields are less than 40 t/ha (see Figures 4.1 and 4.2). Yields in China and Thailand approach the world average of $70 \mathrm{t} / \mathrm{ha}$, but there are still very large gains to be made in other countries.

\section{Long-term trends at country level}

There have been steady increases in agricultural production within all sub-sectors and all countries of the GMS over the past 20 years. Production in major commodity groups, including rice and small livestock, has more than doubled since 1990 (Johnston et al. 2009; FAO 2011). Approximately 1.5 Mha of new croplands have been brought into production, but much of the observed increase in output has been achieved by intensifying cultivation, rather than expanding the agricultural area. Increased yield is attributed to the adoption of technologies underpinning the 'Green Revolution': uptake of improved crop varieties, more effective irrigation, increased use of fertilizers and improved farming practices.

At the national level, there are three main trends related to yields (Figure 4.2): significant increases in yields for all countries; large differences in yields between and within countries; and large remaining yield gaps (Table 4.1). National statistics for yields of field crops other than rice generally show upward trends but are very unstable.

For the GMS, excluding Yunnan and Guangxi, the increase in rice yields averaged across all seasons over the last 20 years is between 50 and $100 \mathrm{~kg} / \mathrm{ha} / \mathrm{year}$. The largest increase has been in Vietnam and the smallest increase in Thailand. Statistics for Myanmar vary widely according to sources; data shown are from FAO (FAO 2011) based on government statistics, and from United 
Figure 4.1 Yield trends for major crops in the GMS at national level.
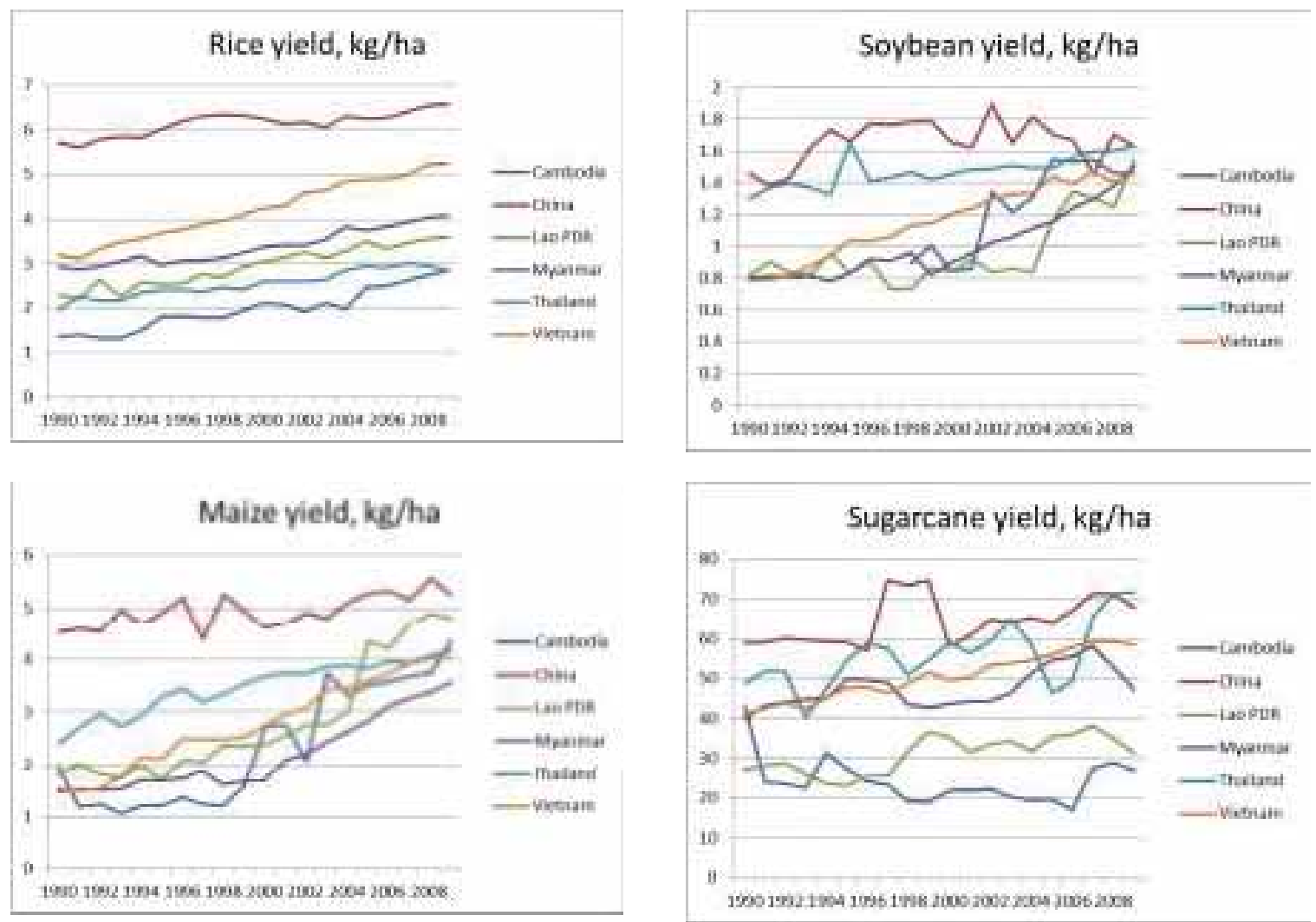

States Department of Agriculture (USDA) (reported in Dapice et al. 2010). The USDA estimates are significantly lower than those from FAO, and indicate a decline in rice yields over the last 10 years, with current yields being the lowest in the region. This has been attributed to a range of causes, including droughts and crop failure, poverty restricting the ability of farmers to invest in fertilizers and irrigation, underinvestment in agricultural infrastructure, plus market-related issues such as export bans (Dapice et al. 2010).

At this scale, the impacts of annual climate conditions are not apparent. The severe regional drought of 1998 was not reflected by a national-level drop in yield or total production (except in Myanmar); neither was the drought of 2004 in Thailand, despite estimates that it affected 2 Mha of crops (Bank of Thailand 2005). This concurs with the results of Ding et al. (2005) for southern China and Pandey et al. (2007) for Thailand, regarding the difficulties of detecting even major drought events in national production statistics.

Similarly, the theoretical yield potential of maize is around $20 \mathrm{t} / \mathrm{ha}$, although the world average is only $5.2 \mathrm{t} / \mathrm{ha}$. Yields in the GMS are higher than $4 \mathrm{t} / \mathrm{ha}$, apart from in Myanmar and Cambodia. Simulated yields for rainfed maize in Vietnam are 5-6 t/ha (Singh et al. 2009; Chuc et al. 2006); but reported experimental yields for Thailand and Vietnam are 4-5 t/ha (Singh et al. 2009; Fischer et al. 2009).

Yields for cassava vary dramatically according to the soils, rainfall, mode of cultivation and variety. Since it is drought-tolerant, and harvesting can be deferred until required, cassava was traditionally grown as a subsidiary emergency crop, with little active management. In subsistence systems, such as in northern Lao PDR, cassava can be left for up to two years before harvesting; given reasonable soils this can result in very high yields. In poorly managed systems using lowyielding varieties, yields can be very low at less than $5 \mathrm{t} / \mathrm{ha}$. However, in highly managed systems, 
Figure 4.2 Spatial patterns of yield variation at provincial level (2009, except Myanmar 2005).
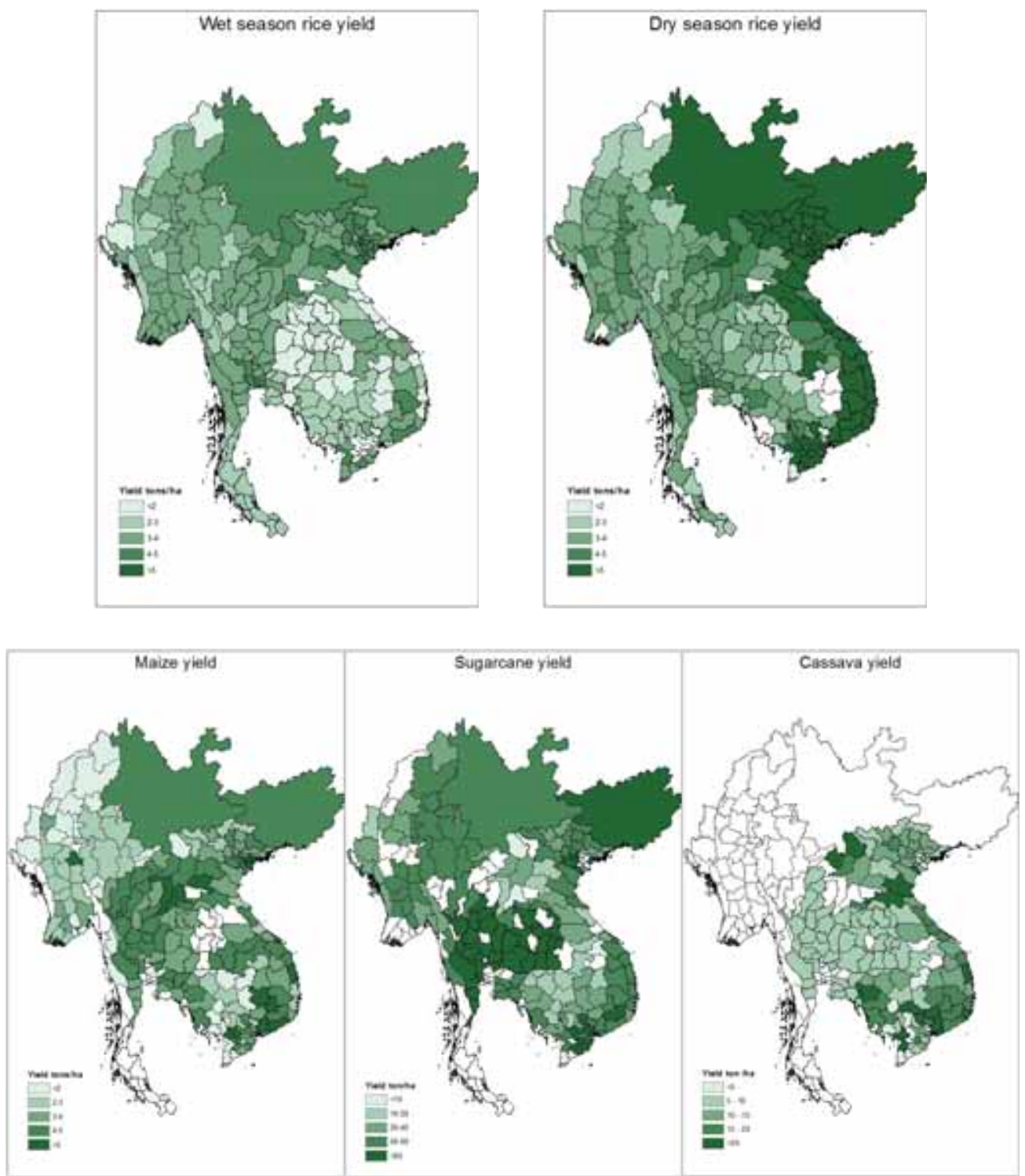

yields of over $25 \mathrm{t} / \mathrm{ha}$ are reported, for example, from Tay Ninh Province in Vietnam. The largest change in cassava yields in the GMS has come about through the development and adoption of new high-yielding and high-starch varieties. These varieties, largely based on CIAT germplasm and joint breeding programs, now occupy about $80 \%$ of the area planted with cassava in the GMS. Where new varieties have been adopted, the national yields have, on average, doubled. These higher- yielding and higher-starch varieties and the development of new markets for cassava starch, partially as a result of the new varieties, have resulted in major changes to the production of cassava, much of which is still undertaken by smallholders. From 2000 to 2010, the area of cassava harvested each year in Vietnam doubled. At the same time, the average yield doubled, largely due to new varieties, resulting in a more than fourfold increase in production. Although starting from a much lower base in terms of area and yield, during the same period, the area of cassava in Cambodia increased more than tenfold and production more than doubled. These developments have huge potential for poverty alleviation in rainfed upland systems, although such rapid changes need to be managed carefully, in terms of the biophysical resources and markets. 
Analysis of provincial level yields by country and AEZ

Provincial yields for a range of common crops for the latest year of record (2005 in Myanmar; 2008 in Cambodia; 2009 in all other countries) are mapped in Figure 4.2. Yields were disaggregated to AEZs using GIS techniques; the resulting average yields in each AEZ by country are given in Tables 1.1-1.4. In general, yield differences between countries are higher than differences between AEZs within countries. Analyzing spatial patterns of production and yield within countries can help explain the large differences between them.

The Highlands of Yunnan have significantly higher yield for rice than lowlands and uplands (dominantly in Guangxi); yields for other field crops (maize and sugarcane) are marginally lower in the highlands. Rice yields in Yunnan (6.1 t/ha) are close to the national Chinese average. Since the 1990s, significant increases have been achieved through intensification and a shift from upland rice to highly managed terraced montane paddy, under a concerted government campaign to reduce cultivation in steep lands. In Guangxi, the average yield of $5.3 \mathrm{t} / \mathrm{ha}$ is significantly lower than the Chinese average, and has only increased slowly since 1990 (Ding et al. 2005), but it is still amongst the highest in the GMS. This is partly due to levels of access to irrigation (around a third of cropped area) that are relatively high for the GMS, but low for China. In addition, Guangxi experiences many droughts (the probability of meteorological drought is $15 \%$ - see Figure 2.7). Ding et al. (2005) estimated that drought in southern China, including Guangxi, results in yield losses at the farm level of $9-43 \%$, depending on the location and irrigation facilities. Aggregated to the provincial level, the effects were not statistically significant, due to heterogeneity across the provinces. This is not inconsistent with large losses at the farm level, since the impacts of drought may be quite localized. Similar results were found for non-rice crops.

In Lao PDR, rice yields are reasonably consistent across AEZs at the aggregate level; but this masks a large yield difference between different cultivation methods, since dry- and wet-season rice are cultivated almost equally in both lowlands and uplands. Dry-season irrigated rice has an average yield of $4.8 \mathrm{t} / \mathrm{ha}$ nationally, but constitutes only $10 \%$ of the total crop. Wet-season rice, $75 \%$ of the total crop, averages $3.8 \mathrm{t} / \mathrm{ha}$, but varies from $2.3 \mathrm{t} / \mathrm{ha}$ in Attapeu to $5.0 \mathrm{t} / \mathrm{ha}$ in Houaphan. Yields are higher in the northern provinces, where small areas of wet-season rice are grown under more intensive conditions in montane paddy, than in the central provinces where the bulk of the country's rice is cultivated on the Savannakhet and Vientiane plains, with only limited access to supplementary irrigation. Savannahkhet, with $10 \%$ of cropland irrigated, has a significantly lower yield (3.5 t/ha) than the Vientiane Plains, where approximately $20 \%$ is irrigated, and the yield is 4.1-4.4 t/ha. Yields for upland rice (grown in the wet season) are consistently much lower than for lowland rice (1.7-1.9 t/ha compared to $3.8 \mathrm{t} / \mathrm{ha}$ for lowland rice). Upland rice constitutes $15 \%$ of the national crop, grown mainly in the uplands and highlands. Yields of field crops in Lao PDR have increased in line with regional averages, overall, but vary widely between provinces due to varying levels of intensification and modernization. For example, yield for sugarcane varies from less than $10 \mathrm{t} / \mathrm{ha}$ for small areas of upland cultivation, to $30 \mathrm{t} / \mathrm{ha}$ for the main crop grown on the Savannakhet Plains.

In Thailand, yields for non-rice crops have increased rapidly since the 1970s, and are now among the highest in the region for a range of crops including sugarcane, cassava and soybeans. This increase has resulted from agricultural modernization, with the adoption of high rates of irrigation, improved crop varieties, high levels of agricultural chemicals and increasing commercialization of production. Rice, however, has followed a different trend. Only a small proportion of rice is grown in the deltas; instead, large areas of the deltas have been converted to irrigated cultivation of field crops (sugarcane, maize, soybean). The majority of the rice crop (80\% of total production) is grown in the rainfed lowland areas of the Isan and Central Thai Plains as a wet-season crop 
growing low-yielding but high-value jasmine varieties; yield in the lowland plains is significantly lower than that in other areas (2.3 t/ha compared to $4 \mathrm{t} / \mathrm{ha}$ in the delta), reflecting less intensive, lower-input production systems, with variable rainfall and limited supplementary irrigation. Dryseason rice constitutes around 2.4 Mha, 20\% of planted areas, which is significantly lower than the total area of large- and small-scale irrigation projects (3.9 Mha). Low uptake of dry-season cultivation is attributed to a range of reasons including uncertainties in irrigation supply, low profits obtained from rice relative to the returns obtained from higher-value crops, and the opportunity costs of labor in Thailand's more diversified economy (Nesbitt 2002). Despite this, Thailand is the only country in the GMS where rice is increasing as a proportion of cropped area. This is a consequence of Thailand's success as a rice exporter, along with a government guarantee of a base price for rice, first introduced in 2008 and currently being proposed again (Bangkok Post 2011).

In Myanmar, reported wet-season rice yields are in the range 3-4 t/ha over most regions, with lower yields (2-2.5 t/ha) in the highland areas of the Eastern and Western Hills where upland cultivation is more dominant. Dapice et al. (2010) considers that actual yields may be up to 50\% less than reported yields, with a decline in long-term yields attributed, in part, to climate conditions. Reported dry-season rice yields average $3.8 \mathrm{t} / \mathrm{ha}$, which is lower than all other countries except Thailand. This may reflect the fact that a proportion of the dry-season crop is un-irrigated recession rice, which usually has a lower yield. Pulses are an important crop in Myanmar, but are not grown elsewhere in the GMS. Reported total yields are in the order of 1.1-1.25 t/ha; significantly higher than the world average of $0.9 \mathrm{t} / \mathrm{ha}$ and almost double that of India's yield of $0.62 \mathrm{t} / \mathrm{ha}$. Pulses are an important export for Myanmar.

In Cambodia, over $85 \%$ of rice production is in traditional wet-season lowland paddy, with average yields of around $2.5 \mathrm{t} / \mathrm{ha}$ across all AEZs. While this has increased over the last ten years with the uptake of improved varieties and some increase in fertilizer use, it is still the lowest in the region. Dry-season production takes place predominantly in the delta and on the Tonle Sap Floodplain; average yields of 4.2 t/ha in these areas are high for Cambodia, but lower than the regional average for the dry-season crop. As in Myanmar, a proportion of dry-season rice is unirrigated recession rice, which generally has lower yield than fully irrigated dry season paddy. Floating deepwater rice, which has low yields (around $1 \mathrm{t} / \mathrm{ha}$ ), formerly an important component of Cambodia's crop particularly in the Tonle Sap region, has declined to less than 5\% of the total cropped area. Reported yield in Kampong Thom Province, representative of differences between cultivation types, are 1-1.5 t/ha for floating rice; $2 \mathrm{t} / \mathrm{ha}$ for rainfed rice; and $3-5 \mathrm{t} / \mathrm{ha}$ for recession rice (DAE 2010). Efforts to improve productivity of recession rice through improved varieties and water management have resulted in large yield gains in Kandal and Battambang. The lowest reported yields, of $1.8 \mathrm{t} / \mathrm{ha}$, are in the northeastern provinces of Ratnakiri and Mondulkiri, where upland rice predominates.

Analysis of 13 years of provincial-level data indicates a high level of yield variability, spatially and temporally. To separate progressive yield gains from seasonal variability, a linear trend was fitted to the time series, and coefficient of variation (CV) was calculated for the de-trended data. The median increase in yield for rice and maize spans a wide range. Yields in the upland provinces of Ratnakiri, Odtar Meanchay and Mondulkiri have not increased significantly over the period, while those in the floodplain provinces of Phnom Penh, Takeo and Kampong Cham have increased, on average, by more than $100 \mathrm{~kg} / \mathrm{ha} /$ year over the period. Yield gains have been erratic, with very high seasonal variability, which is reflected in the high de-trended CV. In all provinces, the correlation with annual rainfall is very low. In some cases, significant drought events have decreased provincial yields - for example, Figure 4.3 shows where low rainfall in 1998 and 2002 in Svay Rieng are reflected in similar decreases in de-trended yield. However, the low yield of 
Figure 4.3: Comparison of rice and maize yields with rainfall for selected provinces in Cambodia.
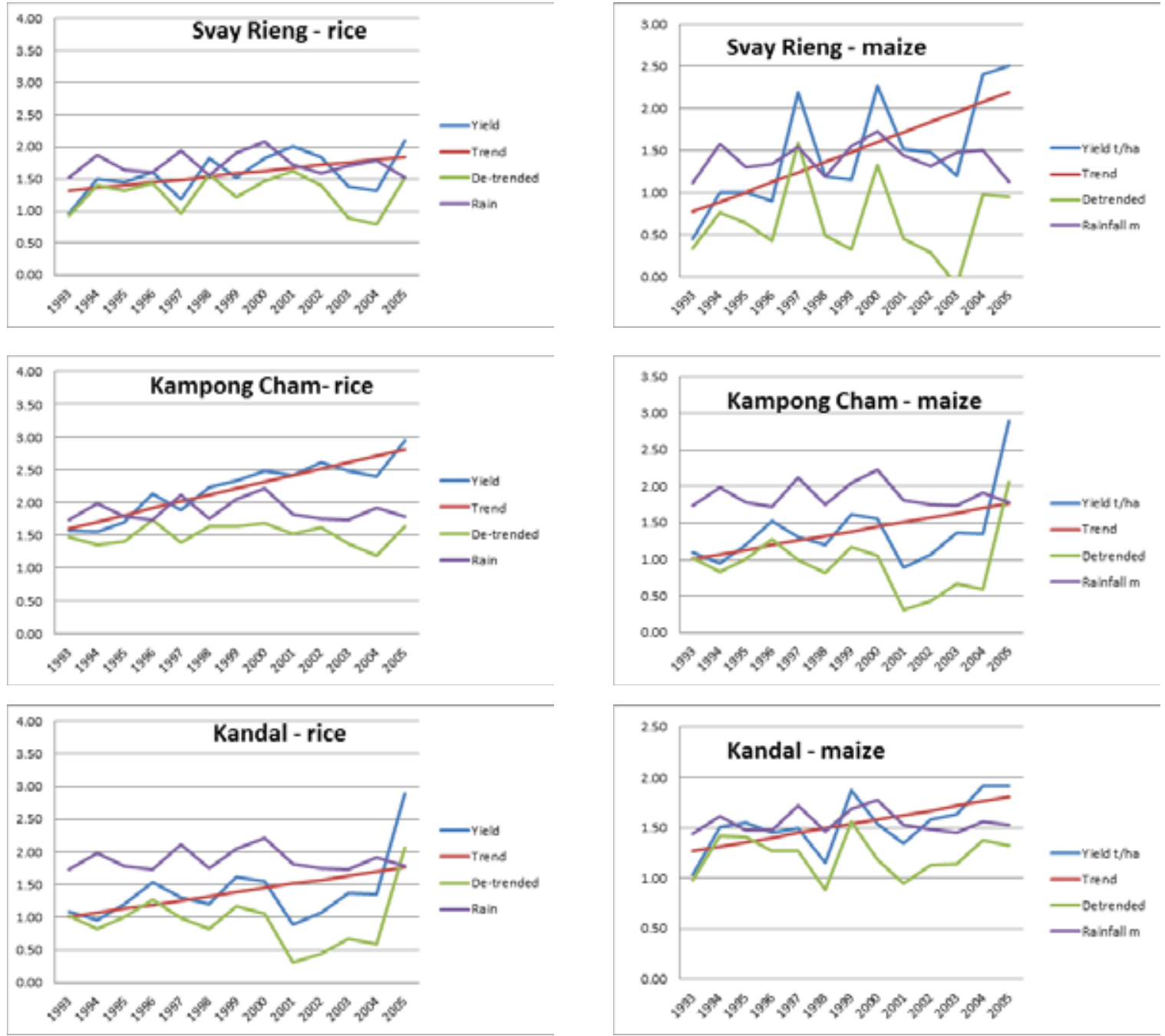

2004 was not related to rainfall, but due to insect pest attacks (Try Thuon, consultant, Phnom Penh, Cambodia, pers. comm.).

Vietnam's remarkable increase in average rice yields from $3 \mathrm{t} / \mathrm{ha}$ to more than $5 \mathrm{t} / \mathrm{ha}$ over the last 20 years has been achieved through a mix of strategies including improved varieties, agronomic practices and water management. An important component has been the shift from a dominantly wet-season crop (summer/autumn - planted in July) to two dry-season crops (winter - planted in November; spring/summer - planted in April). Both crops benefit from a significant component of rainfall and more favorable growing conditions in the dry season. The traditional monsoon crop, with an average yield of less than $4.5 \mathrm{t} / \mathrm{ha}$, now comprises less than $25 \%$ of total plantings and accounts for only $10 \%$ in the Mekong Delta. The biggest differences in yield occur between seasons, rather than regions. Within the seasons, there is a clear gradient of decreasing yield from the deltas to the uplands, with comparatively low yields (less than $3 \mathrm{t} / \mathrm{ha}$ ) only in the monsoon crop in mountain provinces of the northern and north-central regions; these include a component of low-yielding upland rice.

Analyzing the 15-year longitudinal dataset (Figure 4.4) illustrates two points. First, the increase in yields in Vietnam has been remarkably consistent for both rice and maize; in 50 of the 60 
provinces examined, the data fits a linear trend for rice yields with an R2 of 0.75 or above. The median rate of increase has been $120 \mathrm{~kg} / \mathrm{ha} / \mathrm{year}$ for both rice and maize. Second, production is very stable; the year-to-year variability in yield, separate to the increasing trend, is very much lower than in Cambodia and this is reflected in much lower values of linearly de-trended CV (see Table 4.2). However, as in Cambodia, there is no significant correlation between mean annual rainfall and yield at the provincial level, even for the 2004 drought, which is estimated to have affected about one million people in eight highland provinces, with production losses of USD 80 million (Pandey et al. 2007). Yield impacts are related to shorter water-stress periods, and the impacts vary spatially.

Figure 4.4: Comparison of rice and maize yields with rainfall for selected provinces in Vietnam.
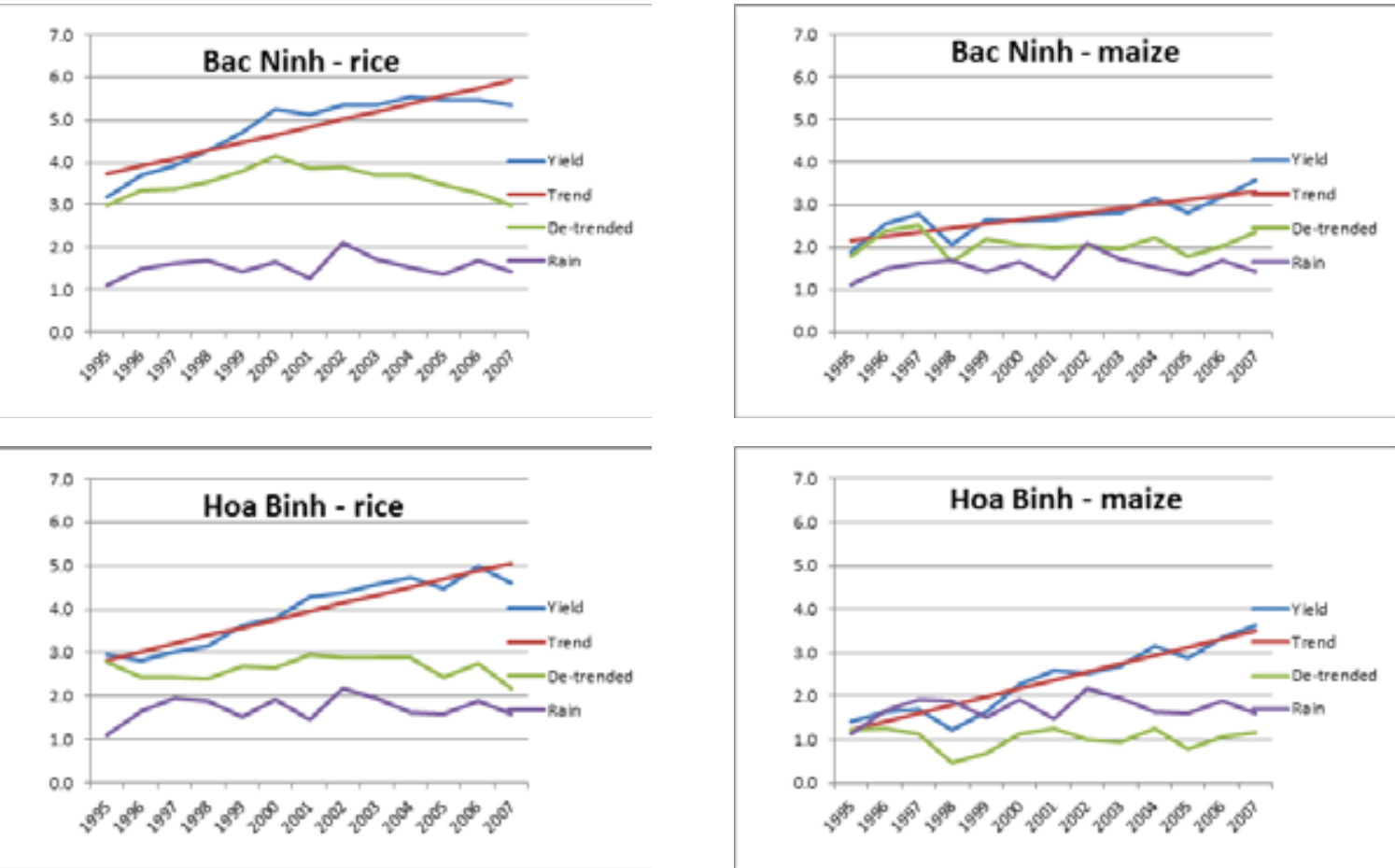

Table 4.2: Statistics for yield trends in Cambodia and Vietnam over time and compared to rainfall.

\begin{tabular}{|l|c|c|c|c|}
\hline \multirow{2}{*}{} & \multicolumn{2}{|c|}{ Cambodia } & \multicolumn{2}{c|}{ Vietnam } \\
& Rice & Maize & Rice & Maize \\
\hline Median annual increase in yield (t/ha) & 0.05 & 0.07 & 0.12 & 0.12 \\
\hline Yield increase range & $0-0.16$ & $0-0.17$ & $0.04-0.21$ & $0.04-0.31$ \\
\hline Fit of linear trend & & & & \\
\hline$\%$ of provinces with R2 $>0.75$ & $10 \%$ & $5 \%$ & $83 \%$ & $71 \%$ \\
\hline Median CV (de-trended) & $20 \%$ & $28 \%$ & $6 \%$ & $12 \%$ \\
\hline CV range & $14-43 \%$ & $16-122 \%$ & $2-14 \%$ & $2-52 \%$ \\
\hline Median R2 yield versus rainfall & 0.03 & 0.08 & 0.08 & 0.05 \\
\hline $\begin{array}{l}\text { Range correlation coefficient } \\
\text { for yield versus rainfall }\end{array}$ & $-0.47-0.45$ & $-0.47-0.66$ & $-0.76-+0.67$ & $-0.54-+0.79$ \\
\hline No. of provinces & & & & 60 \\
\hline
\end{tabular}




\section{PART 5: AGRICULTURAL WATER MANAGEMENT INTERVENTIONS}

Water-related risks often inhibit investment in a range of other measures that can contribute to increasing yields, so improving water management and reducing these risks is a first step to making other improvements. The observed increases in yields over the last 20 years and remaining differences between and within countries indicate that there are significant gains that can be made. Some of those gains will come from a shift to irrigation, but full-scale dry-season irrigation is not the only model (Rockström et al 2007). In this study, we do not consider large- to medium-scale irrigation systems. This is not because they are not effective; when implemented well, they have clearly made a huge difference to the productivity and livelihoods of millions of people (Mukherji et al. 2009). However, the focus of this study is to identify small-scale interventions to make the best use of rain where it falls and that can be implemented at farm to community scale. Reducing risks in predominantly rainfed systems can also increase yields. The challenge is to find the most productive balance between irrigated and rainfed systems. Small-scale AWM interventions may also be important within large irrigation systems, to provide flexibility that is lacking in larger systems. Many of these interventions will not be concerned with managing the delivery of water but with increasing the efficiency of water use.

Previous and ongoing studies have identified a broad suite of AWM interventions that can be used by smallholders to improve livelihoods. For example, the AWM Solutions project hosts a database of more than 150 examples of AWM technologies applied in 13 countries (http://awmsolutions.iwmi.org). WOCAT (World Overview of Conservation Approaches and Technologies - www.wocat.net) provides an online database of more than 500 technologies and approaches for conservation agriculture, including a range of measures directed primarily at water management. The $3 \mathrm{R}$ project (www.bebuffered.com) hosts a collection of documents and case studies on techniques for managing water through recharge, retention and reuse.

AWM interventions fall into three broad classes: measures to reduce water use or demand onfarm; measures to control and/or increase water supply; and enabling or accompanying measures. The technologies and approaches range from traditional methods of water use to modern innovations such as biodegradable plastic mulches. The challenge is to find the most appropriate and effective interventions. Water management must be tailored to specific applications, taking account of the broader context of how water supports livelihoods generally. This context not only includes the physical environment and crop types, but also economics, cultural factors and community dynamics. Interventions that are suitable in the more developed agroeconomies of Thailand and Vietnam may not be suitable in Cambodia or Laos, and vice versa, even under similar physical conditions. Even within a single farm system, localized constraints such as soil type and ability to invest vary at farm level. Most importantly, water is only one constraint to agricultural production. To realize the full benefits of decreasing water-related risks, an integrated approach is required, incorporating other factors that affect production, particularly crop and livestock nutrition, plus value chains and access to markets. Existing studies indicate that there is very significant unexploited potential for agricultural use of groundwater in the GMS. Groundwater issues are discussed in detail in Part 6, Groundwater in GMS.

Given the diversity of approaches available, we present a brief overview of the types of interventions, along with six case studies of AWM approaches to explore the issues that arise in particular contexts, and the opportunities and constraints for scaling up and out. 


\section{Demand management measures}

A range of technologies are available to decrease the overall water demand within a farming system, either by changing crop management or retaining soil moisture more effectively. These are generally classed as conservation agriculture measures. WOCAT (2007) list four main types of soil water management interventions:

- Agronomic: related to soil management, soil cover, crop mixtures and rotations. Generally implemented as part of farming activities, with additional conservation benefits.

- Vegetative: the use of vegetation to prevent erosion, slow water movement across the landscape and reduce evaporative losses from bare soils. Examples include vegetative strips, cover crops and agroforestry.

- Structural measures to retain water and prevent erosion, such as check dams or contour banks.

- Management measures such as land-use zoning, set-aside and cut-and-carry fodder systems.

Measures are often combined either by being superimposed on the same plot, or dispersed over a catchment (for example, afforestation in the upper catchment along with check dams in gullies), or phased over time.

Agronomic measures are implemented as part of farming activities, but may also have off-farm conservation benefits by reducing soil erosion, increasing recharge or improving water quality. Minimum tillage, stubble mulching and other soil-conservation practices reduce evaporation from the soil surface, making more water available for crops. Use of mulching in drip-irrigation systems can significantly reduce water use. Modern approaches to mulching using plastics have had wide uptake in intensive systems in the uplands of Thailand and Yunnan, but these approaches have environmental impacts and biodegradable alternatives are being explored (Steenbergen et al. 2011).

Soil water-holding capacity can also be improved using traditional techniques for managing soil carbon, or applying soil ameliorants such as organic matter (waste materials) and/or inorganic natural minerals, including clays, that have a positive impact on the water- and nutrient-holding capacity of soils. For example, Noble and Suzuki (2005) reported typical yield increases between $30 \%$ and $100 \%$ in rainfed, lowland and organically grown rice when soils were treated with bentonite clays in farmer-initiated field studies in northeast Thailand. Currently, the use of biochar (solid material obtained from the carbonization of biomass in a process similar to charcoal production) is being investigated for agricultural applications. Adding biochar can improve soil functions, by improving how efficiently nitrogen fertilizer is used, and increasing $\mathrm{pH}$, organic carbon and exchangeable cations, and by improving soil physical properties, such as field capacity and water retention (Chan et al. 2007). Biochar is also an effective means to sequester carbon, an environmental service that smallholder farmers could be paid for. IWMI is conducting trials on using biochar in Napok and Veunkham in Lao PDR (Wolde Bori, IWMI, East Africa and Nile Basin office, Addis Ababa, Ethiopia, pers. comm.).

Changing the planting time, crop type and/or area of crop planted in response to seasonal conditions is a common mechanism for coping with water stress. Such adaptations often form an integral part of local farming systems. Pandey et al. (2007) pointed out that there can be large opportunity costs associated with these methods if risk-averse farmers employ strategies that reduce impacts in poor years but limit productivity in good years. For example, they might use droughttolerant but low-yielding traditional rice varieties. In lowland paddy systems where irrigation is available, large gains in both production and yield have been made by shifting from traditional 
monsoon crop to early wet-season paddy, using fast-growing cultivars grown with partial irrigation. This has been the case, for example, in the Mekong Delta (Nesbitt 2002) and in Myanmar (DAP 2011). Such changes are only feasible if supported adequately. In Myanmar, there are reports that actual areas cultivated were lower than planned. Farmers blamed this on costs (for pumping water or for extra fertilizer), as well as a lack of water and labor shortages (Independent Mon News Agency 2011).

Breeding drought-tolerant crop varieties that have high water-use efficiencies will also contribute to increasing yields in water-limiting environments. Trials of drought-tolerant rice varieties in Kampong Cham and Siem Reap in Cambodia increased yields from farmers' fields by 1.0 to $1.6 \mathrm{t} / \mathrm{ha}$ (from $1.9 \mathrm{t} / \mathrm{ha}$ to $3.5 \mathrm{t} / \mathrm{ha}$ ) compared to currently used varieties (CURE 2009). Similarly, submergence-tolerant varieties currently being introduced in India and the Philippines can significantly reduce crop losses due to flooding (Barclay 2009).

The System of Rice Intensification (SRI) is a technique for growing rice where paddy fields are not kept flooded during the vegetative growth stage, and a range of other measures are also taken. The performance of SRI is the subject of intense debate (see, for example, Dobermann 2004; Uphoff et al. 2011), but the Government of Cambodia has enthusiastically embraced the technique. SRI was included in the country's National Strategic Development Plan (NSDP) for 2006-2010 to raise productivity in the rice sector, and then in the revised NSDP for 2009-2013. Supporters of SRI report many benefits in addition to yield increases, such as resistance to pests, diseases and abiotic stresses such as drought and storm damage, and less chemical pollution of soil and water resources. Critics dispute the higher yields and highlight the need for significantly higher labor inputs for weeding; since fields are not flooded, weeds are much more of a problem. They also suggest that many farmers do not have a sufficiently high level of water control in their largely rainfed wet-season production systems. A global field trial was conducted in 2009-2011 by researchers from Cornell University, Wageningen University and the International Rice Research Institute (IRRI). The results are reported in Uphoff et al. (2011).

In Latin America, the yield gains from introducing semi-dwarf varieties have been equaled by giving careful attention to good agronomic practices (Jennings 2007). Analysis of yield gaps between farms and regions, identified seven critical agronomic factors, namely: inappropriate seeding dates missing the peak solar radiation period after panicle initiation; heavy seeding densities leading to lodging; pest and disease issues; repeated aerial spraying rather than seed treatment to control insects; inadequate weed control; poor fertilization practices, including the application of urea into water; and late establishment of permanent irrigation. Reducing problems resulting from the most limiting of these factors were decreased, so yields began to increase, with the eventual increase in yield equaling the increase due to improved genetics.

Agroforestry systems are playing an important role in the transition from shifting cultivation to permanent agriculture in the highlands of the GMS. Regional agroforestry systems are very diverse. They include plantation tree cropping (rubber, teak); intercropping of cash crops (tea, coffee, cardamom, cocoa), rotation of trees and crops; and sylvo-pastoral systems incorporating livestock. Another important trend in land use is a shift towards cut-and-carry fodder systems for livestock, aimed at reducing land degradation and erosion from extensive grazing in forests and natural grasslands. Well-designed arrangements of semi-perennial forages and/or perennial tree crops on land contours means that the annual cropping of upland rice and other upland crops can continue between the contours or be continued once the inter-contour areas have been restored through a fallow or selected rotation. Restoration involves stabilizing the soil, reducing weeds, limiting erosion, and improving soil chemical and physical fertility by building up organic matter and boosting biological nitrogen fixation. These changes can have significant impacts on the water 
balance of catchments, acting both to retain runoff and increase evapotranspiration from the growth of natural vegetation. Agroforestry (Steenbergen et al. 2011) and the use of semi-perennial forages and strip cropping, resulting in the replacement or restoration of degraded vegetation, are important components of approaches to protect and rebuild water 'buffers' at a landscape scale.

\section{Supply measures}

AWM measures to improve the supply of water range from simple hand watering to full-scale irrigation. Capturing and storing water is only the starting point. Measures are also required to transfer water to, and/or remove water from, fields and efficiently apply water to plants. Waterlifting technologies such as mechanized pumps, treadle pumps and hand pumps can be used for the former, while clay-pot subsurface irrigation, bucket irrigation and direct application by hose are examples of technologies that fulfil the latter role. Drainage and reuse may also be important in managing water supply (Steenbergen et al. 2011).

In many cases, improving the leveling of rainfed paddy fields can have a significant effect on lowland rice production, especially when combined with measures to reduce water loss such as developing a hardpan, better bund management, or making small improvements in water delivery through contouring and on-farm ponds.

The source of the water and scale of operations will have an effect on which measures are suitable (Table 5.1). Sources include soil water, surface water and groundwater. Each of these storage types mediates rainfall at different spatial and temporal scales. Soil water stores operate locally and over short periods of days to months; surface water in rivers and lakes are seasonally recharged and spatially dispersed; and groundwater stores operate on a range of spatial and temporal scales, depending on the aquifer's characteristics. These range from shallow seasonally recharged local aquifers to large regional aquifers where recharge takes decades or longer. Capture and storage measures span a continuum from in-situ water retention and soil and water conservation (SWC) measures (planting pits, infiltration ditches, contour banks) to ex-situ rainwater harvesting and storage technologies (small earth dams, tanks, hand-dug shallow wells, runoff harvesting) to large dams (Figure 5.1). Each presents different options for access and use. Most of the capture and storage technologies identified are familiar and commonly applied. Many of these techniques are already in use in the region. For example, the use of small on-farm storage ponds is widespread in Thailand (see case study on Northeast Thailand: Farm ponds). Others have been trialed in other parts of the world, but their relevance for the GMS has not yet been investigated.

Groundwater irrigation is not extensively developed in the region, compared to South Asia, although the use of shallow tube wells in seasonally recharged alluvial aquifers has increased over the last 10 years. All the region's large river systems have associated alluvial aquifers with mostly unexplored potential for groundwater use. For example, in Cambodia, extensive shallow groundwater reserves exist around the Tonle Sap Floodplains and between the Bassac and Mekong rivers. Water levels in wells follow the river height for distances up to $30 \mathrm{~km}$ on each side of the Bassac River, with a lag time of a few weeks, indicating that the aquifers are constantly being recharged (CIAP 1999). Aquifers provide storage (by retaining water longer than in the river) and transmission (since canals or pipes are not required to transport the water as is the case with irrigation directly from the river).

Techniques are available to enhance seasonal recharge to groundwater through the use of weirs, check dams and flood spreading. These methods are referred to as managed aquifer recharge (MAR) and can be applied at a range of scales. For example, Lacombe et al. (2005) 
Table 5.1 AWM interventions to control and improve supply of water (Molden et al. 2009).

\begin{tabular}{|c|c|c|c|c|c|c|}
\hline Scale & Water source & Water control & Water lifting & Conveyance & Application & Drainage and reuse \\
\hline \multirow[t]{3}{*}{$\begin{array}{l}\text { Smallholder } \\
\text { farm-level }\end{array}$} & Rainwater & \begin{tabular}{|l|} 
SWC \\
In-situ water \\
Farm ponds \\
Cistern/underground \\
ponds \\
Roof water \\
harvesting \\
Recession \\
agriculture
\end{tabular} & $\begin{array}{l}\text { Treadle pumps } \\
\text { Water cans }\end{array}$ & $\begin{array}{l}\text { Drum } \\
\text { Channels } \\
\text { Pipes }\end{array}$ & $\begin{array}{l}\text { Flooding } \\
\text { Direct } \\
\text { application } \\
\text { Drip }\end{array}$ & $\begin{array}{l}\text { Drainage of } \\
\text { waterlogging } \\
\text { Surface drainage } \\
\text { channels } \\
\text { Recharge wells }\end{array}$ \\
\hline & $\begin{array}{l}\text { Surface } \\
\text { water }\end{array}$ & $\begin{array}{l}\text { Spate and } \\
\text { flooding } \\
\text { Diversion } \\
\text { Pumping }\end{array}$ & $\begin{array}{l}\text { Micro pumps } \\
\text { (petrol, diesel) } \\
\text { Motorized pumps }\end{array}$ & $\begin{array}{l}\text { Channels } \\
\text { Canals } \\
\text { Pipes (rigid, } \\
\text { flexible) }\end{array}$ & $\begin{array}{l}\text { Flood and } \\
\text { furrow } \\
\text { Drip } \\
\text { Sprinkler }\end{array}$ & $\begin{array}{l}\text { Surface drainage } \\
\text { channels } \\
\text { Drainage of } \\
\text { waterlogging }\end{array}$ \\
\hline & Groundwater & $\begin{array}{l}\text { Spring protection } \\
\text { Hand-dug wells } \\
\text { Shallow wells }\end{array}$ & $\begin{array}{l}\text { Gravity } \\
\text { Treadle pumps } \\
\text { Micro pumps } \\
\text { (petrol, diesel) } \\
\text { Hand pumps }\end{array}$ & $\begin{array}{l}\text { Channels } \\
\text { Canals } \\
\text { Pipes (rigid, } \\
\text { flexible) }\end{array}$ & $\begin{array}{l}\text { Flood and } \\
\text { furrow } \\
\text { Drip } \\
\text { Sprinkler }\end{array}$ & $\begin{array}{l}\text { Surface drainage } \\
\text { channels } \\
\text { Drainage of } \\
\text { waterlogging } \\
\text { Recharge wells }\end{array}$ \\
\hline \multirow[t]{3}{*}{$\begin{array}{l}\text { Community } \\
\text { or } \\
\text { catchment }\end{array}$} & Rainwater & $\begin{array}{l}\text { SWC } \\
\text { Communal ponds } \\
\text { Recession } \\
\text { agriculture } \\
\text { Sub-surface dams }\end{array}$ & $\begin{array}{l}\text { Treadle pumps } \\
\text { Water cans }\end{array}$ & $\begin{array}{l}\text { Drum } \\
\text { Channels } \\
\text { Pipes }\end{array}$ & $\begin{array}{l}\text { Flooding } \\
\text { Direct } \\
\text { application } \\
\text { Drip }\end{array}$ & $\begin{array}{l}\text { Drainage of } \\
\text { waterlogging } \\
\text { Surface drainage } \\
\text { channels }\end{array}$ \\
\hline & $\begin{array}{l}\text { Surface } \\
\text { water }\end{array}$ & $\begin{array}{l}\text { Spate and flooding } \\
\text { Wetland } \\
\text { Diversion } \\
\text { Pumping } \\
\text { Micro-dams }\end{array}$ & $\begin{array}{l}\text { Micro-pumps } \\
\quad \text { (petrol, diesel) } \\
\text { Motorized pumps } \\
\text { Gravity }\end{array}$ & $\begin{array}{l}\text { Channels } \\
\text { Canals } \\
\text { Pipes (rigid, } \\
\text { flexible) }\end{array}$ & $\begin{array}{l}\text { Flood and } \\
\text { furrow } \\
\text { Drip } \\
\text { Sprinkler }\end{array}$ & $\begin{array}{l}\text { Surface drainage } \\
\text { channels }\end{array}$ \\
\hline & Groundwater & $\begin{array}{l}\text { Spring protection } \\
\text { Hand-dug wells } \\
\text { Shallow wells } \\
\text { Deep wells }\end{array}$ & $\begin{array}{l}\text { Gravity } \\
\text { Treadle pumps } \\
\text { Micro-pumps } \\
\text { (petrol, diesel) } \\
\text { Hand pumps } \\
\text { Motorized pumps }\end{array}$ & $\begin{array}{l}\text { Channels } \\
\text { Canals } \\
\text { Pipes (rigid, } \\
\text { flexible) }\end{array}$ & $\begin{array}{l}\text { Flood and } \\
\text { furrow } \\
\text { Drip } \\
\text { Sprinkler }\end{array}$ & $\begin{array}{l}\text { Surface drainage } \\
\text { channels } \\
\text { Recharge wells } \\
\text { and galleries }\end{array}$ \\
\hline $\begin{array}{l}\text { Subbasin, } \\
\text { basin }\end{array}$ & Surface water & Large dams & $\begin{array}{l}\text { Gravity } \\
\text { Large-scale } \\
\text { motorized pumps }\end{array}$ & $\begin{array}{l}\text { Channels } \\
\text { Canals } \\
\text { Pipes (rigid, } \\
\text { flexible) }\end{array}$ & $\begin{array}{l}\text { Flood and } \\
\text { furrow } \\
\text { Drip } \\
\text { Sprinkler }\end{array}$ & $\begin{array}{l}\text { Surface drainage } \\
\text { channels } \\
\text { Drainage reuse }\end{array}$ \\
\hline
\end{tabular}

reported that farm dams in northeastern Thailand maintained water levels in adjacent fields. In Maharashtra, India, groundwater-retention weirs have been constructed to retain and head-up the subsurface flow in rivers, in order to replenish wells upstream of the weir and improve soil moisture (Steenbergen et al. 2011). On a more ambitious scale, Pavelic et al. (Forthcoming) have proposed that similar technologies could be used in the Chao Phraya Basin to divert flood flows to extensive shallow alluvial aquifers. This would help mitigate floods and improve groundwater supply at catchment scale.

How water is stored and seasonally redistributed has impacts on water availability downstream. This effect is not restricted to the construction of surface water reservoirs; for example, Lacombe et al. (2008) demonstrated that erosion-protection banks and small reservoirs in the headwaters of a catchment in Tunisia resulted in a decrease in annual runoff of up to $50 \%$. Similarly, reforestation has been demonstrated to decrease overall water yield from catchments by up to $30 \%$ per year in 
Figure 5.1 Continuum of water storage options (McCartney and Smakhtin 2010).

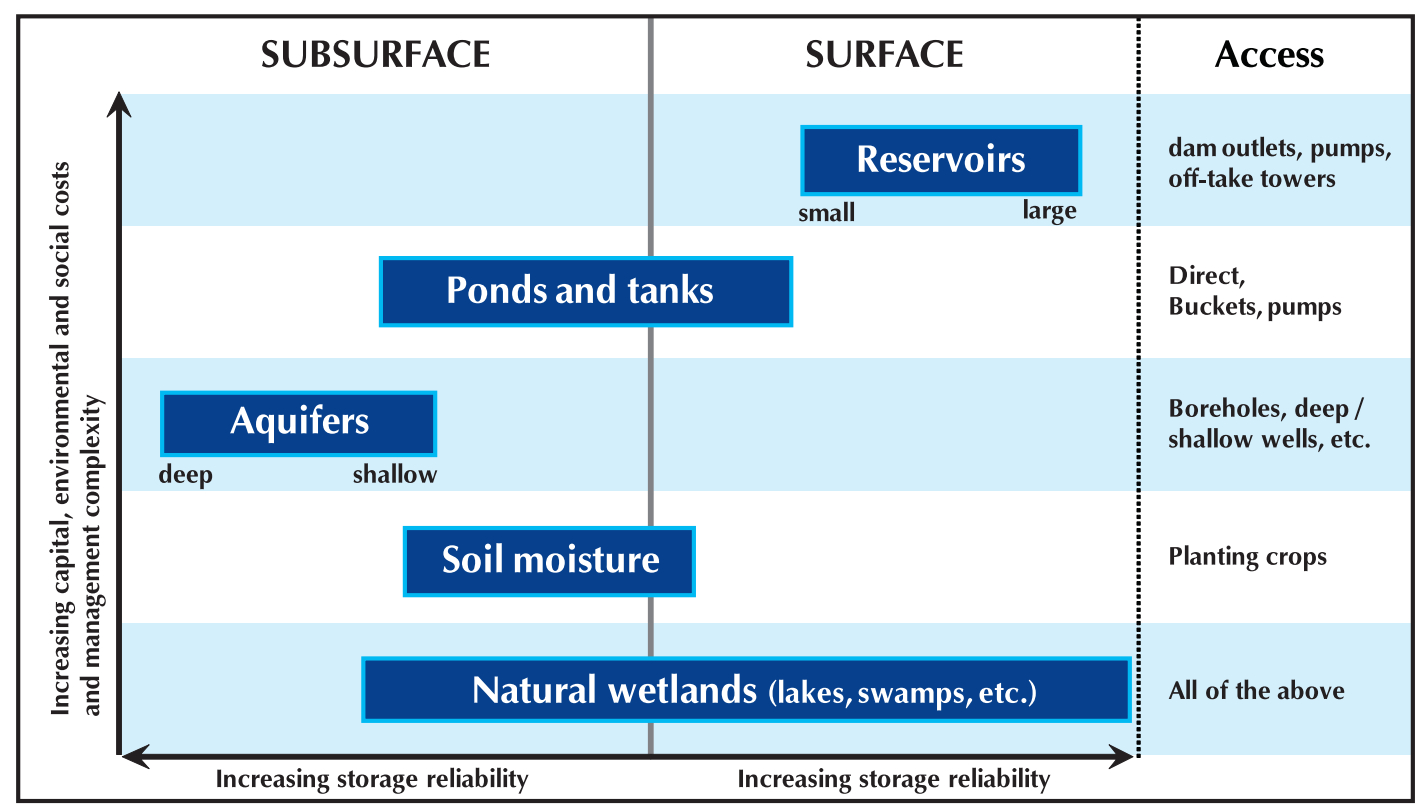

tropical southern China (Ge Sun et al. 2006). Pumping from aquifers can lower the water table, reduce spring discharges and can cause wetlands to dry up. Where groundwater supplies baseflow for streams, it can also reduce flow in rivers. Downstream impacts of AWM interventions must be considered as an integral part of project planning. Steenbergen et al. (2011) discussed the importance of considering water storage and use at landscape scales, taking into account the '3Rs': retention to slow the outflow of water; recharge to shallow groundwater and soil moisture; and reuse to extend the chain of water users. An integrated approach to managing land and water is needed, built on understanding how and where water is retained and transmitted through the landscape, and the interactions between climate, hydrogeology, ecology and economics. These links are multifaceted and specific to each landscape.

How water is conveyed and delivered can be critical to the success or failure of an intervention. For example, estimates suggest that only $6 \%$ of large-scale irrigation systems in Cambodia are working fully, with failures blamed largely on degraded canal systems (Thuon and Bastakoti 2010). The reasons for this are partly technical and partly institutional (including assigning responsibility for operation and maintenance $(\mathrm{O} \& M))$. Small-scale interventions to give farmers more flexibility in accessing water can complement and improve the efficiency of large-scale irrigation systems. In floodplains where shallow groundwater systems are directly linked to river flows, aquifers can be used as natural conveyance systems; the use of individual pumps for farmers to pump directly from groundwater removes the need for canals.

With pumping and lifting technologies, the costs of initial equipment and power can be limiting for smallholders. Fuel costs are a deterrent to irrigation in Myanmar and Cambodia, for example. Low-technology treadle and bicycle pumps have been very effective in some contexts in Africa and India, but have had limited uptake in others. When promoting these technologies, it is important to understand the context for use, including the availability and opportunity costs for labor. Viability will depend on the farming system and the economic circumstances of individual farmers. In India, large-scale policy measures affecting access to, and cost of, electricity have been critical in both promoting and regulating groundwater use (Shah et al. 2008). 


\section{Supporting/enabling measures}

AgWater Solutions Project (2011) stressed the importance of supporting and enabling measures to boost the uptake of AWM. These include a very wide range of issues: institutional arrangements and government policy; land and water title and access rights; availability of finance and micro-credit; improved information; development of supply chains and markets; and community involvement, education and empowerment.

Clarifying land and water titles and rights is an essential precursor to investing in AWM measures. Where landownership or access is not clear, or is precarious, farmers are unwilling to invest in improvements. In Cambodia, one effect of the social disruption of war and the Khmer Rouge period has been a breakdown in the system of land title. Markussen (2008) found that in rural Cambodia, agricultural land held with a paper documenting ownership had higher productivity and a greater value than other plots.

Water rights can pose more difficult problems; traditionally, water has been considered a common-pool resource in GMS societies. Resolving inequities in water access, therefore, requires community collaboration. For example, in upland areas of Lao PDR it is common for upland communities to grow montane paddy in small gravity-fed irrigation systems supporting a few hectares of rice. Paddies further from the river have less access to water, which is a source of community conflict. In Luang Nam Tha, these problems were resolved by communal agreement to allow water through to the paddies further from the river so that farmers could irrigate their crops after seeding (D. Fredericks, consultant, pers. comm.).

Understanding the social dynamics of communities is essential when determining whether investments in AWM will be equitable and accessible to all groups within a community. Gaining acceptance from the relevant stakeholders and institutions at different levels is vital for effective implementation of AWM. In some cases, informal community arrangements may parallel or supercede formal government structures. For example, in Burkina Faso, Mikhail et al. (2011) mapped a complex web of institutional arrangements for managing small reservoirs, and found that the formal water governance system had limited influence on decision making. Instead, this role was dominated by information community structures. As these tended not to coordinate across sectors, their capacity to deal with off-site impacts was limited (Mikhail et al. 2011). Social network and gender analysis are important components of any initial assessment when planning AWM interventions.

Drought and flood insurance provides a buffer for smallholders against the impacts of climate variability. Farmers in developed countries often use Insurance to protect them against weather risks; similar approaches are being investigated for developing countries (Nieto et al. 2010). Balzer and Hess (2010) concluded that insurance based on rainfall indices has potential as a market-oriented tool for managing climatic risks in specific contexts. However, this would require public and private sector investment and support to be feasible in wider applications.

Farmers in developed countries rely heavily on weather forecasting to plan and manage farm operations. Initiatives are under way to provide 3-5 day and seasonal forecasts for farmers in India, to help inform the choices they make about sowing, harvesting, cultivar selection, farm-input management, plus pest and disease prognosis and control measures (ACIAR 2011). Bulletins are disseminated using media such as newspapers, radio, TV, the internet and mobile phones. Flood warnings are available for the Mekong river through the Mekong River Commission (MRC) (www. mrcmekong.org). 


\section{Identifying the right AWM interventions}

Some important and consistent messages have emerged from major programs investigating AWM options internationally; for example, AWM Solutions, Agwater in Challenging Contexts and 3R. These can be summarized under the concepts of diversity, context and scale (AgWater Solutions Project 2011; Steenbergen et al. 2011).

Diversity: no single solution will fit the needs of all the farmers in a community. Even within the same cultural, agricultural and ecological system, individual farmers will have their own methods for using the land and water resources they have, and will face different physical and economic constraints. Any solutions will need to be relevant to a range of livelihood choices, and provide technology, price and financing options, so that farmers can make their own choices. Information is as important as hardware.

Context: water management interventions must be integrated with agronomic improvements for farmers to gain full benefit. The multiple uses of water, beyond agricultural needs, must also be considered when assessing interventions. It is important to leverage water within broader rural livelihoods, taking account of socioeconomic and agroecological contexts. Water is inextricably linked to larger landscape processes; by improving water management, it is possible to also improve soil conditions, vegetation cover and micro-climates. Managing water must be seen as part of broader landscape management, taking account of impacts on other ecosystem components and services.

Scale: implementation and impacts of AWM cut across scales from field to catchment. The cumulative impacts of multiple small-scale interventions can be very important, both economically and ecologically. Opportunities for scaling-up and scaling-out, and the impacts of doing so, need to be carefully assessed.

The AWM Solutions project has outlined strategies for identifying the most appropriate suite of AWM interventions that could be applied directly within the GMS. The project's approach is to enable planners to assess the technological, biophysical, social and institutional landscapes in which AWM solutions operate and then understand the opportunities, constraints and impacts of their use, at the national-to-regional level. The emphasis is on in-depth consultations with local stakeholders, so planners understand the different livelihood strategies in the region, can identify where AWM is an entry point for improving livelihoods and recognize constraints to changing water management. There is explicit recognition that this will vary not only between, but also within, regions, and that multiple options are needed.

Once water planners have identified promising AWM technologies relevant to the region, they need to systematically analyze the viability of making these interventions at scales from farm to watershed. A methodology known as Rapid Participatory Opportunities and Constraints Analysis (RPOCA) is used to assess the impacts of AWM practices on economic, social and institutional dynamics, input and output markets, resource sustainability, and external influences and impacts. This process involves analyzing how dependent communities are on different sources of water, along with potential interactions and impacts of interventions at watershed scale. It is also important to analyze the institutional capacity required to implement different interventions and deal with potential impacts. 


\title{
AWM case studies
}

\author{
Northeast Thailand: Farm ponds \\ Location: Isan Plateau, Northeast Thailand
}

AEZ: Lowland plains

\section{The agricultural context}

Northeast Thailand, known as Isan, makes up a third of the country. Lowland rice is the dominant crop, with cassava, sugarcane, maize, vegetables and rubber also grown. Over $90 \%$ of rice is grown in the wet season. Farms are mostly smallholdings, with an average size of 2.5 ha per household. Soils are sandy, low in fertility and prone to salinity. The tropical savannah climate brings three seasons: rainy (mid-May to late-October), cold and dry (November to mid-February) and hot and dry (mid-February to mid-May). Total annual rainfall is around $1,500 \mathrm{~mm}$, with $80 \%$ of rain falling from June to September; because this rainfall is often not stored, and irrigation is only available across $17 \%$ of the region, farmers regularly suffer from droughts.

During the past two decades, there have been initiatives to construct ponds on farms as part of the 'New Theory' of agriculture promoted by King Bhumiphol, to mitigate drought at farm level and promote diversification of crops (Lacombe et al. 2005). In 2005, a survey into water use on homesteads was conducted in 130 households in the Buriram, Mahasarakam, Khorat and Yasothon provinces (Penning de Vries and Ruaysoongnern 2010). Ponds were used to water vegetable gardens and orchards, to support large livestock and to rear fish. Ponds were also used to provide supplementary irrigation for rice, but where possible, paddies were watered using runoff or public sources of water, such as canals. Drinking and domestic water were taken from piped water or wells. Farms without ponds tended to use around half the piped water of that used by farms with ponds, suggesting that the lack of a pond was not compensated for by using extra piped water.

\section{Homesteads with ponds perform better}

Farms with ponds tended to have higher incomes and produce fish (with significant exceptions). Total income per homestead, including the value of home consumption, was over THB 100,000 (USD 2,900) for farms with a pond, and one quarter less on farms without a pond. Households without a pond produced fewer vegetables and had no surplus to sell; the same applied to animal products. As well as being lower, incomes from farms with no ponds were less diversified than those from farms with ponds. This implies that farms without ponds are more vulnerable to drought and flooding. The farms with ponds are probably more resilient to ecological and economic pressures (Tipraqsa et al. 2007). Another study in the Khon Kaen Province found that farms with ponds generated an additional income of $85 \%$ from vegetable production, which often constituted about half of annual farm income (Wangkahart et al. 2006).

\section{What type of pond is best?}

Additional work has studied the influence of size, shape and location of farm ponds. One study of 110 farms with ponds in northeast Thailand found large differences, in layout, pond design and cropping patterns. Sizes, proportions of plots, choice of crop species and proximity to public water outside the farm were all highly variable. Optimal sizes suggested by previous research ranged from $12 \%$ to $30 \%$ of the farm size.

The Bo-Nam Farm Simulation model (Penning de Vries et al. 2005) was developed to explore the optimal size of a pond. The model produces results for different scenarios to determine the 
performance of a farm over a range of pond sizes in response to farming style, weather patterns or technological and management innovations. The findings suggested that, for a farmer who seeks stability and rates subsistence of his family and farm as priorities, as is the case for many farmers in northeast Thailand, the optimum pond size would be around $10 \%$ of the farm surface area. The project demonstrated the role that farm simulation models can play in helping farmers make informed decisions to optimize their water-use performance.

It is important to note that there is no single 'right' size or type of pond; the optimum size of a pond depends on farmer preferences and needs, and on the way a farm is managed. For example, by using soil ameliorants such as bentonite to improve soil water-holding capacity and thereby cut water demand, a farmer can reduce the size of the pond required for supplementary irrigation.

\section{Ponds and groundwater}

Farm ponds are closely linked to local water tables. Depending on their position in the landscape, farm ponds can act as both recharge and discharge zones for groundwater. Wangkahart et al. (2006) found that lateral seepage into ponds from groundwater was important in maintaining water levels during the dry season; conversely, farm ponds can also provide seepage to increase groundwater recharge. Groundwater and farm ponds can provide complementary water sources at different times of the growing season (Lacombe et al. 2005).

Small-scale ponds capturing water individually have a very limited impact, but at larger scales may collectively affect downstream flows and recharge to groundwater. Under arid conditions in Tunisia, large numbers of small dams in the upper catchment significantly reduced downstream runoff (Lacombe et al. 2008).

\section{Opportunities for upscaling}

Farm ponds offer an effective way to store water from the rainy season for use during dry spells. Water from ponds can serve multiple purposes, from fulfilling domestic uses if rainwater harvesting or piped water is insufficient, to irrigating crops and trees, and nurturing livestock and fish. Modeling can help answer questions on the optimal size and location of ponds, given information on the local terrain, weather and cropping patterns. In Thailand, existing farmer networks offer a means of communicating findings.

Although these studies were limited to northeast Thailand, similar climate, agronomic and soil conditions exist over large areas of the lowland plains, particularly in central Myanmar and northwest Cambodia. The region's tropical savannah climate also covers large parts of Asia, Africa and South America. Farm ponds could, therefore, also provide a cost-effective solution for optimizing performance on homesteads in other parts of the globe. However, fully assessing the cumulative impacts of many small dams on downstream flows is important, ahead of implementation.

Hoa Binh: Integrating water management into conservation agriculture

Location: Hoa Binh, Vietnam

AEZ: tropical uplands

\section{The agricultural context}

Hoa Binh is a mountainous province within Vietnam's northwestern region. It has a tropical monsoon climate, with a rainy season spanning May to September and a dry season between October and April. Around $1,800 \mathrm{~mm}$ of rain falls each year, 85 to $90 \%$ of it during the rainy season. The average temperature is $23{ }^{\circ} \mathrm{C}$ but this drops to as low as 5 to $10{ }^{\circ} \mathrm{C}$ in the dry season. The 789,000 -strong population comprises 30 discrete groups, including the Muong (63\%), Kinh (27\%) and Thai (4\%). 
Around $85 \%$ of people live in rural areas. Hydropower from the Hoa Binh Dam contributes almost half of GDP in the region; agriculture, forestry and fisheries contribute around $30 \%$.

Paddy rice has traditionally been grown in valley bottoms, where the soil is fertile and more water is available. The two cropping seasons are spring (February to May) and summer (July to October). Lately, water scarcity has prompted some lowland farmers to switch to planting cash crops such as maize, peanut or soybean in the spring season. Upland farmers grow rainfed cassava, maize, sugarcane, fruit trees and agroforestry species, under conditions of sloping land and water scarcity. Soil erosion has had a severe impact on upland farming; average crop yields are $30 \%$ to $40 \%$ lower in sloping upland areas than in lowland flat areas. Remnant forests in the upland areas contain native species and important medicinal plants. There have been several recent reforestation programs, to provide incomes and protection against soil erosion and landslides.

\section{Resolving upland issues}

In Thanh Ha watershed in Hoa Binh, upland farmers suffered from erosion, insufficient water and unstable prices. As part of the program, 'Participatory Watershed Management for Reducing Rural Poverty and Land Degradation in Semi-Arid Tropical Asia', a number of interventions were introduced. These were geared at conserving rainwater, reducing land degradation and replenishing soil nutrients through biological nitrogen fixation (Mula Rosana et al. 2007).

The development of pits and ponds has proven very effective at reducing soil erosion and retaining water. Following the program, there are now some 200 pits around Thanh Ha, measuring 0.5 to $7 \mathrm{~m}$ across. One farmer said that fruit yields on his litchi plantation had risen by $30 \%$ to $40 \%$ as a result. Conservation agriculture techniques were introduced to complement the provision of water through ponds. These included introducing improved varieties of legume plus watermelon crops; using polyethylene mulching; constructing stone barriers (stone bunds, bench terraces and contours) and supplementary physical structures (pits, contour canals, percolation tanks); and applying micronutrients and Rhizobia soil bacteria that fix nitrogen. The introduction of these techniques, combined with the development of ponds, resulted in a rise in well levels from 1.5 to $2 \mathrm{~m}$ in this area.

After improved cultivars of soybean, groundnut and mung bean were introduced in 2003-2004, the cultivated area of these crops increased while maize declined. The use of polyethylene mulch resulted in a doubling of some crop yields. Applications of micronutrients and Rhizobia reduced the nitrogen requirement by 15 to $30 \mathrm{~kg}$ ha-1, and increased yields by up to $20 \%$. Gliricidia proved to be an effective barrier against soil erosion and also provided a source of green manure to improve soil fertility. This fast-growing perennial tree can be pruned six to eight times a year to provide 80 to $100 \mathrm{t}$ of nitrogen-rich biomass.

The biophysical improvements noted by farmers following interventions included improved soil structure, plus reduced runoff and soil erosion. These were complemented by better yields, higher income, reduced use of weed killer and fertilizers, plus access to new foods and education.

\section{Opportunities for upscaling}

The problems encountered in Hoa Binh, primarily low productivity on steeply sloping lands with high rates of erosion, are common across the uplands of the GMS. Growing populations and moves to reduce shifting cultivation are placing increasing pressure on land resources. Deforestation and degradation in the uplands are linked to declining water yield from catchments, with impacts on production from adjoining lowlands. High rates of erosion and sedimentation can jeopardize valuable hydropower production, for example. Finding more sustainable modes of production in the uplands is an urgent priority. 
Integrated approaches to soil and water management developed and trialed in Hoa Binh could be applied across northwest Vietnam, northern Laos and Myanmar in areas with similar topography and farming systems.

\section{Small reservoirs in the Tonle Sap Floodplain: The cost of getting it wrong}

Location: Chamnar Krom, Tonle Sap Floodplain, Cambodia

AEZ: deltas and floodplains (Tonle Sap Floodplain)

\section{The agricultural context}

Chamnar Krom commune in Kampong Thom Province is on the floodplain of Tonle Sap (Great Lake) in Cambodia. Tonle Sap is the largest freshwater lake in Southeast Asia and is a biodiversity hot spot. In 1997, it was nominated as a United Nations Educational, Scientific and Cultural Organization (UNESCO) biosphere because of its ecological, economic and sociocultural value. In the wet season, the lake fills from the floodwaters of the Mekong, swelling to greater than 15,000 $\mathrm{km}^{2}$; in the dry season, it acts as a giant retention pond, slowly releasing water to the delta. The Tonle Sap system is the heart of the Mekong freshwater fishery, and accounts for $60 \%$ of total fish produced in Cambodia. The inland fishery is valued at USD 500 million and contributes to $12 \%$ of total GDP, more than rice production. Almost half of the population work full-time or part-time as fishers (So Nam 2009).

The flood pulse supports rice-fish systems that are the main livelihood for communities around the lake. Traditionally, deepwater, or floating, rice was cultivated in the flood zone of the lake, with lowland paddy in higher zones. Canals to provide supplementary irrigation in the wet season were constructed in the early 1970s, but have fallen into disrepair. Yields of lowland rice have fallen significantly from $3-3.5 \mathrm{t} / \mathrm{ha}$ in the 1970s to around $2 \mathrm{t} / \mathrm{ha}$, due to declining soil fertility. Average farm size is also declining as populations grow. In response, there has been a trend since the 1990s towards cultivation of higher-yielding recession and dry- season rice (3-4 t/ha).

\section{Reservoirs for the dry season}

During the late 1990s and early 2000s more than 20 small reservoirs with adjacent bunded areas for dry- season rice were constructed on the Tonle Sap Floodplain in Chamnar Krom commune. Each reservoir is between 100 and 150 ha in size, and is designed to store wet-season floodwaters for irrigation in the dry season. The reservoirs were constructed by local entrepreneurs at a cost of around USD 80 - USD 100,000. The dry-season rice production areas were rented to farmers from within the commune or from Siem Reap Province at KHR 1 million (or USD 250) per hectare, per season (DAE 2010). Similar reservoirs were constructed in other parts of Kampong Thom and Siem Reap provinces.

The reservoirs were constructed by individual entrepreneurs, apparently without reference to commune or provincial planning procedures, and in some cases may have involved illegal land acquisition (Diepart 2010). After the chaos of Cambodia's Khmer Rouge years, determining who has the title to land is an ongoing problem, with land grabs by the wealthy and powerful individuals being a common occurrence.

\section{Unintended impacts of building reservoirs}

Community consultations in 2009 (DAE 2010) reported that the reservoirs cut the connection among, and between, water bodies during recession of the annual flood in October, disrupted fish migration and movement from the Tonle Sap to other water bodies, and affected flooded forest 
and grasslands. Concerns were raised that the chemical fertilizers, herbicides and pesticides used for recession and dry-season rice cultivation in these areas could affect water quality, with impacts on human health, fish stocks and wild animal populations. A survey conducted by Diepart (2010) on attitudes to similar reservoirs in nearby Srayov commune, indicated that they provided new employment opportunities, but also engendered conflicts. The existence of such large private areas restricted access to common ponds, and all respondents considered that capture of fish fingerlings inside the reservoirs resulted in a decrease in their total fish catch.

In June 2010, the Ministry of Water Resources and Meteorology announced that 30 such reservoirs on the Tonle Sap Floodplain in Kampong Thom would be destroyed, to protect the environment. The Director General of the Fisheries Administration estimated that such reservoirs had devastated around 100,000 ha of flooded forest around the lake, depleting fish stocks (Phnom Penh Post 2010).

\section{Lessons for other areas}

On a technical level, the reservoirs operated reasonably well, filling the demand for dry-season irrigation to increase yields. However, social and environmental outcomes were poor - the reservoirs restricted the formerly common-pool resources of land, water and fish to a small group of wealthier farmers and caused conflict within the community. Cumulative environmental impacts of multiple small-scale developments had serious consequences for floodplain biodiversity and productivity.

This example emphasizes the need for thorough assessments of community needs and potential impacts of multiple small-scale developments at different scales to be made prior to implementation. It is important to understand common issues, strategies and problems across different communes and sectors, and assist in setting policies for managing shared zones. A shared vision for managing common-pool resources must be negotiated, taking account of ecosystem links and processes.

Yunnan: Coping with drought

Location: Yunnan, China

AEZ: subtropical highlands

\section{The agricultural context}

Yunnan Province lies in southwest China and covers $396,000 \mathrm{~km}^{2}$, some $4 \%$ of the nation. It is mountainous, with some peaks in the northwest extending as high as 3,000 $\mathrm{m}$ above the valley bottoms. The province is rich in biodiversity and natural resources. Around $83 \%$ of the 45 million inhabitants of Yunnan work within agriculture. Different zones have temperate, subtropical and tropical climates. There are two growing seasons with summer crops of rice, corn, tobacco, beans, mulberry leaves and potato from April to September, then winter crops of wheat, beans and rapeseed from September to April.

The average rainfall is $1,100 \mathrm{~mm}$ per year, but there are distinct wet and dry seasons. Rain falls mainly between May and October. Although rainfall is relatively abundant, Yunnan suffers from recurring droughts, due to the late arrival of rain in spring and/or short-term dry spells during the summer monsoon. Most farmland is rainfed and sloping, with limited irrigation, especially in the mountains.

\section{A province beset by climate extremes}

Although Yunnan is crossed by more than 600 rivers, and has the third highest per capita water resource of China's provinces, it has experienced a warming climate and 12 drought years since the late 1980s. Droughts occurred in 1987, 1988, 1989, 1992, 1993, 1997, 2003, 2004, 2005, 2006, 
2007 and 2009, with each drought affecting an area exceeding half a million hectares. The recent trend has been for severe drought to strike between March and June when most summer crops need water to grow. Then, from July to September, when the crops need sunshine to ripen, there has been too much precipitation. Winter crops have also been affected by drought, between November and March. The main impacts have been loss of agricultural production, reduced drinking water for humans and livestock, food shortages, increased prices of food, energy and industrial items, and reduced volumes of water in reservoirs.

The drought in 2009-2010 was particularly severe: by April 2010, some 3.2 Mha of food crops and cash crops were affected, of which 2 Mha were damaged and over 1 Mha could not be harvested. The direct economic loss exceeded CNY 12 billion. More than three million people lacked food, and large numbers of people and animals had insufficient drinking water (Caizhen 2010).

\section{Investigating responses to long-term drought}

Observing the way in which Yunnan has been affected and responded to these droughts provides an opportunity to learn for climatic shifts elsewhere in the future. A study was conducted between 2005 and 2010 (Caizhen 2010), largely based on field visits to nine administrative villages in four prefectures. Researchers conducted household and village surveys, interviewed key officials and held focus groups. Questions asked were related to access to assets, agriculture and livestock production, livelihoods, migration, remittances, water-related hazards, insurance, plus coping and adaptation responses. The aim of the survey was to assess the methods of coping and adaptation instigated by the government, communities and households.

Strategies proposed and implemented by local authorities and the Chinese Government for adapting to drought included:

- converting paddy fields to dryland, intercropping and interplanting different types of crops, compensating the loss of winter crops with summer crops, using plastic film to prevent evaporation and late autumn planting;

- encouraging labor migration, so villagers left if the drought prevented them from planting their crops and returned if the rains came;

- providing anti-drought equipment, such as water pumps, water pipes, diesel engines and plastic buckets, and assistance to dig wells;

- providing drinking water by truck, water tanker and oxcart to households with no water, from February 2010, after several months of drought; and

- urging locals to cut down thirsty eucalyptus trees.

Most households responded by diversifying their crop production away from growing only rice. They also reduced their livestock numbers from the usual two or three pigs, sheep or goats to just one for self-consumption. As more people began to sell livestock, because there was not enough food to feed the animals, the prices fell. Many villagers and households built water ponds, dams, cellars, water jars or tanks. However, many were only filled with rainwater, so these dried out during periods of drought. Households tended, traditionally, to store enough rice for one to three years. They also pickled vegetables and preserved meat to last through the lean months. Domestic washing was reduced to using a cloth to wash the body and washing underwear but no other clothes.

\section{Plentiful water but poor management}

So, why was there such a big impact from the droughts in a relatively water-rich area, where agriculture is of great importance to economic development? By 2007, 5,403 reservoirs were in 
place in Yunnan, along with aqueducts and channels for carrying water to paddy fields. However, much of this infrastructure was developed in the 1960s and 1970s and was no longer working effectively. Irrigated area decreased from $45 \%$ in 1997 to $36 \%$ in 2008, which is much lower than the average in China.

Many of the hydropower stations in Yunnan are designed purely to generate energy. They do not have functions that provide water for irrigation or drinking water. There is also a conflict between hydropower and irrigation; in the dry season in winter, when farmers need water for crops, hydropower stations also need water. In the summer, when there is too much rain, farmers do not need water, but this is when hydropower stations release water. Current national water conservancy policy only supports investments in large and middle-sized reservoirs. But in the mountainous areas, the land is not suitable for such large-scale projects and poor farmers do not have the ability to build their own reservoirs.

Allocation of water favors urban areas and industry, rather than rural regions and agriculture. During the 2009-2010 drought, around 10 million people in rural areas, a third of the rural population, did not have safe drinking water. However, urban areas were supplied with drinking water from large reservoirs. Poverty affected 13\% of Yunnan's inhabitants in 2007, compared with $1.6 \%$ across China as a whole. Poor households had limited resources and income sources to help them cope with the drought. The study concluded that socioeconomic and institutional vulnerabilities were limiting the ability of rural inhabitants to adapt and cope in times of drought (Caizhen 2010).

\section{Lessons for other areas}

Drought is a common phenomenon across the GMS, particularly in the drier zones of northeast Thailand, Myanmar and northern Yunnan. Drought hits hardest in agricultural communities without secure water sources. Constructing large reservoirs for urban supply and hydropower does not protect local farmers from the effects of drought. Effective responses to drought must come at the local level. Water-harvesting technologies, such as ponds, small dams and water cellars, are important drought-proofing tools for communities, providing water for drinking, livestock and crops. Other methods that can help reduce risk include crop diversification, generating off-farm income and farmer insurance.

Case study: Shallow groundwater in the Cambodian Mekong Delta

Location: Svay Rieng, Cambodia

AEZ: Delta (Cambodian Mekong Delta)

\section{The agricultural context}

The province of Svay Rieng lies in southeast Cambodia, close to the border with Vietnam. Annual rainfall is $1,400 \mathrm{~mm}$ to $1,700 \mathrm{~mm}$, concentrated between May and October. Much of the area is inundated by the annual flood of the Mekong between July and December, which recedes slowly after the end of the monsoon.

Svay Rieng is among the country's largest, poorest and most densely populated provinces. It occupies low-lying land on the floodplain of the Mekong River. Low-lying areas, inundated during the wet season, are mainly used to grow recession rice, with small areas of irrigated dry-season rice. The rest of the province comprises lowland terraces. These areas support homesteads whose inhabitants grow rice in the wet season and vegetables in the dry season. The soils have low fertility. Many households raise buffalo, cattle, pigs, chickens and fish. 


\section{Floods and droughts threaten crops}

In most parts of Svay Rieng, only a single annual crop of rice is grown, watered by rainfall or receding floodwaters. There is a high risk of failure of this crop; in 2000, 2001 and 2002, the region suffered from floods, while in 2008, 2009 and 2010 it experienced drought. Meanwhile, in 2004 and 2008 there were large losses due to the brown hopper insect pest (Nilaparvata lugens). Access to irrigation would allow farmers to provide supplementary water to safeguard the wet-season rice crop. It would also allow flexibility in planting dates, so they could plant later to avoid the worst of insect pest attacks and late-season flooding. It could also be used to extend the cropping season to a second or even third crop.

\section{Groundwater use for agriculture: Pros and cons}

Svay Rieng has fairly abundant groundwater resources that can be accessed by hand pumps or shallow open wells. In the past, wells were mostly used to provide water for domestic uses. However, in places where groundwater is easily accessible using simple flush bored wells and diesel pumps, there has been a rapid and unregulated expansion in groundwater irrigation. A groundwater-use survey showed that between 2002 and 2005, the number of domestic hand pumps more than doubled to almost 60,000 and that the number of engine-powered irrigation pumps rose from 1,603 to 2,675 (IDE 2005).

In Thnot commune, in 2001 and 2008, famers experiencing water shortages had to buy water from neighboring communities in Vietnam to protect their small dry-season crop. In 2009, villagers started to develop tube wells to provide water for irrigation; each well cost around KHR 1 million (USD 250) and could irrigate 2-3 ha of dry-season rice. Good yields (greater than $3 \mathrm{t} / \mathrm{ha}$ ) were produced in 2009 using the tube wells. However, the costs of pumping using diesel are high, and if the rice price is low, profits are marginal. Water can be pumped manually, but with high labor requirements (Thuon 2011).

Although farmers using tube wells have reported encouraging results, there have been observations in some areas of over-pumping and wells drying out. In Thnot, farmers reported having to pump at night (when demand is lower) to get sufficient water. Consultations with stakeholders in other parts of Svay Rieng where tube wells are used indicated that water tables had fallen. Dry wells had threatened domestic as well as agricultural uses, and caused hardship for many people (IDE 2005).

\section{Constraints and potential for developing groundwater}

When assessing the sustainability of groundwater use, and the likelihood and potential severity of local shortages, it is essential to understand the hydrogeology of the area, including rates of replenishment, the size of groundwater stores and sustainable limits of abstraction. The potential to exploit groundwater in Svay Rieng is high because there are several confined aquifers within 100 meters of the surface (Kokusai Kogyo Co. Ltd. 2002). On the Mekong Floodplain, aquifers are closely linked to the river, and groundwater is replenished by the annual flood but seasonal shortfalls could threaten crop production. The high level of use for drinking water means that care must be taken not to disrupt domestic supplies.

Water quality is important when evaluating the feasibility of irrigation. Many wells in Svay Rieng contain water with elevated iron, manganese and potassium concentrations. High levels of arsenic are also common in aquifers on the Cambodian Floodplain. A water-quality assessment is needed to evaluate the suitability of water for irrigation purposes, following studies on groundwater quantity and flow. This should include the tolerance of crops to the chemistry of the available groundwater. 
Other factors requiring consideration include the cost of installing and operating wells, access to credit and the possibility of using electricity to reduce pumping costs.

\section{Opportunities for upscaling}

The floodplains of the major rivers, both in the deltas and on the lowland plains further upstream, have deep alluvial sequences and offer good prospects for farmers to exploit shallow groundwater resources. Shallow dug wells and tube wells have transformed irrigation in South Asia by replacing or supplementing large irrigation schemes (Shah 2009). There is potential for Cambodia, Lao PDR and Myanmar to 'leapfrog' directly to flexible irrigation systems based on groundwater, without the investment costs involved in large irrigation schemes. However, a thorough assessment of groundwater potential is an essential first step.

Case study: Montane paddy in upland Lao PDR

Location: Luang Prabang Province, Lao PDR

AEZ: Uplands

\section{The agricultural context}

Phonexay District in Luang Prabang Province, northern Lao PDR, comprises sloping lands at elevations of between $250 \mathrm{~m}$ and 1,600 m. Much of the district is remote and sparsely populated by a mix of Khmu and Hmong ethnic minorities. Traditional livelihoods rely on shifting cultivation (swidden agriculture) of upland rice and other crops, with farmers also dependent on forest products and grazing livestock. Growing populations and government policy to eradicate shifting cultivation, combined with moves to protect forest lands, have limited areas where farmers can grow crops. This has resulted in a shortening of the swidden cycle, causing yields to decline, and increasing food shortages and poverty. The overall poverty in Luang Prabang is $27 \%$, but poverty is much more common in sloping lands and in remote areas (Lao Department of Statistics 2008).

\section{Seeking ways to increase production}

Markets in remote areas of Luang Prabang are not sufficiently developed to enable farmers to replace rice with cash crops. There is a need to develop new rice areas and improve productivity of existing areas. To increase rice production in the uplands, the government has developed small irrigation schemes in flat areas in valleys. These usually cover a few tens of hectares, but suitable areas are limited. Another response has been for individual farmers or communities to build terraces for montane paddy. Between 1990 and 2002, the area of montane paddy in the northern region of Lao PDR increased by $70 \%$. By 2009, paddy rice (rainfed and irrigated) made up 55\% of total area planted to rice in the northern region.

\section{Higher yields, less labor}

A survey of villages in northern Lao PDR (Linquist et al. 2007) found that farmers developed paddy terraces because: land available for rice was insufficient due to land allocation policies; and paddy rice produced higher yields and required less labor. Average yields of upland rice in surveyed villages was 1-2 t/ha, compared to yields of 3-4 t/ha for montane paddy. Households with more than half a hectare of paddy did not experience rice shortages in the ten years prior to the survey, but families with less than 0.1 ha experienced shortages in at least one year in two. The shift to paddy production increased the rearing of livestock, important as a source of cash income, and 
allowed farmers to grow more cash crops on upland fields. They continued to grow upland rice for home consumption and to reduce the risk of crop losses, since the timing of the upland rice harvest varies from that of cash crops.

\section{Limitations and benefits of expanding paddy}

Sloping fields are converted to paddy terraces by moving soil to make flat areas; the greater the slope, the more soil must be moved, and the higher the establishment costs. Canals and weirs to provide water for irrigation must also be constructed. Constructing terraces requires a high input of labor, and it takes several years for yields to stabilize on new terraces. However, it only takes around four years to recoup those costs through better rice yields and labor savings (Linquist et al. 2007).

As well as individual farmers obtaining improved yields, there can be significant off-site benefits from terracing. Erosion rates from terraces are much lower than from cultivation on slopes, and higher productivity reduces pressure on existing land and avoids the need to open up new areas. Assume that $1.5 \mathrm{t} / \mathrm{ha}$ can be obtained in a three-year crop cycle with one year of rice cultivation and two years fallow, compared with 3 t/ha in montane paddy. For every hectare of paddy developed, the upland rice area could decrease by 7 ha in areas with one crop per year or 14 ha in parts with double cropping. This is very significant as it could free up land for reforestation, addressing deforestation issues.

Suitable areas for paddy development are limited, so this should not be seen as the only alternative to growing upland rice. Obvious areas for conversion have already been developed, so costs for future developments are likely to be higher. Investment costs may prevent poor households from developing paddy, so authorities would need to consider introducing incentives. It would also be important to consider water availability, along with the impacts of new developments on wetlands, riparian areas, groundwater recharge and runoff.

\section{Opportunities for upscaling}

More than half of the total area of the GMS consists of sloping uplands and highlands. These hilly and mountainous areas comprise a mix of steep slopes with flatter fields towards valley bottoms. Making more of the flatter lands available for paddy production and intensifying production from the rice paddies, could help reduce pressure on the fragile steep areas. In Yunnan, improvements in yields of rice grown in irrigated paddies and upland areas has led to a reduction in the planted areas of upland rice (Pandey 2005), allowing steep lands to be taken out of production.

Taking a landscape perspective can help achieve an acceptable balance of relatively intensive crop production and land conservation that avoids soil erosion and degradation. However, making the transition requires incentives that will encourage farmers to change their farming practices. 


\section{PART 6: GROUNDWATER IN GMS}

\section{Current situation}

Recent reports have highlighted the potentially important role of groundwater in socioeconomic development across the GMS (Eastham et al. 2008; Johnston et al. 2009; IUCN 2011). One way in which this may be realized is by expanding and intensifying areas under irrigated agriculture. Groundwater provides a buffer against the limitations and uncertainties of rainfall availability by supplementing surface water supplies, particularly during the dry season and in low rainfall years. It can also be the sole provider of water in areas lacking other surface water resources.

Country-level data recently reported from a global inventory of census statistics (Siebert et al. 2010), indicates that the current extent of groundwater irrigation is less than $10 \%$ of total irrigated area for five Mekong countries: Cambodia, Lao PDR, Myanmar, Thailand and Vietnam (Table 6.1). Such figures grossly understate the critical role of groundwater in some areas and highlight the large potential for future expansion. The figures show wide divergence between individual countries. This reflects the fact that the region is far from homogeneous, with vastly contrasting hydrogeological and socioeconomic conditions.

Table 6.1. Estimates of groundwater irrigation in five GMS countries. Source: Siebert et al. (2010).

\begin{tabular}{|l|c|c|c|}
\hline Country & $\begin{array}{c}\text { Groundwater } \\
\text { irrigated area } \\
\text { (ha) }\end{array}$ & $\begin{array}{c}\text { Total } \\
\text { irrigated area } \\
\text { (ha) }\end{array}$ & $\begin{array}{c}\text { Percentage of total } \\
\text { under groundwater } \\
\text { irrigation }\end{array}$ \\
\hline Cambodia & $0^{\#}$ & 241,823 & $0.0^{\#}$ \\
\hline Lao PDR & 200 & 271,703 & 0.1 \\
\hline Myanmar & 100,000 & $2,073,000$ & 4.8 \\
\hline Thailand & 481,063 & $5,279,860$ & 9.1 \\
\hline Vietnam & 32,000 & $3,200,000$ & 1.0 \\
\hline
\end{tabular}

\# underestimates known levels of development

In absolute and percentage terms, groundwater irrigation is highest in Thailand, where groundwater reserves are high and the related knowledge base and institutional arrangements are probably the most advanced (Foster 2008). Within large irrigation canal schemes, such as at Phitsanulok in the central plains of the Chao Phraya Basin, groundwater accounts for $13 \%$ of total use in wet years and $19 \%$ in dry years. At the tail-end of the distribution system, groundwater use is much higher due to supply shortfalls (Bejranonda et al. 2006).

In Myanmar, groundwater resources are known to be vast but are largely unreported in the English literature. The use of groundwater is second-highest across the GMS, with the level of development in this one country eclipsing areas of Cambodia, Lao PDR and Vietnam combined. In Myanmar, 90\% of total groundwater use is reportedly for irrigation (Naing 2005).

In Vietnam, small but significant agricultural groundwater developments have been made within the coastal plains, deltas and upland areas. These support cultivation of staple grains such as rice, as well as cash crops (WEPA n.d.a). Institutional arrangements and general knowledge of the resource potential and groundwater use across subregions appears to be good.

In contrast, groundwater irrigation in Lao PDR is almost entirely absent for agricultural development (IBRD and WB 2005), with garden-scale pilot activities just beginning to emerge 
(Dr. H. Hamada, IWMI-Laos, pers. comm.). Groundwater resources are known to be vast. Although largely untapped within farming, they are the mainstay of village and domestic supplies in many rural areas.

Official figures indicate that there is no groundwater irrigation in Cambodia (Table 6.1), but in reality it is thriving in the central and southern provinces (Eastham et al. 2008; IDE 2005).

\section{The expanding role of groundwater}

Increasing evidence suggests that a steady, 'quiet' groundwater revolution is taking place in many GMS countries, as has happened in South Asia in recent decades. It seems that farmers are increasingly turning to groundwater use, not only within the river valley and delta areas where access is generally easier and yields are more assured, but also in the upland areas (Molle et al. 2003; Mukherji et al. 2009; Johnston et al. 2009). Expansion of irrigation in the GMS has been fuelled by some of the Green Revolution technologies, including cheaper and more efficient pumps and reduced drilling costs.

Evidence of the growth in groundwater development comes from figures showing 800,000 pumps in operation in Vietnam, lifting surface water from rivers and groundwater from shallow alluvial aquifers (Shah 2009). Similarly, in Thailand, the number of pumps increased from 500,000 in 1985 to 3 million in 1999. Facon (2002) estimated that 280,000 tube wells were in use in the Makhamtao-Uthong canal irrigation area of the Chao Phraya Basin alone, and noted that an 'explosion' in groundwater use had occurred in the previous five years. Groundwater here is withdrawn from large-diameter dug wells sited in alluvial material using low-lift mechanical suction pumps mounted on two-wheeled tractors. Falling water tables in recent years have seen farmers lowering pump-sets down these wells to enable continued groundwater extraction.

Pump numbers have also shown similar increases in Cambodia where there are at least 25,000 community water-supply and large-diameter motorized tube wells used for irrigation. Around 2,000 manually operated shallow wells are being installed annually (WEPA n.d.b). Groundwater irrigation is known to take place in: Siem Reap, Battambang and Kampong Chhnang provinces of the Tonle Sap region; Kampong Cham Province of the Phnom Penh region; and Prey Veng, Svay Rieng, Takeo and Kandal provinces. An inventory of equipment in use in Prey Veng and Svay Rieng provinces in the southeast part of the country, revealed around 15,000 motorized, hand and treadle pumps in operation specifically for irrigation (IDE 2005). Shallow alluvial aquifers found around the Tonle Sap Lake and bordering the Mekong, Tonle Sap and Bassac rivers enable farmers to install shallow dug and tube wells to produce dry-season crops.

\section{Current problems}

Opportunities to expand agricultural groundwater use across much of the GMS are likely to be large, given that current levels of withdrawal are low compared to the high rates of recharge that replenish the shallow aquifers each wet season. The need to maintain a delicate balance between demand and supply underpins sustainable management of groundwater. Achieving sustainability comes through good governance that supports policies and practices based upon understanding availability and dynamics of the physical resource, patterns and trends of groundwater use, and the behavior and motivations of users. Wherever groundwater use for irrigation intensifies in an unregulated way, overdraft-related problems associated with declining water levels tend to follow, significantly increasing pumping costs incurred by farmers and placing stress on environmentally 
sensitive wetlands and waterways that rely heavily on inputs from groundwater during dry periods. In extreme cases, groundwater overexploitation dries out wells and causes water quality to deteriorate.

In Thailand, heavy use of groundwater as a substitute for surface water irrigation during the dry season has resulted in ongoing and continuous decline in groundwater levels in many areas. These include the major command areas in Phitsanulok, Sukhothai and Phichit provinces of the Chao Phraya, and the Chi River Basin in the northeast. Falling water tables in the central plains have sparked efforts to correct the groundwater balance through pilot-scale managed aquifer recharge (MAR) trials. These have been underway since 2009 (DGR 2011).

In the Central Highlands of Vietnam, a rapid expansion in groundwater irrigation for cash crops, predominantly thirsty coffee plantations, has reportedly resulted in the usual symptoms of overuse. Whether these impacts are local or at a broader scale is unclear, given that, at an aggregated scale, total annual abstraction amounts to just 1\% of the available resource (Pham Quy Nhan 2011).

In the Mekong Delta region, over-pumping for irrigation, industrial and domestic uses is resulting in falling groundwater levels and saltwater intrusion (IUCN 2011). In Cambodia, the recent rapid and unregulated growth of small-scale groundwater irrigation in some provinces has led to concerns about the sustainable limits of groundwater development. Anecdotal evidence suggesting that domestic water supply wells have been affected by nearby irrigation pumping (IDE 2005) has fuelled this debate.

\section{Pathways forward}

The recommendations which follow implicitly assume that there are large untapped groundwater reserves in the GMS that represent an important physical resource to mitigate the effects of climate change and variability, and that could contribute to achieving the Millennium Development Goals (MDGs). The authors propose that by adequately addressing key technical and governancerelated issues at this relatively early stage of development within the GMS, the major problems characteristic of more highly evolved groundwater economies such as India and China can be avoided.

A knowledge base, with access via a common platform and language, on which groundwater management plans for sustainable development could be formulated, is generally lacking across the GMS. Within the Mekong River Basin alone, there are four transboundary aquifers shared between neighboring countries (Zaisheng et al. 2010). It is likely that heightened cooperation of these shared resources will be needed as development pressures increase.

This report has identified numerous existing or emerging problems that have yet to be examined in detail, and from which many unanswered research questions arise. Technical studies are required on the nature and sustainability of groundwater resources, for example, and on natural and anthropogenic hazards that may limit uptake, such as contamination from arsenic or pollution. Innovative engineering approaches, including managed aquifer recharge to alleviate seasonal shortfalls and vertical drainage to address problems of waterlogging and salinization, will be needed to exploit the potential offered by groundwater resources. Better information is needed on the significance of groundwater irrigation to local and regional economies, the pace and patterns of growth of its use, and the potential for the resource to alleviate poverty. Formal and informal institutional arrangements to support and regulate groundwater use are also required; assessments of the suitability of participatory irrigation management (PIM) for small-scale groundwater-fed irrigation systems would be helpful in this regard. 


\section{PART 7: SYNTHESIS AND RECOMMENDATIONS}

Agroecosystems of the GMS can be described using six zones with broadly similar biophysical conditions and farming systems, though with local variants in each country and different levels of transition from traditional subsistence systems to more modernized, intensive production. Farming systems in the GMS fall into two distinct groups: those where inundated rice production predominates ('lowland' systems); and those where rice and a mix of other crops are grown under non-flooded, aerobic conditions ('upland' systems). Both systems exist in all AEZs depending on local topography. However, inundated rice systems generally predominate in the deltas and lowland plains, while upland systems are more widespread in the sloping uplands and highlands.

Throughout the GMS, annual rainfall is more than adequate to support rainfed cropping but the highly seasonal distribution, driven by the southwest monsoon, restricts the growing season to 6 or 8 months of the year. Producing a crop during the dry season requires some degree of water management. Crops are very vulnerable to shifts in the timing of rainfall, with the late onset or early cessation of wet-season rains affecting production in both wet and dry seasons. Production losses associated with drought are more commonly induced by short-term rainfall deficits within the wet season than by shortfalls in total annual rainfall. Meteorological drought tends to be localized, and rarely affects large areas in a single year. Hydrological drought, due to low flows in major rivers, can have widespread effects within each basin.

The distinction between irrigated and rainfed cropping in lowland systems is often blurred. Growing lowland rice intrinsically involves water management to maintain inundated conditions, but most of the wet-season crop is rainfed, in the sense that water comes mainly from rainfall, or from receding seasonal floods. However, supplementary irrigation is also common. Dry-season crops are planted just before or after the wet season to take advantage of rainwater coming at the start or end of that season, plus residual soil moisture. On average, more than half of crop water requirements for irrigated crops is derived from rainfall. Because of the importance of floodrecession agriculture, water levels in the major rivers are as important to rainfed cropping as to irrigated production. Hydrological drought, caused by the seasonal flood being reduced in extent, can be as important for rainfed crops as local rainfall deficits.

Analyzing the suitability of a range of major crops for rainfed cultivation emphasizes the critical importance of water management in regional production, since most crops are constrained in terms of rainfall. Indica-type paddy rice, the region's major crop, is highly sensitive to water availability and suitable for cultivation only with careful water management. While highly productive lowland rice systems are possible where water supply is assured throughout the season, there are many marginal rainfed lowland-rice systems where farmers face a high risk of having insufficient water for a good yield. Other important crops, including maize, sugarcane and, to a lesser extent, cassava, are only marginally suitable in terms of precipitation, indicating high-production risks and the need to assure water for the crop through good soil water management and supplementary irrigation. The analysis highlights risks involved in the rapid spread of rubber and coffee as plantation crops in the region, since both have significant constraints in terms of both temperature and rainfall requirements, and are not suitable over wide areas.

There is significant variation in productivity from different farming systems, reflected in differences in yield across AEZs and between countries. Gains in yield across a range of crops over the last 20 years have come about through adequate water management, improved varieties and better agronomic practices. The largest yield gaps are in two areas. The first is where lowland rice is cultivated in traditional wet-season paddy systems on the lowland plains of Cambodia, northeast Thailand, Lao PDR and Myanmar. Here, yields of 2-3 t/ha lag far behind those achieved in the 
deltas, particularly in Vietnam, through a shift to fully or partially irrigated dry-season production using high-yielding varieties. Yields achieved through this type of cultivation reach 5-6 t/ha. Despite this transition being possible on the lowland plains, the cultivation of dry-season rice has not been adopted here, even where irrigation infrastructure is available. This is attributed to a range of causes, including low profits attainable from dry-season rice, farmer preference for other dry-season crops, water shortages and inappropriate or poorly managed irrigation infrastructure.

The second major yield gap occurs in the uplands, across a range of crop types. Upland rice crops, grown under aerobic conditions have lower potential yields than inundated rice in lowland systems. However, very significant gains in yield have been made in Yunnan by farmers cultivating aerobic rice varieties combining upland drought-resistance with lowland high-yields, using integrated agronomic practices including partial irrigation. Large increases in productivity are also possible through a shift to montane paddy where suitable land is available, or can be created through terracing. Yields of non-rice crops are also low across most of this AEZ, reflecting difficult agricultural conditions on sloping lands with poor soils.

Water management is a critical first step in improving yields; when water-related risks are reduced, farmers are more willing to invest in other yield-increasing strategies. A wide range of technologies and approaches have been developed to help farmers manage water better in agricultural systems. These range from simple mulching to reduce evaporative losses, to handling soils in ways that reduces erosion, retains or boosts organic matter, or improves waterholding capacity and helps plants source water and nutrients, through to full irrigation. There is a continuum between rainfed and irrigated systems: the aim of AWM is to make best use of rain where it falls, and find ways to supplement deficits. A more useful distinction is made between different scales of water management interventions: farm; community; and larger scale. Past investments in large-scale irrigation have not always brought expected gains in yield. For example, Thailand has the highest level of irrigation infrastructure development in the region but the lowest rice yields (but with stable production and high revenues). It is important to work across scales to identify where gains in production can be made most effectively. Collective small-scale interventions may be able to achieve similar outcomes to large-scale projects, but with lower costs and greater ownership and involvement. PIM is an example of cross-scale management.

AWM interventions fall into three broad classes: measures to reduce water use or demand onfarm; measures to control and/or increase water supply, including but not only based on irrigation; and enabling or accompanying measures. Combinations of different approaches are always required. Productivity is not only about increasing yields from single crops. Water management interventions might not specifically be aimed at improving yields, but towards diversification that will improve overall production and revenues by providing biological and economic resilience.

Successful water management is dependent on the specific condition of each field and farmer. Therefore, identifying appropriate management interventions must be done in context, directed by farming system, physical environment, socioeconomic and cultural factors, and community dynamics. Working in India and Africa, the AWM Solutions project has developed strategies to assess the technological, biophysical, social and institutional landscape in which AWM solutions operate and enabling practitioners to understand the opportunities, constraints and impacts of their use. The emphasis is on in-depth consultation with local stakeholders, so planners understand the natural, physical, human, social and financial assets, and the varying livelihood strategies of individuals in the region. They can use this knowledge to identify where AWM is an entry point for improving livelihoods and consider the constraints to changing water management. This approach could be applied directly in the GMS context. 
Water is inextricably linked to larger landscape processes. Therefore, the cumulative effects of multiple small-scale interventions and land-use decisions can have significant impacts on the way that water is transmitted and retained at catchment scales. AWM interventions should be seen in the context of improving the overall capacity of a landscape to provide water storage, stabilizing and increasing production and water buffers, and improving resilience to climate variability.

Groundwater use for agriculture in the GMS is currently limited, accounting for less than $10 \%$ of total irrigated areas. However, this varies widely across the region and official statistics may not represent the real situation. There has been a rapid expansion in the number of small pumps in use over the last 10 or 20 years, suggesting that farmers are increasingly using groundwater, not only within the river valley and delta areas but also in the uplands. Groundwater provides significant advantages over formal surface water irrigation systems in terms of flexibility and lower infrastructure costs. The potential for expanding groundwater use is high, particularly in the large alluvial systems of the region's major rivers, where the annual flood replenishes 'underground natural irrigation systems'. In some systems, there are options for enhancing groundwater availability through managed aquifer recharge. A comprehensive assessment of the opportunities for, and barriers to, increased groundwater use is a high priority for the region.

A strong defining feature of agricultural systems in the region is the rapid pace of change, driven by a complex mix of large-scale forces and unplanned individual land-use choices. For example, in upland Lao PDR, farmers shift rapidly to large-scale planting of maize or rubber in response to external buyers, and a few years later shift again. A common perception is that these changes occur over large areas of land in very short time frames, but neither the proportion of the population engaged in these activities nor the social or environmental impacts are well understood. In this context, land-use planning has a hard time keeping up with unplanned changes. In Vietnam, these gyrations have been stabilized; cross-country sharing of its experiences could be beneficial to other nations. Resettlement schemes, mining, establishing commercial plantations and constructing hydropower dams also change the conditions and landscapes within which people attempt to secure their livelihoods. Given that farmers often need to shift rapidly in response to external forces, and adjust to new environments and conditions, developing the capacity of populations to adapt and building supporting institutions are high priorities. Discussions of sustainability need to encompass how landscapes can function as a whole while supporting a variety of cropping and farming systems. The focus must, therefore, be on nurturing fundamental ecosystem services that support agricultural production, such as soil fertility, nutrient cycling, water cycling and pollination services, rather than simply assessing the potential for individual crops.

To illustrate the range of issues inherent in identifying and implementing AWM interventions in different systems, six case studies were presented, as follows:

- Northeast Thailand: small farm ponds offer an effective way to store water from the rainy season for supplementary irrigation of crops during dry spells or in the dry season. Ponds also provide water for domestic uses, rearing livestock and supporting fish. Homesteads with ponds had higher and more diversified incomes than those without ponds. Ponds can provide additional income and a buffer against drought. They can also contribute to local recharge and help to maintain water levels in adjacent paddy fields.

- Hoa Binh, Vietnam: an integrated set of conservation agriculture measures, including water management, were introduced to combat erosion, improve water supply and increase incomes in sloping upland farming systems in northwest Vietnam. Measures included: constructing small ponds, bunds and terraces; digging percolation pits and tanks; 
planting vegetation strips; green manure; plastic mulches; improved cultivars; and using micronutrients and Rhizobia. Farmers reported significant yield increases and more reliable water availability, allowing them to diversify crop types, which further increased income. Soil erosion and runoff were also reduced.

- Chamnar Krom, Tonle Sap: small reservoirs were built by private entrepreneurs on the Tonle Sap Floodplain to provide dry-season irrigation for rice. The reservoirs disrupted flow and fish migration on the floodplain, and affected flooded forests and grasslands. They also engendered community conflicts through inequity of access. The cumulative impacts from 30 reservoirs were of sufficient concern that the government ordered removal of the structures in 2010. The case study illustrates the importance of understanding linkages between sectors and scales, and the need to find a shared vision for managing commonpool resources and to protect ecosystem services.

- Yunnan: drought has affected parts of Yunnan in 13 of the last 24 years, with particularly severe impacts in 2009 and 2010. In these years, more than 80\% of food crops were affected, and 10 million people and 5 million head of livestock had insufficient drinking water. Policies giving precedence to urban and hydropower demands exacerbated rural shortages. Proposed responses are at a range of scales, from field-level efforts to diversifying crops and converting paddy to upland crops; to farmer insurance; to proposals for purpose-built reservoirs (separate from hydropower developments).

- Svay Rieng: use of tube wells to pump shallow groundwater as supplementary irrigation for recession rice has been successful in safeguarding crops during dry spells and raising yields in Svay Rieng, and also allows more flexibility in the planting date. This has been an important consideration in years with severe insect pest attacks. Groundwater is replenished by the annual flood, and there is potential to increase the extent of pumping. However, the costs of pumping (by diesel) are high, and returns are marginal unless the price of rice is high. There are also concerns about water quality (iron (Fe), manganese ( $\mathrm{Mn})$ and arsenic (As)) and the potential for increased use of groundwater for irrigation to conflict with its established widespread use for domestic supply.

- Luang Prabang: yields from upland rice in shifting cultivation systems have declined as fallow periods have decreased with population growth. In response, some farmers are switching to produce montane paddy rice in terraced uplands. Terraces have high labor costs to establish, but annual yields of montane paddy are 2 to 3 times higher, annual labor inputs smaller and freed-up upland plots can be used for cash crops, so that set-up costs are recouped within about four years. Building terraces can relieve pressure on upland systems. One hectare of terraced paddy rice can produce the equivalent of 7 ha or more of upland rice, depending on the fallow-cropping cycle of the upland rice. This can be further increased if a second lowland rice crop can be grown, although in many cases the supplementary water is more effectively used on a high-value crop that requires less water.

\section{Priority areas for regional interventions in rainfed agriculture}

Improvements in agricultural water management are an important entry point for improving crop yields and farm productivity. A wide range of AWM interventions are available, ranging from onfarm agronomic measures to catchment-scale technologies for enhancing water supply (Table 7.1). 


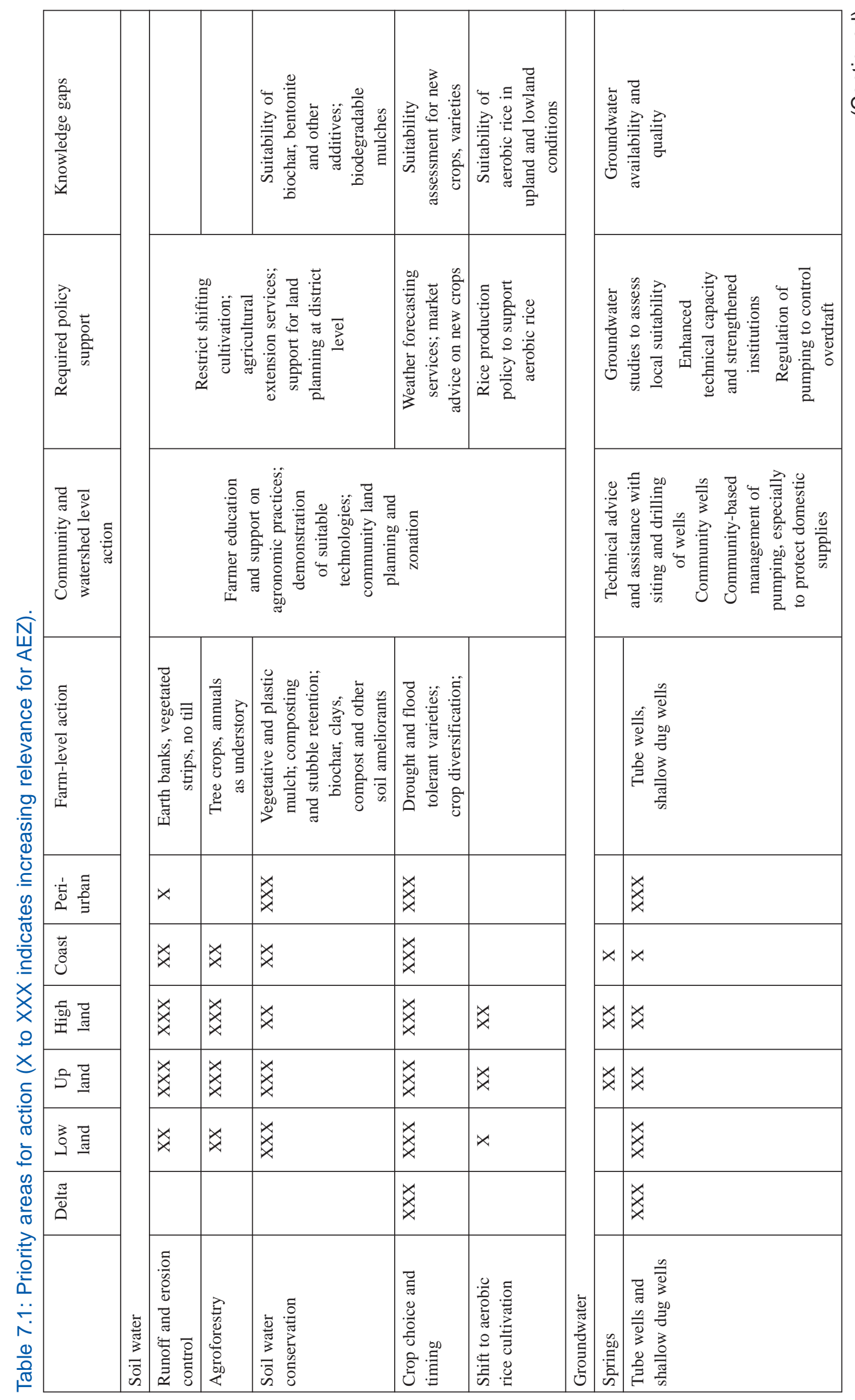




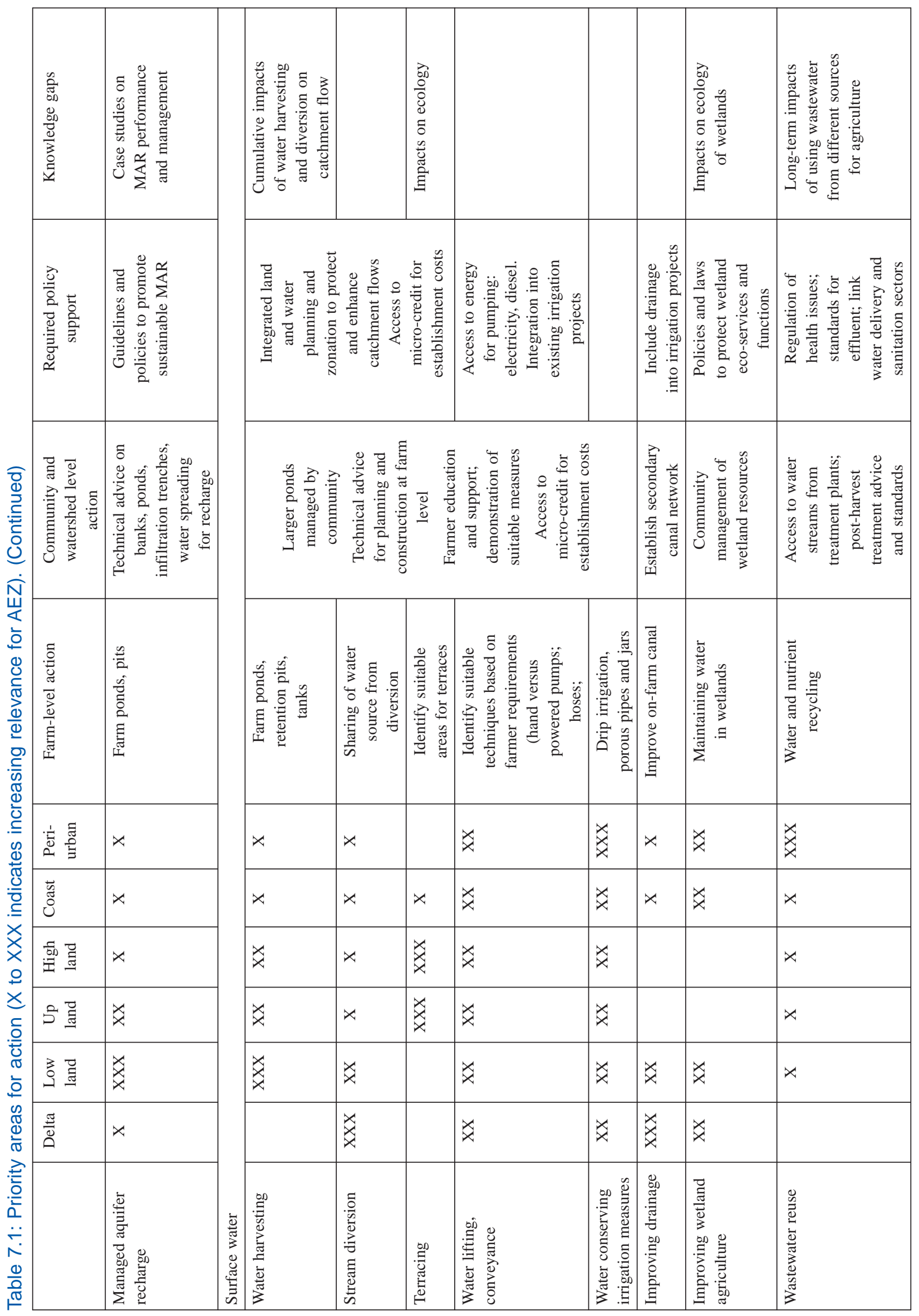


Interventions for AWM are, by their nature, specific to local conditions and context. In any system, a diverse range of measures may be needed to address issues at different scales, and to provide farmers with flexibility in terms of cost and production systems. While many measures will be implemented on-farm, supporting actions may be required at community or watershed level, and appropriate policies and institutions are also necessary. Table 7.1 outlines some of the main groups of interventions that may be appropriate for each agroecological zone. However, an analysis of farming systems and livelihood assets of local people must be the starting point for any AWM program.

At the regional scale, we have identified three priority areas to move AWM forward:

- A regional situation analysis for AWM interventions in the GMS, based on the approach developed in Africa and South Asia under the AWM Solutions project.

- An assessment of options for different modes of irrigation development in the lowland plains of Cambodia, Myanmar and Lao PDR, as a precursor to large proposed investments.

- Development of methods for landscape planning at watershed scale, to optimize integration of water management with agronomic practices and livelihood strategies.

Integrated assessment of alternative modes of irrigation in the lowland plains

The lowland plains of Cambodia, Lao PDR, northeast Thailand and Myanmar have been identified as being prospective areas for developing large-scale irrigation schemes to increase dry-season cropping, improve production, reduce poverty and increase food security. These areas all host a large component of national production. However, they have significant yield gaps for lowland rice, as well as for crops including maize and sugarcane that are grown, either rainfed or partially irrigated, during the dry season. In all three countries, there is the potential to open up significant new tracts of land (see Johnston et al. 2009), with interest in developing commercial plantations for a range of crops, including rubber, oil palm, cassava and sugarcane, particularly if water supplies could be assured.

Large investments in irrigation have been proposed. In Cambodia, ambitious plans for irrigation development have been outlined, with 26 projects and over USD 1 billion in investment being officially approved by the Royal Cambodian Government over the next five years (Thuon and Bastakoti 2010). Many of these proposed projects are in the lowland plains surrounding Tonle Sap. For example, a loan of USD 546 million has been offered from Kuwait for building an irrigation dam on the Stung Sen (The Economist 2009). Meanwhile Chinese loans have been proposed for Myanmar to construct joint hydropower and irrigation infrastructure to expand irrigation in the dry zone around Mandalay (IRN 2009).

Past developments of large-scale irrigation in these areas have had mixed success. In Cambodia, the majority of irrigation schemes in the inland plains around Tonle Sap are mainly used to supplement irrigation of wet- season rice. Thuon and Bastakoti (2010) report that, based on data available from a total of 2,525 irrigation schemes in Cambodia, only $6 \%$ are considered as 'functioning well', while 32\% are 'partly functioning' and 62\% are 'not functioning'. In Myanmar, intensity of use in large irrigation schemes in the Dry Zone is generally sub-optimal. For example, the Sedawgyi Dam project runs at $61 \%$ of its total command area, with the remaining area used for rainfed agriculture (UNDP 2006). This mirrors the experience in northeast Thailand (Nesbitt 2002; Molle and Floch 2008). Inappropriate infrastructure, a lack of farmer knowledge of dry-season cultivation techniques, other labor opportunities in the dry season from seasonal migration to the cities, plus operating and maintenance problems have contributed to the low uptake of dry-season irrigation in the region. Before investments are made in formal large-scale irrigation schemes, a thorough assessment of other options should be made. 
In all these areas there is potential to develop small-scale irrigation without needing to construct large storage facilities. Potential for groundwater use is considerable; all are situated on large floodplains with deep alluvial sequences and shallow aquifers linked to the river. The feasibility of groundwater pumping for irrigation on the Savannakhet Plain is currently being tested (Hirosmasa Hamada, IWMI, Southeast Asia, pers. comm.). In Myanmar, large groundwater reserves have been identified in the plains of Sagaing province (UNDP 2006). There is also the potential to use small-scale storages such as farm and community ponds. Climate and topography are comparable to northeast Thailand, where farm ponds have been very successful in improving farm incomes and diversifying production. Lacombe et al. (2005) point out that there can be synergies between farm ponds and groundwater, as ponds can enhance recharge and conversely, groundwater can fill ponds. Moreover, shallow groundwater stores are retained longer in the dry season as they are not subject to evaporative losses.

An important aspect when using groundwater or on-farm storages is that water is available on site and on demand for the farmer. This is important in two regards. First, it allows a high degree of flexibility, so that farmers can choose the crop type and scheduling, allowing diversification. One reason cited for the low-level use of formal irrigation schemes in Cambodia is that the systems are designed for inundated rice production with high water demand and cannot provide sufficient flexibility in water supply for farmers to produce other crops, such as upland cash crops or ricefish systems. Second, it means that costs for public infrastructure are minimized. Aquifers act as both storage and transmission conduits, removing the need for reservoirs, canals and associated construction, plus operation and maintenance costs, which are usually borne by the government or donors. However, groundwater pumping costs, if met entirely by the farmer, can be prohibitively high. A comparative assessment of the full costs and benefits of formal versus informal irrigation schemes, including analysis of infrastructure and O\&M costs, is needed before decisions are made regarding investment in large infrastructure. Such an assessment could be the starting point for exploring mechanisms to use public savings from large-scale infrastructure to offset on-farm costs for small-scale developments.

An integrated assessment of options for irrigation development in the lowland plains in Cambodia, Myanmar and Lao PDR would need to examine:

- farming systems in each area to define potential irrigation demands, including an assessment of dry-season versus wet-season demands;

- the importance of rice-fish systems, and the feasibility of maintaining rice-field fish production;

- groundwater potential and sustainable yields based on hydrogeological studies;

- the feasibility of farm or community ponds, based on hydrological and soil analyses;

- institutional arrangements needed to enable different modes of irrigation development;

- comparative economic cost-benefits for proposed large-scale irrigation developments and small-scale alternatives; and

- potential synergies between developments at different scales and conjunctive surface water and groundwater use. 


\section{Landscape planning in uplands}

Degradation of, and low productivity from, the uplands of the GMS have been the focus of much concern and study over the last 20 years. A range of management options and approaches have been proposed and trialed, including: agroforestry; conservation agriculture to reduce erosion; changes in livestock management, such as cut-and-carry and improved fodder systems to protect vegetation; improvements in upland rice cultivation; terracing for montane paddy; and smallscale water management including weirs, ponds and diversion of streams for valley irrigation. Many of these approaches have had considerable success in improving production at field level, and governments and donor agencies are seeking ways to 'scale up and scale out' such projects so they can effect changes over larger areas. In these areas, large-scale unplanned developments and changes to farming systems are also occurring in response to external drivers, and even as unintended consequences of policy. It is important to understand that changes from large-scale 'scale out', both planned and unplanned, are not limited to field-level shifts multiplied over the landscape but can alter how the landscape functions as a whole. Ideally, these interventions would add up to more than the sum of their parts. To quote Steenbergen et al. (2011):

"What is important is the entire transformation of landscapes: not piecemeal interventions that do not add up. If landscapes are transformed at scale, many processes change with it: the hydrology, the sedimentation processes, the micro-climates, the soil chemistry and nutrient cycle and the regeneration of vegetation cover. ... Most importantly, with scale comes the transformation of lives and economies."

Making transformations at a landscape scale involves managing the links between land use and the way water moves through the landscape. Steenbergen et al. (2011) describe this in terms of water 'buffers'; areas where water can be stored and retained. Buffers operate at a range of scales from soil moisture to deep aquifers, linked by climate, hydrogeology (infiltration zones, deep aquifers, interaction with rivers), slope and soil condition (infiltration capacity) and land cover. Improvements to how water is retained and recharged can be achieved in different parts of the landscape using varying techniques. There are opportunities to work with existing programs that promote and demonstrate land conservation approaches, but move the focus from field to landscape scale, by taking account of cumulative impacts and interactions. Assessments of land suitability and landscape inventories can be extended to map water retention and recharge zones, and identify priority areas for applying AWM. Meanwhile, planners can use hydrological and water-balance modeling to assess the cumulative impacts of small-scale changes at catchment scale.

Just as AWM interventions are suitable for, and have varying impacts on, different niches in the biophysical landscape, they are also suitable for, and have varying impacts on, different niches in the social and livelihood landscape. Scenarios can assess trends and encompass the cumulative impact of a variety of land-use choices and AWM interventions on water cycles, soil nutrients and livelihoods at these larger scales. This type of project could build on, and complement, current initiatives in land-resource assessment and planning. These include the major investment in agro-biodiversity in Lao PDR by the Swiss Agency for Development and Cooporation (SDC), the Agrobiodiversity Initiative, and an initiative promoting waterwheels as a low-cost poverty alleviation technology by CARE. The work requires a combination of quantitative and qualitative scenario building and modeling improving the evidence base not only on environmental (water, land, biodiversity) impacts at larger scales but also on how changes will affect livelihood options now and as played out into possible futures. 


\section{AWM Situation Analysis for the GMS}

The AWM Solutions project led by IWMI has developed an approach for making comprehensive situation analyses, and developing evidence-based recommendations, for small-scale water interventions to find water-related measures that can improve the productivity of rainfed agriculture. The aim is to assess the agroecological, socioeconomic, technological and institutional context for interventions, to find ways to leverage water most effectively within given livelihood systems. The situation analysis is usually carried out by collecting and examining national data, and consulting stakeholders through participatory mapping workshops involving national experts from different fields. The situation analysis for each country has the following components:

- Mapping livelihood zones, based on farming systems and rural livelihood strategies, to identify the main needs and constraints. These zones are mapped as relatively homogeneous geographical areas in terms of natural resources, agro-climate and socioeconomic conditions.

- Producing maps of areas where there is potential for AWM to improve livelihoods. This involves studying the physical availability of surface water and groundwater resources and identifying areas with the highest need, using population and poverty maps, plus local knowledge, to identify areas where lack of water management is a major constraint.

- Identifying specific AWM solutions and mapping the geographical area where these are likely to have the highest impact on livelihoods.

- Estimating the potential benefits of investing in AWM, in terms of the likely number of beneficiaries and application area.

The approach has been developed and tested in Africa and South Asia, and is directly applicable to the GMS. Given the similarity in farming systems across the GMS, a regional rather than a national approach is warranted, with the potential to capitalize on experience across national borders. The situation analysis provides the basis for identifying promising case studies and demonstration sites for on-the-ground implementation at both field and watershed level. Estimating the potential benefits and beneficiaries can contribute to preparing business cases for investment by donors and private sector investors. Examples of the approach can be found on the AWM Solutions website (http://awm-solutions.iwmi.org/). FAO, with support from the US Department of State, is currently examining the feasibility of this approach in Asia (G. Santini, FAO, pers. comm.). 


\section{REFERENCES}

Adamson, P.; Bird. J. 2010. The Mekong: A drought-prone tropical environment? International Journal of Water Resources Development 26(4): 579-594.

ACIAR (Australian Centre for International Agricultural Research). 2011. Weather forecasts for Indian farmers. Available at http://aciar.gov.au/node/13541 (accessed on February 8, 2012).

ADB (Asian Development Bank). 2009. The economics of climate change in Southeast Asia: A regional review. Manila, Philippines: ADB. Available at www.adb.org/Documents/Books/Economics-Climate-Change-SEA/PDF/EconomicsClimate-Change.pdf (accessed on January 23, 2012).

ADB. 2010. Greater Mekong Subregion. Available at www.adb.org/GMS/ (accessed on January 23, 2012).

AgWater Solutions Project. 2011. Available at http://awm-solutions.iwmi.org/ (accessed in May, 2011).

Balzer, N.; Hess, U. 2010. Climate change and weather risk management: Evidence from index-based insurance schemes in China and Ethiopia. Chapter 8 in Revolution: From food aid to food assistance - Innovations in overcoming hunger, (eds.), Omamo, S.W.; Gentilini, U.; Sandström, S. Rome: World Food Programme. Available at http:// documents.wfp.org/stellent/groups/public/documents/newsroom/wfp225958.pdf (accessed on January 23, 2012).

Bangkok Post. 2011. Rice pledging - a recurring corruption nightmare. September 24, 2011. Available at http://www. bangkokpost.com/news/local/258042/rice-pledging---a-recurring-corruption-nightmare (accessed on March 30, 2012).

Bank of Thailand. 2005. The Inflation Report - January 2005. Bangkok, Thailand: Bank of Thailand. Available at http:// www.bot.or.th/English/MonetaryPolicy/Inflation/Download/Doc_LibInflation\%20Report/5.1.1full_eng.pdf (accessed on January 23, 2011).

Banterng, P.; Hoogenboom, G.; Singh, P.; Pathak, P.; Wani, S.P.; Patanothai, A.; Tongpoonpol, S.; Atichart, S.; Srihaban, P. 2008. Quantifying Yield Gaps and Abiotic Stresses in Rain-fed Production Systems of Thailand. Global Theme on Agroecosystems Report no. 45. Patancheru 502 324, Andhra Pradesh, India: International Crops Research Institute for the Semi-Arid Tropics. $36 \mathrm{pp}$.

Barclay, A. 2009. Scuba rice: Stemming the tide in flood-prone South Asia. Rice Today 8(2): 26-31. http://beta.irri.org/ news/images/stories/ricetoday/8-2/SCIENCE_Scuba_rice.pdf (accessed on February 8, 2012).

Bejranonda, W.; Koontanakulvong, S.; Koch, M.; Suthidhummajit, C. 2006. Groundwater modeling for conjunctive use patterns investigation in the Upper Central Plain of Thailand. In.. 12p. International Symposium Darcy 2006 - Aquifers Systems Management, May 30-June 1, 2006, Dijon, France

Boochabun, K.; Tych, W.; Chappell, N.A.; Carling, P.A.; Lorsirirat, K.; Pa-Obsaeng, S. 2004. Statistical modelling of rainfall and river flow in Thailand. Journal of the Geological Society of India 64: 503-515.

CA (Comprehensive Assessment of Water Management in Agriculture). 2007. Water for food, water for life: A comprehensive assessment of water management in agriculture. London: Earthscan; Colombo: International Water Management Institute.

Caizhen, L. 2010. Coping, adaptation and vulnerability to drought in Yunnan, China, In: ICID 2010 - Second International Conference on Climate, Sustainability and Development in Semi-arid Regions, August 16-20, 2010, Ceará Convention Center, Fortaleza, Ceara, Brazil.

Chan, K.Y.; Van Zwieten, L.; Meszaros, I.; Downie, A.; Joseph, S. 2007. Agronomic values of greenwaste biochar as a soil amendment. Soil Research 45(8): 629-634.

Cheesman, J.; Bennett, J.W. 2005. Natural resources, institutions and livelihoods in Dak Lak, Vietnam. Managing Groundwater Access in the Central Highlands of Vietnam: Working Paper No. 1. Australian Centre for International Agricultural Research (ACIAR) Project: ADP/2002/015. Canberra: The Australian National University.

Chuc, N.T.; Singh, P.; Srinivas, K.; Ramakrishna, A.; Chinh, N.T.; Thang, N.V.; Wani, S.P.; Long, T.D. 2006. Yield gap analysis of major rainfed crops of northern Vietnam using simulation modeling. Global Theme on Agroecosystems Report No. 26. Andhra Pradesh, India: International Crops Research Institute for the Semi-Arid Tropics (ICRISAT).

CIAP (Cambodia-IRRI-Australia Project). 1999. Cambodia-IRRI-Australia Project annual research report. Phnom Penh, Cambodia: CIAP, 178p.

CURE (Consortium for Unfavorable Rice Environments). 2009. Activities of CURE in Cambodia. Unpublished report compiled for USAID.

DAE (Department of Agricultural Extension). 2010. Agro-ecosystem analysis, Chmnar Krom Commune - CAEA Report. Phnom Penh, Cambodia: Department of Agricultural Extension. 
DAP (Department of Agricultural Planning). 2011. Myanmar Agriculture in Brief. Nay Pyi Taw, Myanmar: Department of Agricultural Planning, Union of Myanmar.

Dapice, D.O.; Vallely, T.; Wilkinson, B. 2010. Revitalizing agriculture in Myanmar: Breaking down barriers, building a framework for growth. Report prepared for International Development Enterprises. Available at ash.harvard.edu/ extension/ash/docs/Myanmar.pdf (accessed on January 23, 2012).

Devendra, C.; Thomas, D. 2002. Smallholder farming systems in Asia. Agricultural Systems 71(1-2): 17-25.

DGR (Department of Groundwater Resources). 2011. Pilot study and experiment on Managed Aquifer Recharge using ponding system in the Lower North Region River Basin, Pitsanulok, Sukhothai, and Pichit provinces. Bangkok, Thailand: Department of Groundwater Resources Report.

Diepart, J.-C. 2010. Cambodian peasant's contribution to rural development: a perspective from Kampong Thom province. Biotechnol. Agron. Soc. Environ. 14(2), 321-340

Ding,S.; Pandey, S.; Chen, C.; Bhandari, H. 2005. Drought and farmers' coping strategies in poverty-afflicted rural China. Paper presented at conference on Social Protection for Chronic Poverty, Manchester, UK, February, 2005. Available at http://www.sed.manchester.ac.uk/research/events/conferences/documents/Social\%20Protection\%20 Papers/Ding.pdf (accessed in September, 2011).

Dobermann, A. 2004. A critical assessment of the system of rice intensification (SRI). Agricultural Systems 79(3): 261-281.

Eastham, J.; Mpelasoka, F.; Mainuddin, M.; Ticehurst, C.; Dyce, P.; Hodgson, G.; Ali, R.; Kirby, M. 2008. Mekong river basin water resources assessment: Impacts of climate change. Water for a Healthy Country National Research Flagships. Canberra, Australia: Commonwealth Scientific and Industrial Research Organisation (CSIRO). 153p.

Eriyagama, N.; Smakhtin, V.; Gamage, N. 2009. Mapping drought patterns and impacts: A global perspective. Colombo, Sri Lanka: International Water Management Institute. 31p. (IWMI Research Report 133).

Facon, T. 2002. Asian irrigation in transition - service orientation, institutional aspects and design/operation/infrastructure issues. Paper presented at the Conference on Asian Irrigation in Transition - Responding to the Challenges Ahead, April 22-23, 2002, Asian Institute of Technology, Bangkok, Thailand.

FAO (Food and Agriculture Organization of the United Nations). 1978. Report of the Agro-Ecological zones project. Volume 1. Methodology and results for Africa. World Soil Resources Report No. 48. Rome, Italy: FAO. 158p.

FAO. 2008. Digital agricultural atlas of the Union of Myanmar. Available at http://dwms.fao.org/atlases/myanmar/ index_en.htm (accessed on January 24, 2011).

FAO. 2011. FAOSTAT database. Available at http://faostat.fao.org (accessed on January 23, 2011).

Fischer, G.; Van Velthuizen, H.; Hizsnyik, E.; Wiberg, D. 2009. Potentially obtainable yields in the semi-arid tropics. Global Theme on Agroecosystems Report no. 54. Andhra Pradesh, India; International Crops Research Institute for the Semi-Arid Tropics (ICRISAT). 68p.

Foster, S. 2008. Thailand: Strengthening capacity in groundwater resources management. Case Profile Collection Number 1. Revised version. Sustainable Groundwater Mangement: Lessons from Practice. GW-MATE and the World Bank Report.

Franquin, P. 1969. Analyse agro-climatique en région tropicales saison pluvieuse et saison humide : Applications. Cahier ORSTOM, série biologique 9: 65-95.

Ge Sun; Guoyi Zhou; Zhiqiang Zhang; Xiaohua Wei; McNulty, S.G.; Vose, J.M. 2006. Potential water yield reduction due to forestation across China. Journal of Hydrology 328(3-4): 548-558.

Heisey, P.W.; Edmeades, G.O. 1999. Maize production in drought-stressed environments: Technical options and research resource allocation. Part 1 of CIMMYT 1997/98 World maize facts and trends; Maize production in drought-stressed environments: Technical options and research resource allocation. Mexico DF: International Maize and Wheat Improvement Center. 36p.

Hijmans, R.J.; Cameron, S.E.; Parra, J.L.; Jones, P.G.; Jarvis, A. 2005a. Very high resolution interpolated climate surfaces for global land areas. International Journal of Climatology 25: 1965-1978.

Hijmans, R.J.; Guarino, L.; Jarvis, A.; O’Brien, R.; Mathur, P.; Bussink, C.; Cruz, M.; Barrantes, I.; Rojas, E. 2005b. Diva-GIS version 5.2 manual. Available at http://www.diva-gis.org/docs/DIVA-GIS5_manual.pdf (accessed on January 24, 2012).

Hortle, K.G.; Troeung, R.; Lieng, S. 2008. Yield and value of the wild fishery of rice fields in Battambang Province, near the Tonle Sap Lake, Cambodia. MRC Technical Paper No. 18. Vientiane, Lao PDR: Mekong River Commission (MRC).

IBRD (International Bank for Reconstruction and Development) and WB (World Bank). 2005. Lao PDR environment monitor. Available at http://siteresources.worldbank.org/NEWS/Resources/report-en.pdf (accessed August 31, 2011) 
IDE (International Development Enterprises). 2005. Strategic study of groundwater resources in Prey Veng and Svay Rieng (Phase 1). Final Report. Seila Task Force Secretariat, Rural Poverty Reduction Project (IFAD Loan No.: 623-KH), Phnom Penh, Cambodia, December 23, 2005.

Independent Mon News Agency. 2011. Summer paddy project at Moulmein not fill. Available at http://monnews. org/?p=2229 (accessed on January 25, 2012)

Inman-Bamber, N.G.; Singels, A.; Muchow, R.C. 1998. A systems approach to benchmarking for sugarcane production in Australia and South Africa. Proceedings of the South African Sugarcane Technologists Association 72: 3-9.

IRN (International Rivers). 2009. Nu (Salween) River. Available at http://internationalrivers.org/en/china/nu-salween-river (accessed June, 2009).

IUCN (International Union for the Conservation of Nature). 2011. Groundwater in the Mekong Delta. Discussion Paper. 11p. Available at http://cmsdata.iucn.org/downloads/iucn__groundwater_in_mekong_delta_25_may_11_w.pdf (accessed on January 24, 2012).

Jennings, P. 2007. Rice revolutions in Latin America. International Rice Research Institute (IRRI). Rice Today 6(2): 38

Johnston, R.; Hoanh, C. T.; Lacombe, G.; Noble, A.; Smakhtin, V.; Suhardiman, D.; Kam Suan Pheng, Choo Poh Sze. 2009. Scoping study on natural resources and climate change in Southeast Asia with a focus on agriculture. Report prepared for the Swedish International Development Cooperation Agency (Sida). Vientiane, Lao PDR: International Water Management Institute, Southeast Asia (IWMI-SEA).

Kirby, M.; Mainuddin, M.; Eastham, J. 2010. Water-use accounts in CPWF basins: Simple water-use accounting of the Mekong Basin. CPWF Working Paper: Basin Focal Project series, BFP02. Colombo, Sri Lanka: The CGIAR Challenge Program on Water and Food (CPWF). 27pp.

Kokusai Kogyo Co. Ltd. 2002. The study on groundwater development in Southern Cambodia. Final Report, January 2002. Japan International Cooperation Agency, Ministry of Rural Development, Phnom Penh, Cambodia.

Kripalani, R.H.; Kulkarni, A. 1997. Rainfall variability over South-east Asia - connections with Indian monsoon and ENSO extremes : new perspectives. International Journal of Climatology 17: 1155-1168.

Kwanyuen, B. 2008. Comparative study of rainfall in the north of Thailand. Department of Irrigation Engineering. Faculty of Engineering, Kasetsart University, Thailand. Pp. 1-9. Available at http://std.cpc.ku.ac.th/delta/conf/ Acrobat/Papers_Eng/Volume\%201/Banchaa.pdf (accessed on March 30, 2012).

Lacombe, G.; Bousquet, F.; Kuper, M.; Boonmun, C.; Phupak, S.; Naivinit, W.; Vejpas, C.; Trébuil, G. 2005. How farmers can manage variability in the rice ecosystem of northeast Thailand: The contribution of agent based modelling. In: Proceedings of the 2005 International Conference on Simulation and Modelling, (eds.) Kachitivichyanukul, V.; Purintrapidan, U.; Utayopas, P., Bangkok, Thailand, January 17-19, 2005. 345-352 pp.

Lacombe, G.; Smakhtin, V.; Hoanh, C.T. Forthcoming. Rainfall trends in the Central Mekong Basin: 1953-2004. To be submitted to Theoretical and applied climatology in October 2011.

Lacombe, G.; Hoanh, C.T.; Smakhtin, V. 2012. Multi-year variability or unidirectional trends? Mapping long-term precipitation and temperature changes in continental Southeast Asia using PRECIS regional climate model. Climatic Change. Doi: 10.1007/s10584-011-0359-3.

Lacombe, G.; Cappelaere, B.; Leduc, C. 2008. Hydrological impact of water and soil conservation works in the Merguellil catchment of central Tunisia. Journal of Hydrology 359: 210-224.

Lao Department of Statistics. 2008. Lao expenditure and consumption survey 2007-2008. Vientiane, Lao PDR: Department of Statistics, Ministry of Planning and Investment.

Lefroy, R.; Collet, L.; Grovermann, C. 2010. Potential impacts of climate change on land use in the Lao PDR. Vientiane, Lao PDR: Deutsche Gesellschaft für Technische Zusammenarbeit (GTZ) GmbH. 77p.

Linquist, B.; Trösch, K.; Pandey, S.; Phouynyavong, K.; Guenat, D. 2007. Montane paddy rice: Development and effects on food security and livelihood activities of Highland Lao farmers. Mountain Research and Development 27(1): 40-47.

MAFF. 2009. Agricultural statistics. Available online at Ministry of Agriculture, Forestry and Fisheries, Cambodia.

Manton, M.J.; Della-Martin, P.M.; Haylock, M.R.; Hennessy, K.J.; Nicholls, N.; Chambers, L.E.; Collins, D.A.; Daw, G.; Finet, A.; Gunawan, D.; Inape, K.; Isobe, H.; Kestin, T.S.; Lefale, P.; Leyu, C.H.; Lwin, T.; Maitrepierre, L.; Ouprositwong, N.; Page, C.M.; Pahalad, J.; Plummer, N.; Salinger, M.J.; Suppiah R.; Tran, V.L.; Trewin, B.; Tibig, I.; Yee, D. 2001. Trends in extreme daily rainfall and temperature in Southeast Asia and the South Pacific: 1961-1998. International Journal of Climatology 21(3): 269-284. 
Markussen, T. 2008. Property rights, productivity, and common property resources: Insights from rural Cambodia. World Development 36(11): 2277-2296. Available at http://www.sciencedirect.com/science/article/pii/S0305750X0800171X (accessed on February 8, 2012).

McCartney, M.; Smakhtin, V. 2010. Water storage in an era of climate change: addressing the challenge of increasing rainfall variability. Blue paper. Colombo, Sri Lanka: International Water Management Institute (IWMI). 14p.

Mikhail, M.; Cambridge, H.; Cinderby, S.; de Bruin, A.; Stein, C. 2011. Opportunities for Agricultural Water Management interventions in the Nariarlé watershed in Burkina Faso. AWM Solutions Policy Brief. Stockholm, Sweden: Stockholm Environment Institute. Available at http://awm-solutions.iwmi.org/Data/Sites/3/Documents/PDF/ publication-outputs/learning-and-discussion-briefs/Nariarle\%20PB\%20110603.pdf (accessed on January 25, 2012).

Mitchell, T.D.; Jones, P.D. 2005. An improved method of constructing a database of monthly climate observations and associated high-resolution grids. International Journal of Climatology 25: 693-712.

Molden, D.; Awulachew, S.B.; Conniff, K.; Rebelo, L.-M.; Mohamed, Y.; Peden, D.; Kinyangi, J.; van Breugel, P.; Mukherji, A.; Cascao, A.; Notenbaert, A.; Demise, S.S.; Neguid, M.A.; el Naggar, G. 2009. Nile Basin Focal Project. Synthesis report. Colombo, Sri Lanka: CGIAR Challenge Program on Water and Food (CPWF). Available at http:// cgspace.cgiar.org/bitstream/handle/10568/3871/PN59_IWMI_Project\%20Report_Dec09_final.pdf?sequence=1 (accessed on April 2, 2012).

Molle, F.; Floch, P. 2008. Megaprojects and social and environmental changes: The case of the Thai "water grid". Ambio: A Journal of the Human Environment 37(3): 199-204.

Molle, F.; Shah, T.; Barker, R. 2003. The groundswell of pumps: Multilevel impacts of a silent revolution. Paper prepared for the ICID-Asia Meeting, Taiwan, November, 2003. 18p.

Mukherji, A.; Facon, T.; Burke, J.; de Fraiture, C.; Faurès, J.-M.; Füleki, B.; Giordano, M.; Molden, D.; Shah, T. 2009. Revitalizing Asia's irrigation: To sustainably meet tomorrow's food needs. Colombo, Sri Lanka: International Water Management Institute (IWMI); Rome, Italy: Food and Agriculture Organization of the United Nations (FAO).

Mula Rosana, P.; Wani, S.P.; Wangkahart, T.; Thang, N.V.; Supama, Y. 2007. Improved livelihood system of farm households through community watersheds learnings and insights from Thailand and Vietnam: Global Theme on Agroecosystems Report no. 38. Research Report. Andhra Pradesh, India: International Crops Research Institute for the Semi-Arid Tropics. 56p.

Naing, M.M. 2005. Paddy field irrigation systems in Myanmar. Proceedings of the Regional Workshop on the Future of Large Rice-based Irrigation Systems in Southeast Asia. Co-sponsored by Evaluation Study of Paddy Irrigation under Monsoon Regime (ESPIM) project funded by the Government of Japan, Ho Chi Minh City, Vietnam, October 26-28, 2005. pp. 120-130.

Nesbitt, H. 2002. Future trends in agricultural production. In: The MRC Basin Development Plan - Monographs. BDP Library Volume 11. Vientiane, Lao PDR: Mekong River Commission (MRC).

Nieto, J.D.; Cook, S.; Lundy, M.; Fisher, M.; Sanchez, D.; Guevara, E. 2010. A system of drought insurance for poverty alleviation in rural areas. CIAT Final Report. Cali, Colombia: International Center for Tropical Agriculture (CIAT).

Noble, A.D.; Suzuki, S. 2005. Improving the productivity of degraded cropping systems in Northeast Thailand: Improving farmer practices with innovative approaches. PAWEES 2005 International Conference, Kyoto, Japan, September 2005.

Pandey, S.; Bhandari, H.; Ding, S.; Prapertchob, P.; Sharan, R.; Naik, D.; Taunk, S.K.; Sastri, A. 2007. Coping with drought in rice farming in Asia: Insights from a cross-country comparative study. Agricultural Economics 37(Issue Supplement s1): 213-224.

Pandey, S. 2005. Land degradation in sloping uplands: Economic drivers and strategies for promoting sustainable land use. In: Sustainable Sloping Lands and Watershed Management Conference December 12-15, 2006, Luang Prabang, Lao PDR.

Pavelic, P.; Srisuk, K.; Saraphirom, P.; Nadee, P.; Pholkern, K.; Chusanathas, S.; Munyou, S.; Tangsutthinon, T.; Intarasut, T. Forthcoming. Balancing-out floods and droughts: Opportunities to utilize floodwater harvesting and groundwater storage for agricultural development in Thailand. Submitted to Water Resources Management.

Peng, S.; Cassman, K.G.; Virmani, S.S.; Sheehy, J.; Khush, G.S. 1999. Yield potential trends of tropical rice since the release of IR8 and the challenge of increasing rice yield potential. Crop Science 39: 1552-1559.

Penning de Vries, F.; Ruaysoongnern, S. 2010. Multiple sources of water for multiple purposes in Northeast Thailand. Colombo, Sri Lanka: International Water Management Institute. 37p. (IWMI Working Paper 137).

Penning de Vries, F.W.T.; Ruaysoongnern, S.; Bhumiwatana, S.W. 2005. The optimal size of farm ponds in N.E. Thailand with respect to farming style and multiple uses of water and under various biophysical and socio-economic conditions. CPWF-MUS Working Paper. Paper presented at the symposium "Management of Tropical Sandy Soils for Sustainable Agriculture," Khon Kaen, Thailand. 
Pham Quy Nhan. 2011. Groundwater resource in Vietnam: Status, problems and challenges. Proceedings of the Asia Pacific Water Forum (APWF) Regional Knowledge Hub for Groundwater Management, "Bringing a Groundwater Agenda to the Surface”, June 2-3, 2011, Bangkok, Thailand.

Phnom Penh Post. 2010. Kampong Thom reservoirs levelled. Available at http://www.phnompenhpost.com/index. php/2010062840096/National-news/kampongthom-reservoirs-levelled.html (accessed June, 2010).

Pixley, K.; Bänziger, M.; Córdova, H.; Crossa, J.; Dixon, J.; Kanampiu, F.; Srivastava, A.; Waddington, S.; Warburton, M. 2006. Past and future innovations in tropical maize improvement. Available at http://www.cgiar.org/pdf/Pixley\%20 and\%20others-Summary-Past\%20and\%20Future\%20Innovations\%20in\%20Tropical\%20Maize\%20Improvement.pdf

Qadir, M.; Wichelns, D.; Raschid-Sally, L.; McCornick, P.G.; Drechsel, P.; Bahri, A.; Minhas, P.S. 2010. The challenges of wastewater irrigation in developing countries. Agricultural Water Management 97(4): 561-568.

Rockström, J.; Hatibu, N.; Oweis, T.Y.; Wanj, S. 2007. Managing water in Rainfed agriculture. Chapter 8 in Water for food, water for life: A comprehensive assessment of water management in agriculture. Colombo: International Water Management Institute; London: Earthscan. Pp. 315-352.

Saito, K.; Linquist, L.; Keobualapha, B.; Phanthaboon, K.; Shiraiwa, T.; Horie, T. 2006. Cropping intensity and rainfall effects on upland rice yields in northern Laos. Plant and Soil 284(1-2): 175-185.

Shah, T. 2009. Taming the anarchy: Groundwater governance in South Asia. Washington, DC: Resources for the Future. 311p.

Shah, T.; Bhatt, S.; Shah. R.K.; Talati, J. 2008. Groundwater governance through electricity supply management: Assessing an innovative intervention in Gujarat, western India. Agricultural Water Management 95(11): 1233-1242.

Sharma, D.; Das Gupta, A.; Babel, M.S. 2006. Trends in extreme rainfall and temperature indices for two river basins of Thailand. Proceedings of the $3^{\text {rd }}$ Asia and Pacific Hydrology and Water Resources Conference, Bangkok, Thailand, October 16-18, 2006.

Siebert, S.; Burke, J.; Faures, J.M.; Frenken, K.; Hoogeveen, J.; Döll, P.; Portmann, F.T. 2010. Groundwater use for irrigation - a global inventory. Hydrology and Earth System Sciences Discussions 7: 3977-4021.

Singh, P.; Aggarwal, P.K.; Bhatia, V.S.; Murty, M.V.R.; Pala, M.; Oweis, T.; Benli, B.; Roa, K.P.C.; Wani, S.P. 2009. Yield gap analysis: Modelling of achievable yields at farm level. Chapter 6 in Rainfed agriculture: Unlocking the potential. Comprehensive Assessment of Water Management in Agriculture Series. Volume 7. Wallingford, UK: CABI International.

Snidvongs, A.; Choowaew, S.; Chinvanno, S. 2003. Impact of climate change on water and wetland resources in Mekong river basin: Directions for preparedness and action. Change 12: 1-54.

So Nam. 2009. Fisheries resources in Cambodia - Current status, key issues, directions. Presentation to USAID team at Inland Fisheries Research and Development Institute (IFReDI), October 2009, Phnom Penh, Cambodia.

Steenbergen, F. van; Tuinhof A.; Knoop, L. 2011. Transforming landscapes transforming lives. The Business of Sustainable Water Buffer Management. Wageningen, the Netherlands: 3R Water Secretariat.

The Economist. 2009. Petrodollars v smallholders. Available at http://www.economist.com/world/asia/displaystory. cfm?story_id=1352798723 April 2009 (accessed in April, 2009).

Thuon, T.; Bastakoti, R.C. 2010. Localizing development and irrigation management system in Cambodia. In: Water governance in Practice: Evidence from local studies in the Mekong Region, (eds.) Bastakoti, R.C.; Floch, P.; Manorom, K.; Lu, X.; Singh, B.T. Selangor, Malaysia: Strategic Information and Research Development Centre (SIRD).

Thuon, T. 2011. Summary notes from Svay Rieng, February-March, 2010. Unpublished report for International Water Management Institute (IWMI).

Tipraqsa, P.; Craswell, E.T.; Noble, A.D.; Smidt-Vogt, D. 2007. Resource integration for multiple benefits: Multi-functionality of integrated farming systems in N.E. Thailand. Agricultural Systems 94(3): 694-703.

Tran, D. 2004. Rice and narrowing the yield gap. FAO Factsheet 5. Rome, Italy: Food and Agriculture Organization of the United Nations. Available at http://www.fao.org/rice2004/en/f-sheet/factsheet5.pdf (accessed in August, 2011).

UNDP (United Nations Development Programme). 2006. Myanmar agricultural sector review and investment strategy. Volume 1 - sector review. United Nations Development Programme http://www.mm.undp.org/UNDP_Publication_ PDF/ASR\%20Vol.1\%20Sector\%20Review.pdf (accessed on March 30, 2012).

UNEP (United Nations Environment Programme) and TEI (Thailand Environment Institute). 2007. Greater Mekong environment outlook 2007. Bangkok, Thailand: United Nations Environment Programme (UNEP); Thailand Environment Institute (TEI). 122p.

Uphoff, N.; Kassam, A.; Harwood, R. 2011. SRI as a methodology for raising crop and water productivity: Productive adaptations in rice agronomy and irrigation water management. Paddy and Water Environment 9(1): 3-11. 
Valentin, C.; Agus, F.; Alamban, R.; Boosaner, A.; Bricquet, J.P.; Chaplot, V.; de Guzman, T.; de Rouw, A.; Janeau, J.L.; Orange, D.; Phachomphonh, K.; Do Duy Phai; Podwojewski P.; Ribolzi. O.; Silvera, N.; Subagyono, K.; Thiébaux, J.P.; Tran Duc Toan; Vadari, T. 2008. Runoff and sediment losses from 27 upland catchments in Southeast Asia: Impact of rapid land use changes and conservation practices. Agriculture, Ecosystems \& Environment 128(4): 225-238.

VN GSO (General Statistical Office of Vietnam). 2011. Agricultural statistics for Vietnam. Data translated and provided by Soils and Fertilizers Research Institute (SFRI), Vietnam. Available at http://www.gso.gov.vn/ (accessed on March 20, 2012).

Visvanathan, C.; Shapkota, P. 2006. Water reuse potentials in Thailand. Thailand: Environmental Engineering and Management, Asian Institute of Technology. Available at http://www.faculty.ait.ac.th/visu/Prof\%20Visu\%27s\%20 CV/Conferance/14/Sacwet.Visu,Shapkota_WW-Reuse.pdf (accessed on January 24, 2012).

Wangkahart, T.; Pathak, P.; Wani, S. P.; Toomsan, B.; Idhipong, S.; Chauchin, S.; Seehaban, P.; Chueychoom, P. 2006. Sustainable agricultural productivity through farm pond option in the integrated watershed management of Northeast Thailand. Proceedings of the Conference on Sustainable Sloping Lands and Watershed Management, December 12-15, 2006, Luang Prabang, Lao PDR. Pp. 246 - 261.

Wani, S.P.; Sreedevi, T.K.; Rockström, J.; Ramakrishna, Y.S. 2009. Rainfed agriculture - past trends and future prospects. Chapter 1 in Wani, P.; Rockstrom, J.; Oweis, T. (eds), Rainfed agriculture: Unlocking the potential. Comprehensive Assessment of Water Management in Agriculture series. Volume 7. Wallingford, UK: CABI International.

WEPA (Water Environment Partnership in Asia). n.d.a. State of water environmental issues: Vietnam. Available at http:// www.wepa-db.net/policies/state/vietnam/overview.htm (accessed on November 19, 2009).

WEPA. n.d.b. State of water environmental issues: Cambodia. Available at http://www.wepa-db.net/policies/state/ cambodia/groundwater.htm (accessed on November 19, 2009).

Whitbread, A.M.; Blair, G.J.; Konboon. Y.; Lefroy, R.D.B.; Naklang, K. 2003. Managing crop residues, fertilizers and leaf litters to improve soil $\mathrm{C}$, nutrient balances and the grain yield of rice and wheat cropping systems in Thailand and Australia. Agriculture, Ecosystems and Environment. 100: 251-263.

WOCAT. 2007. Where the land is greener: Case studies and analysis of soil and water conservation initiatives worldwide, (eds.) Liniger, H.; Critchley, W.

World Bank. 2012. World Development Indicators. Available at http://data.worldbank.org/data-catalog/world-developmentindicators (accessed on February 8, 2012).

WWF (World Wide Fund for Nature). 2009. The Greater Mekong and climate change: Biodiversity, ecosystem services and development at risk. Bangkok, Thailand: WWF Greater Mekong Programme.

Yamamoto, Y.; Oberthur, T.; Lefroy, R. 2009. Spatial identification by satellite imagery of the crop-fallow rotation cycle in northern Laos. Environment, Development and Sustainability 11(3): 639-654.

Yoshida, S. 1981. Climatic environment and its influence. Chapter 2 in Fundamentals of rice crop science. Los Baños, Laguna, Philippines: International Rice Research Institute (IRRI). Pp. 69-111.

Zaisheng, H.; Jing, H.; Lei, N. 2010. Transboundary aquifers in Great Mekong River Basin. Proceedings of the ISARM2010 International Conference "Transboundary Aquifers: Challenges and New Directions", December 6-8, 2010, UNESCO, Paris, France. 